\title{
A Feasibility Study of Reactor-Based Deep-Burn Concepts
}

prepared by

Nuclear Engineering Division

Argonne National Laboratory 


\section{About Argonne National Laboratory}

Argonne is managed by The University of Chicago for the U.S. Department of Energy under contract W-31-109-Eng-38. The Laboratory's main facility is outside Chicago, at 9700 South Cass Avenue, Argonne, Illinois 60439. For information about Argonne and its pioneering science and technology programs, see www.anl.gov.

\section{Availability of This Report}

This report is available, at no cost, at http://www.osti.gov/bridge. It is also available on paper to U.S. Department of Energy and its contractors, for a processing fee, from:

U.S. Department of Energy

Office of Scientific and Technical Information

P.O. Box 62

Oak Ridge, TN 37831-0062

phone (865) 576-8401

fax (865) 576-5728

reports@adonis.osti.gov

\section{Disclaimer}

This report was prepared as an account of work sponsored by an agency of the United States Government. Neither the United States Government nor any agency thereof, nor The University of Chicago, nor any of their employees or officers, makes any warranty, express or implied, or assumes any legal liability or responsibility for the accuracy, completeness, or usefulness of any information, apparatus, product, or process disclosed, or represents that its use would not infringe privately owned rights. Reference herein to any specific commercial product, process, or service by trade name, trademark, manufacturer, or otherwise, does not necessarily constitute or imply its endorsement, recommendation, or favoring by the United States Government or any agency thereof. The views and opinions of document authors expressed herein do not necessarily state or reflect those of the United States Government or any agency thereof, Argonne National Laboratory, or The University of Chicago. 


\section{A Feasibility Study of Reactor-Based Deep-Burn Concepts}

by

T.K. Kim, T.A. Taiwo, R.N. Hill, and W.S. Yang

Nuclear Engineering Division, Argonne National Laboratory

F.Venneri

General Atomics

August 31, 2005

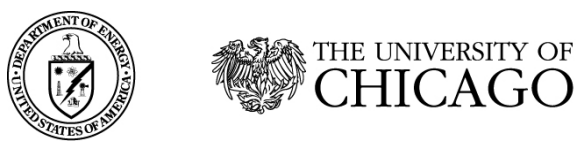





\section{Table of Contents}

Abstract 1

1.0 INTRODUCTION .3

2.0 OVERVIEW OF DEEP-BURN CONCEPTS .5

3.0 COMPUTATIONAL METHODS ………………..............................................

3.1 Monte Carlo Reference Calculations .................................................................10

3.1.1 Number of Neutron Histories in Monte Carlo Calculations .............................11

3.1.2 Temperature Defect of DB-MHR Core ..........................................................13

3.1.3 Whole-Core Depletion Calculation with Monte Carlo Code ...........................14

3.2 Deterministic Whole-Core Depletion Calculations ................................................16

3.2.1 Deterministic Lattice Codes and Models ........................................................16

3.2.2 Whole-Core Depletion Calculation with Deterministic Method .....................19

4.0 ONE-PASS DEEP-BURN TRANSMUTATION .................................................23

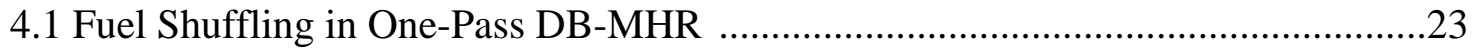

4.2 Sensitivity Calculations for One-Pass DB-MHR …………………......................24

4.2.1 Characteristics of DB-MHR Fuel ………………...................................24

4.2.2 Comparison of Equilibrium and Transitional Cores .........................................26

4.2.3 Effects of Fission Product and Core Geometry Models ..................................28

4.2.4 Effect of Burnup-Independent Cross Section ..................................................29

4.2.5 Optimum Fuel Data for One-Pass DB-MHR .................................................29

4.3 Performance of One-Pass DB-MHR ....................................................................

4.3.1 Impact of Power Level on DB-MHR TRU Consumption ................................32

4.3.2 Axial Shuffling Effect …………………………...................................33

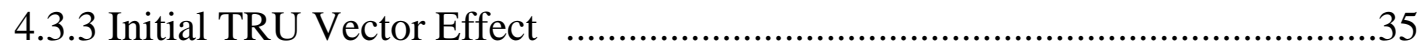

4.3.4 Operating Temperature Effect ......................................................................37 


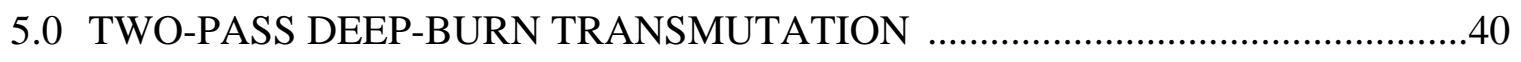

5.1 External Fuel Cycle and Fuel Shuffling in Two-Pass DB-MHR ..........................40

5.2 Determination of Packing Fraction for Second Pass Fuel ...................................43

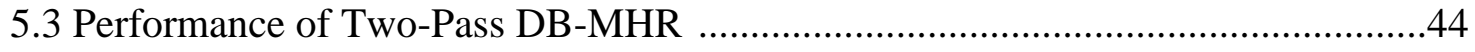

5.4 Performance of Two-Pass DB-MHR with Zero Cooling Time ............................47

5.5 Cylindrical Core of Two-Pass Concept ..........................................................49

5.6 Heterogeneous Fuel Element for Two-Pass Concept ...........................................52

6.0 COMPARISON OF DB-MHR AND IMF CONCEPTS …................................57

7.0 CONCLUSIONS

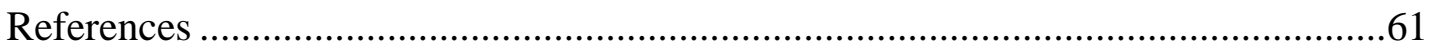




\section{List of Tables}

Table 2.1. Comparison of Design Parameters between DB-MHR and VHTR..................8

Table 3.1. Comparison of MCNP Whole-Core Calculations .........................................12

Table 3.2 Lattice Code Performance in 2D Fuel Block Calculation ..............................18

Table 3.3. Eigenvalue of Initial DB-MHR Core at Cold State .....................................20

Table 4.1. Comparison of Fission Product and Core Geometry Models .........................28

Table 4.2. Sensitivity Results of Burnup-Dependent and Independent Cross Sections ...29

Table 4.3. Performance of 600 MWt One-Pass DB-MHR ............................................32

Table 4.4. Performance of 800 MWt One-Pass DB-MHR ...........................................33

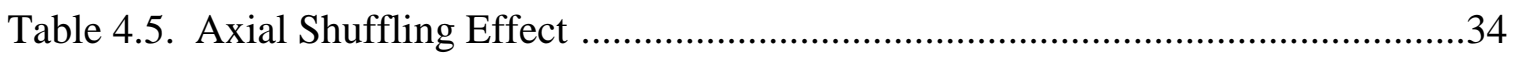

Table 4.6. Comparison of TRU Vector of LWR Spent Nuclear Fuel ............................36

Table 4.7. TRU Consumption of One-Pass DB-MHR for Different TRU Vectors .........37

Table 4.8. One-Pass DB-MHR TRU Consumption for Different Temperatures .............39

Table 5.1. Mass Flow of Two-Pass DB-MHR ..........................................................46

Table 5.2. Mass Flow of Two-Pass DB-MHR without Cooling Time ...........................48

Table 5.3. Mass Flow of Cylindrical Two-Pass DB-MHR ..........................................51

Table 5.4. Mass Flow of Two-Pass DB-MHR Using Heterogeneous Fuel Element........56

Table 6.1. TRU Consumptions in DB-MHR and IMF Concepts..................................57 


\section{List of Figures}

Figure 2.1. Core Layout of Gas-Turbine, Modular Helium Reactor................................5

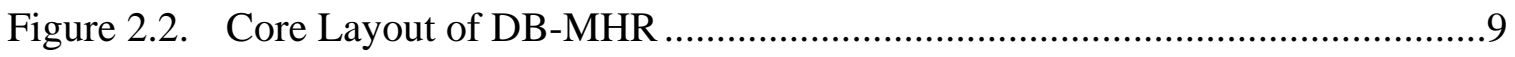

Figure 2.3. One-pass Deep-Burn Concept ...............................................................

Figure 2.4. Two-pass Deep-Burn Concept ...................................................................9

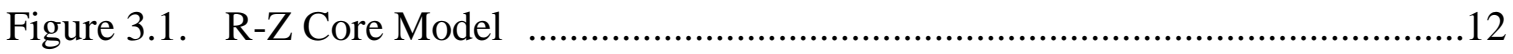

Figure 3.2. Eigenvalue Convergence in MCNP Calculations ......................................13

Figure 3.3. Temperature Defect of DB-MHR Core .................................................14

Figure 3.4. Whole-Core Depletion with MONTEBURNS Code .................................16

Figure 3.5. WIMS8 Procedure for Lattice Calculation ............................................18

Figure 3.6. Benchmarking of Coupled WIMS8/REBUS-3 Calculation .......................20

Figure 3.7. Whole-Core Depletions with Monte Carlo and Deterministic Methods .....21

Figure 4.1. Radial Shuffling Scheme of One-Pass Deep-Burn Concept .......................23

Figure 4.2. Comparison of DB-MHR Core and Assembly Spectra .............................25

Figure 4.3. Depletion Calculations of DB-MHR Whole-Core and Unit Assembly .......25

Figure 4.4. Core Multiplication Factors of Equilibrium and Transitional Cores ...........27

Figure 4.5. DB-MHR Performance as Function of Fuel-to-Moderator Ratio .................30

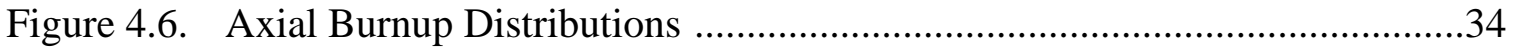

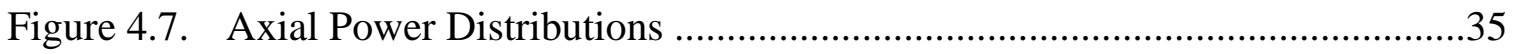

Figure 4.8. K-infinities of Fuel Elements at High and Low Temperatures ...................38

Figure 5.1. External Fuel Cycle of Two-pass DB-MHR Concept ..............................41

Figure 5.2. Radial Shuffling Scheme of Two Pass Deep-Burn Concept ......................42

Figure 5.3. Required TRU Mass from External Feed for $2^{\text {nd }}$ Pass ...............................44

Figure 5.4. Cylindrical Core for Two-Pass Concept ...................................................49

Figure 5.5. Heterogeneous Fuel Element for Two Pass DB-MHR ..............................52

Figure 5.6. Two-Pass DB-MHR Concept Using Heterogeneous Fuel Element .............53

Figure 5.7. REBUS-3 and ORIGEN2 Iteration Scheme for Two-Pass DB-MHR .........54

Figure 5.8. TRU Vector Changes in Two-Pass DB-MHR Iterations .............................55 


\begin{abstract}
A systematic assessment of the General Atomics (GA) proposed Deep-Burn concept based on the Modular Helium-Cooled Reactor design (DB-MHR) has been performed. Preliminary benchmarking of deterministic physics codes was done by comparing code results to those from MONTEBURNS (MCNP-ORIGEN) calculations. Detailed fuel cycle analyses were performed in order to provide an independent evaluation of the physics and transmutation performance of the one-pass and two-pass concepts. Key performance parameters such as transuranic consumption, reactor performance, and spent fuel characteristics were analyzed. This effort has been undertaken in close collaborations with the General Atomics design team and Brookhaven National Laboratory evaluation team.
\end{abstract}

The study was performed primarily for a 600 MWt reference DB-MHR design having a power density of $4.7 \mathrm{MW} / \mathrm{m}^{3}$. Based on parametric and sensitivity study, it was determined that the maximum burnup (TRU consumption) can be obtained using optimum values of $200 \mu$ and 20\% for the fuel kernel diameter and fuel packing fraction, respectively. These values were retained for most of the one-pass and two-pass design calculations; variation to the packing fraction was necessary for the second stage of the two-pass concept.

Using a four-batch fuel management scheme for the one-pass DB-MHR core, it was possible to obtain a TRU consumption of 58\% and a cycle length of 286 EFPD. By increasing the core power to $800 \mathrm{MWt}$ and the power density to $6.2 \mathrm{MW} / \mathrm{m}^{3}$, it was possible to increase the TRU consumption to 60\%, although the cycle length decreased by 64 days. The higher TRU consumption (burnup) is due to the reduction of the in-core decay of fissile Pu-241 to Am-241 relative to fission, arising from the higher power density (specific power), which made the fuel more reactivity over time. It was also found that the TRU consumption can be improved by utilizing axial fuel shuffling or by operating with lower material temperatures (colder core).

Results also showed that the transmutation performance of the one-pass deep-burn concept is sensitive to the initial TRU vector, primarily because longer cooling time reduces the fissile 
content (Pu-241 specifically.) With a cooling time of 5 years, the TRU consumption increases to $67 \%$, while conversely, with 20-year cooling the TRU consumption is about $58 \%$.

For the two-pass DB-MHR (TRU recycling option), a fuel packing fraction of about $30 \%$ is required in the second pass (the recycled TRU). It was found that using a heterogeneous core (homogeneous fuel element) concept, the TRU consumption is dependent on the cooling interval before the $2^{\text {nd }}$ pass, again due to Pu-241 decay during the time lag between the first pass fuel discharge and the second pass fuel charge. With a cooling interval of 7 years (5 and 2 years before and after reprocessing) a TRU consumption of 55\% is obtained. With an assumed "no cooling" interval, the TRU consumption is 63\%. By using a cylindrical core to reduce neutron leakage, TRU consumption of the case with 7-year cooling interval increases to 58\%. For a twopass concept using a heterogeneous fuel element (and homogeneous core) with first and second pass volume ratio of 2:1, the TRU consumption is $62.4 \%$.

Finally, the repository loading benefits arising from the deep-burn and Inert Matrix Fuel (IMF) concepts were estimated and compared, for the same initial TRU vector. The DB-MHR concept resulted in slightly higher TRU consumption and repository loading benefit compared to the IMF concept (58.1\% versus $55.1 \%$ for TRU consumption and 2.0 versus 1.6 for estimated repository loading benefit). 


\section{INTRODUCTION}

Worldwide economic growth is leading to rapid growth in energy demand, straining international energy supplies. Expanding worldwide energy supplies with today's technology mix will exacerbate competition for declining resources while increasing adverse environmental impacts and potential long-term consequences from global climate change. Today, the dominant clean, secure source of energy production is nuclear-generated electricity. Several key developing nations plan aggressive and large-scale implementation of nuclear power. However, accumulation of spent nuclear fuel is a potential impediment to expanded application of nuclear energy. A business-as-usual continuation of current fuel cycle practices could lead to substantial increases in the number of geologic repository sites. For example, a new repository with equal capacity to the Yucca mountain repository would be needed about every 20 or 30 years. [1] Because of their technical, economic, and political challenges, geologic repositories are a scarce resource that could limit the use of nuclear energy.

Technically, the repository capacity is determined by decay heat and regulatory limits for the released dose. Removing transuranics (TRU) and some fission products from the disposed material can provide significant benefits. When the principal heat producers are eliminated from the waste, a typical geologic repository can hold the waste products resulting from at least fifty times more power generation while also reducing long-term radiotoxicity. Additionally, elimination of fissile plutonium isotopes from the waste would remove the potential mining of weapons grade plutonium from the repository. Note that the radiological barrier of fission products will disappear about 100 years, and the plutonium quality will approach that of weapons-grade in 10,000 years because of the much shorter half-life of the Pu-240 than Pu-239. [2] Thus, the use of recycling technology will ease environmental burdens, better use permanent disposal space, and enhance the proliferation resistance.

For the purpose of incinerating plutonium, neptunium, and americium nuclides, DeepBurn, Modular Helium-cooled Reactor (DB-MHR) concept has been proposed by General Atomics (GA), based on the technologies of the graphite moderated Gas-Turbine, Modular Helium-cooled Reactor (GT-MHR). [3] The essential feature of this transmutation concept is the use of the coated fuel particles (TRISO) that are considered strong and highly resistant to 
irradiation. The TRU fuel formed into TRISO particles can be irradiated for a long time in a thermal system, and thereby a very high TRU consumption (in particular fissile nuclides) is expected. The objective of this study is to investigate the feasibility of this deep-burn transmutation concept by confirming the expected high TRU consumption. Two different approaches proposed by GA have been examined: one-pass and two-pass concepts. For both concepts, $\mathrm{Pu}, \mathrm{Np}$, and Am isotopes of LWR spent fuel are fed into DB-MHR, and Cm isotopes are sent to the repository or interim storage. In the one-pass concept, all the TRU nuclides discharged from DB-MHR are directly sent to the repository, but in the two-pass concept, the Pu, $\mathrm{Np}$, and Am isotopes discharged from the first pass are recycled into the second pass and only Cm isotopes are sent to the repository.

A series of parametric and sensitivity studies has been performed to investigate the potential TRU consumption in the deep-burn concepts. These studies include 1) determination of optimum fuel design parameters to maximize the TRU consumption, 2) performance evaluations of the one-pass and two-pass concepts, 3) estimation of the impacts of various design parameters and fuel management scheme such as feed TRU vector, operating temperature, power level, axial shuffling, etc. In addition, alternative deep-burn concepts are introduced in this study. The performance of the DB-MHR concepts were evaluated with whole-core equilibrium cycle analyses carried out by WIMS8/REBUS-3 coupled calculations; burnup-dependent microscopic cross sections were generated from WIMS8 assembly calculations and provided for whole-core REBUS-3 calculations. Prior to main analyses, to test the performance of the WIMS8/REBUS-3 coupled calculation procedure, Monte Carlo depletion calculations were also performed using the MONTEBURNS code.

In Section 2, the deep-burn concepts are briefly summarized. The computational methods are discussed in Section 3. The estimated performance parameters and sensitivity calculation results for the one-pass concept are presented in Section 4. The results for the two-pass deepburn concept are discussed in Sections 5. Alternative two pass loading strategies and core configurations are explored. The performance of the deep-burn concept is compared to conventional LWR system employing non-uranium inert matrix (IMF) fuel forms in Section 6. [4] Conclusions of this study are provided in Section 7. 


\section{OVERVIEW OF DEEP-BURN CONCEPTS}

The $D B-M H R$ concept utilizes thermal neutrons and ceramic coated (TRISO) fuel particles to incinerate the TRU discharged from LWRs. The TRISO fuel particle is considered strong and highly resistant to irradiation; thereby it allows an extensive destruction level of TRU fissile isotopes with thermal neutrons by residing in the core for a long irradiation time. The deep-burn concept has been developed by combining the primary design features of the GasTurbine, Modular Helium-Cooled Reactor (GT-MHR) with the requirement for the thermal transmutation of the transuranics (TRU). It is noted that the GT-MHR is a graphite-moderated, helium-cooled thermal reactor designed for high efficiency operation due to its high coolant temperature, and for passive safety due to the ceramic properties of coated fuel particles and graphite moderator, and due to the annular layout of the core. Figure 2.1 shows the core layout of the GT-MHR core. It consists of hexagonal fuel and reflector elements, and reactivity control materials. The core is designed for a power level of $600 \mathrm{MWt}$ and a low power density $\left(\sim 6.6 \mathrm{~W} / \mathrm{cm}^{3}\right)$.

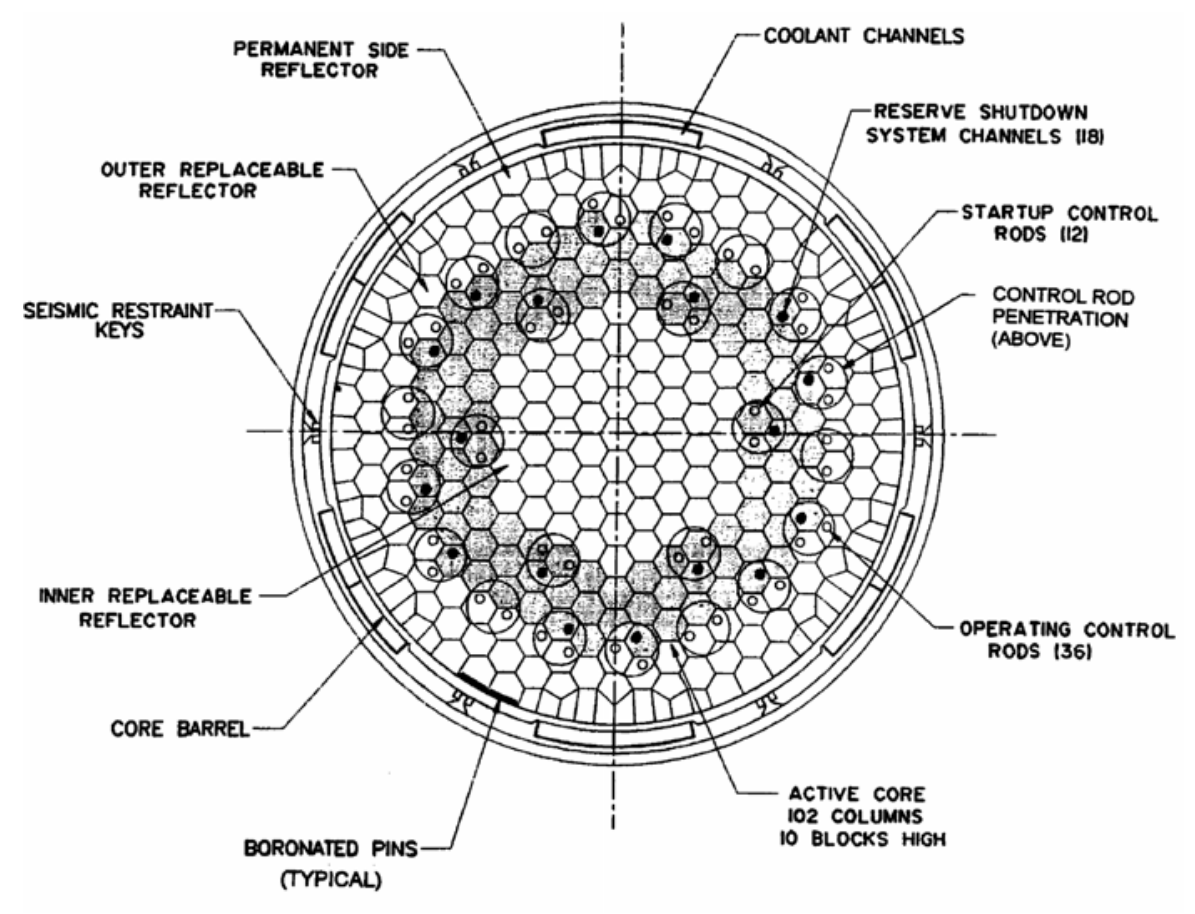

Figure 2.1. Core Layout of Gas-Turbine, Modular Helium Reactor 
The annular core layout is employed for passive decay heat removal. The active core has 102 fuel columns that are located in rings 6, 7, and 8. Ten fuel elements comprise a fuel column. The height of the active core is $7.93 \mathrm{~m}$ and the effective inner and outer core diameters are $2.96 \mathrm{~m}$ and $4.83 \mathrm{~m}$, respectively. Each fuel element contains holes for fuel and burnable poison compacts, and full-length channels for helium coolant flow. The principal fuel element structural material is H-451 graphite in the form of a right hexagonal prism, with a flat-to-flat width of $36.0 \mathrm{~cm}$. The fuel is contained in fuel compacts that are loaded into the fuel holes. Each compact has a diameter of $1.245 \mathrm{~cm}$ and a height of $4.93 \mathrm{~cm}$. TRISO fuel particles are dispersed in the compact graphite medium. The fuel element has 216 fuel compact holes including those for six lumped burnable poison rods and 108 coolant holes. The pitch of the coolant hole or fuel compact is $1.8796 \mathrm{~cm}$ and the radii of the fuel compact and fuel holes are 0.6223 and $0.6350 \mathrm{~cm}$, respectively. There are 102 large coolant holes with $0.794 \mathrm{~cm}$ radius and 6 small coolant holes with $0.635 \mathrm{~cm}$ radius.

The core design of the DB-MHR borrows from the GT-MHR design. The geometry of the fuel element (i.e., graphite fuel block) and the core height are identical to those of the GT-MHR, and the annular core layout is also proposed for the DB-MHR. However, the core configuration, fuel management scheme, and fuel kernel size were changed to enhance the TRU consumption (destruction). These changes include a four-batch fuel management scheme with 144 fuel columns and a smaller kernel diameter relative to GT-MHR. The increased number of batches increases the fuel residence time in the core for a fixed cycle length, and the small kernel size increases the resonance absorption of TRU nuclides by reducing the resonance self-shielding effect.

Figure 2.2 provides the DB-MHR core layout. The gray hexagons denote the inner and outer graphite reflectors, and the other hexagons denote the active core regions. The different colors denote the different batch zones. The 144 fuel columns are grouped into four batches. The design parameters of the DB-MHR core are compared with those of the helium-cooled, graphitemoderated Very High Temperature Reactor (VHTR) [5] in Table 1. The VHTR is also being developed based on the GT-MHR, and it is a leading candidate for the Next Generation Nuclear Plant (NGNP). The design parameters of the DB-MHR and the VHTR are generally similar, but 
several key parameters such as the power density, the specific power density, number of fuel columns, kernel size, packing fractions, and fuel composition are different. The power density of the DB-MHR is about 30\% smaller than that of the VHTR (NGNP) because of the increased number of fuel columns under the same thermal power. The specific power density of the DB-MHR is however increased due to the use of non-uranium fuel (lower mass) and smaller kernel size and packing fraction relative to the NGNP.

In the proposed deep-burn concept, only Pu, Np, and Am isotopes of the TRU recovered from LWR spent fuel are used as DB-MHR fuel, and Cm isotopes are sent to the repository or interim storage. Curium is excluded because it makes fuel fabrication difficult due to its high spontaneous fission rate and decay heat. Two different fuel cycle concepts were proposed by GA: one-pass and two-pass concepts. Figures 2.3 and 2.4 illustrate the one-pass and two-pass concepts, respectively. In the one-pass concept, the fuel resides in the core for four cycles according to the four-batch fuel management scheme, and then the spent nuclear fuel is sent to the repository. In the two-pass concept, however, the $\mathrm{Pu}, \mathrm{Np}$, and $\mathrm{Am}$ isotopes discharged from the first pass are recycled into the second pass and only $\mathrm{Cm}$ isotopes are sent to the repository. In this approach, the total core volume is divided into four zones, and three-fourth are allocated for the first pass (fresh TRU recovered from LWR spent fuel) and one-fourth is allocated for the second pass (recycled TRU from DB-MHR discharge). The two-pass concept utilizes three-batch scheme, and thus the fuel resides in the core for six cycles. 
Table 2.1. Comparison of Design Parameters between DB-MHR and VHTR

\begin{tabular}{|c|c|c|c|c|}
\hline & Design parameter & Unit & DB-MHR & VHTR \\
\hline \multirow{10}{*}{ Core } & Thermal Power & MWt & 600 & 600 \\
\hline & Power density & $\mathrm{W} / \mathrm{cm}^{3}$ & 4.7 & 6.6 \\
\hline & Specific power density & W/g & $250-1700$ & $\sim 100$ \\
\hline & Number of columns & - & 144 & 102 \\
\hline & Number of blocks per column & - & 10 & 10 \\
\hline & Fuel form & - & $(\mathrm{TRU}) \mathrm{O}_{1.7}$ & $\mathrm{UC}_{0.5} \mathrm{O}_{1.5}$ \\
\hline & Number of batch & - & 4 & 2 \\
\hline & Number of columns per batch & - & 36 & 51 \\
\hline & Coolant inlet/outlet temperature & $\mathrm{C}$ & $490 / 850$ & $490 / 850-1000$ \\
\hline & Boron impurity in graphite & ppm & 1.5 & ? \\
\hline \multirow{6}{*}{$\begin{array}{l}\text { Fuel } \\
\text { Column }\end{array}$} & Column pitch & $\mathrm{cm}$ & 36.0985 & 36 \\
\hline & Width of column & $\mathrm{cm}$ & 35.9969 & 35.9969 \\
\hline & Number of fuel pins & - & 210 & 210 \\
\hline & Number of lumped BP & - & 6 & 6 \\
\hline & Number of coolant holes & - & 108 & 108 \\
\hline & Height & $\mathrm{cm}$ & 79.3 & 79.3 \\
\hline \multirow{5}{*}{ Fuel Cell } & Pitch of fuel cell & $\mathrm{cm}$ & 1.8796 & 1.8796 \\
\hline & Radius of fuel hole & $\mathrm{cm}$ & 0.635 & 0.635 \\
\hline & Radius of fuel compact & $\mathrm{cm}$ & 0.6223 & 0.6225 \\
\hline & Radius of coolant hole & $\mathrm{cm}$ & 0.79375 & 0.79375 \\
\hline & Packing fraction & $\%$ & $15-30$ & 25 \\
\hline \multirow{5}{*}{ Particle size } & Kernel diameter & $\mu \mathrm{m}$ & $150-300$ & 425 \\
\hline & Buffer thickness & $\mu \mathrm{m}$ & 150 & 100 \\
\hline & IPC thickness & $\mu \mathrm{m}$ & 35 & 35 \\
\hline & SiC thickness & $\mu \mathrm{m}$ & 35 & 35 \\
\hline & OPC thickness & $\mu \mathrm{m}$ & 40 & 40 \\
\hline \multirow{7}{*}{ Density } & Kernel & & 10.36 & 10.50 \\
\hline & Buffer & & 1.00 & 1.00 \\
\hline & IPC & & 1.87 & 1.90 \\
\hline & $\mathrm{SiC}$ & $\mathrm{g} / \mathrm{cm}^{3}$ & 3.20 & 3.20 \\
\hline & $\mathrm{OPC}$ & & 1.87 & 1.87 \\
\hline & Fuel compact & & 1.74 & 1.20 \\
\hline & Graphite block & & 1.74 & 1.74 \\
\hline \multirow{11}{*}{$\begin{array}{l}\text { Heavy } \\
\text { metal vector }\end{array}$} & $\mathrm{Np}-237$ & \multirow{11}{*}{$\%$} & 4.5941 & \\
\hline & Pu-238 & & 1.3340 & \\
\hline & Pu-239 & & 50.9975 & \\
\hline & $\mathrm{Pu}-240$ & & 20.7970 & \\
\hline & Pu-241 & & 7.5689 & \\
\hline & $\mathrm{Pu}-242$ & & 4.9457 & \\
\hline & Am-241 & & 8.2207 & \\
\hline & $A m-242 m$ & & 0.0304 & \\
\hline & Am-243 & & 1.5118 & \\
\hline & U-235 & & & 14.0 \\
\hline & U-238 & & & 86.0 \\
\hline
\end{tabular}




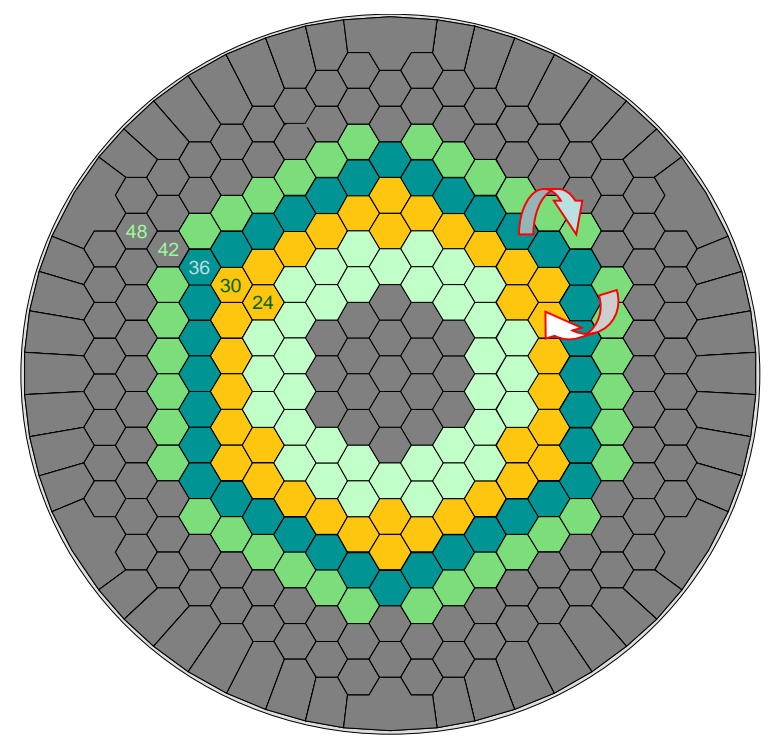

Figure 2.2. Core Layout of DB-MHR

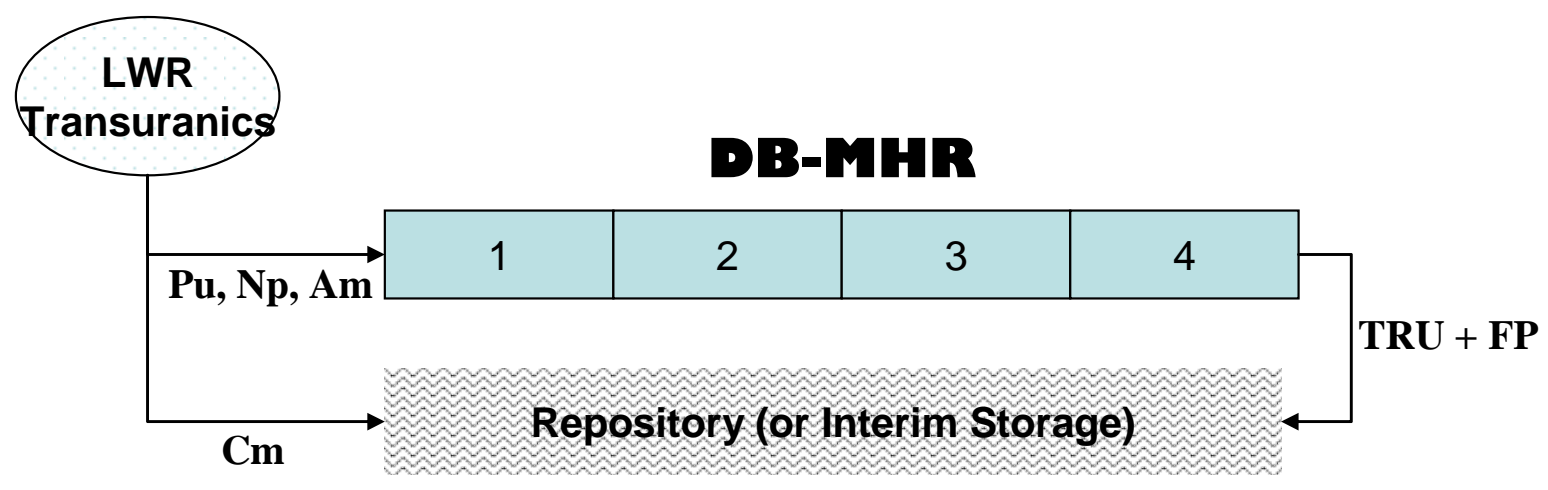

Figure 2.3. One-Pass Deep-Burn Concept

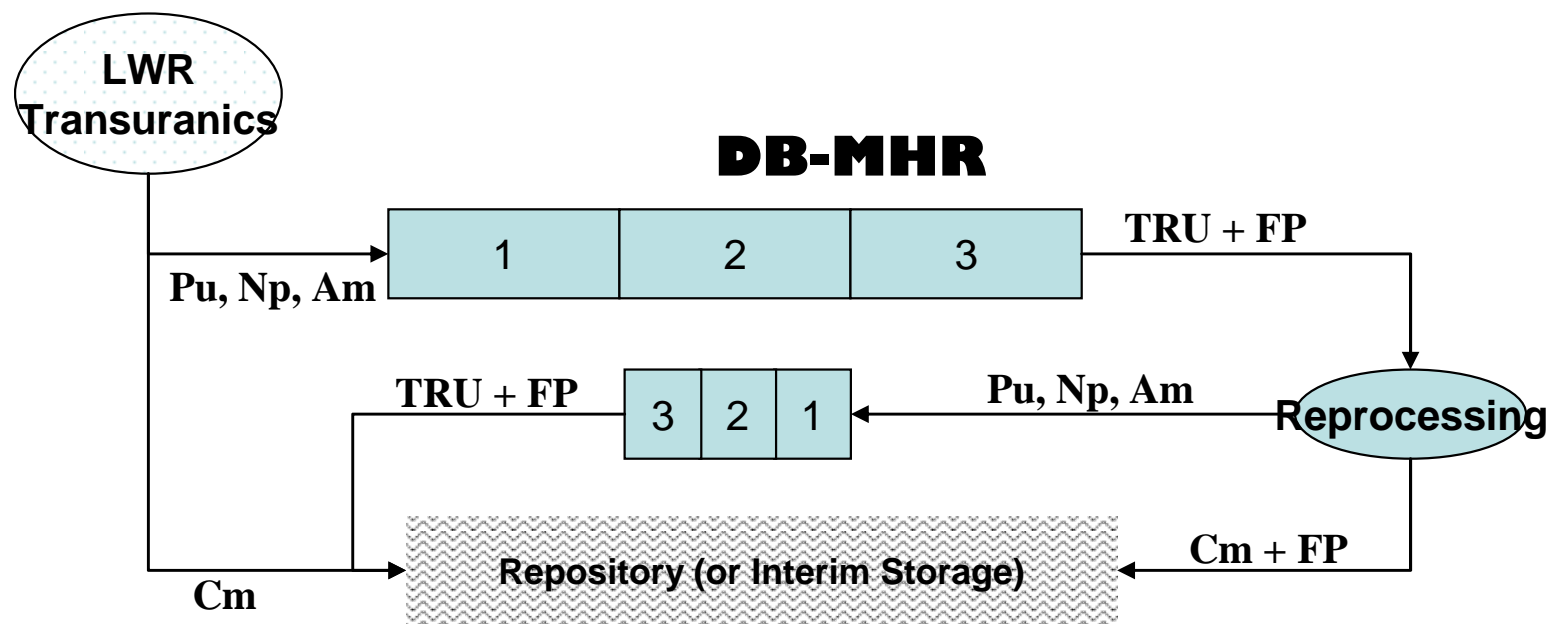

Figure 2.4. Two-Pass Deep-Burn Concept 


\section{COMPUTATIONAL METHODS}

The double heterogeneity of DB-MHR fuel elements caused by the use of coated fuel particles is one of the most distinct characteristics that have to be properly treated in neutronics analysis. The choice of an annular core layout makes the neutron leakage into the inner and outer reflectors more important than in traditional light water reactors. To treat the neutron leakage effects properly, whole-core calculations need to be performed. In previous studies, the applicability of existing computational to the neutronics design and analysis of VHTR was assessed. [6,7] Two deterministic lattice codes WIMS8 [8] and DRAGON [9] were identified to have the capability to model the double heterogeneity effects, and their prediction accuracies were verified against the MCNP4C [10] Monte Carlo code. Furthermore, a whole-core fuel cycle analysis procedure was developed by coupling WIMS8 and REBUS-3 [11] codes, and applied successfully to the NGNP fuel design studies. [5] This WIMS8/REBUS-3 coupled computational procedure was predominantly used in this study for the DB-MHR whole-core fuel cycle analyses. Prior to main analyses, to check the performance of this WIMS8/REBUS-3 coupled calculation procedure, Monte Carlo depletion calculations were also performed using the MONTEBURNS code.

\subsection{Monte Carlo Reference Calculations}

The MCNP4C code was selected for reference whole-core calculations. The MCNP4C code has been extensively used for pebble-bed and prismatic gas-cooled reactor analyses [12-15]. For modeling simplicity and computational efficiency, these analyses approximated the random distribution of coated fuel particles in graphite matrix by regular lattice distributions using the lattice geometry option of MCNP4C. The errors introduced by this approximation were estimated in a previous study [7] by performing pin cell and assembly calculations. It was observed that the MCNP4C eigenvalues obtained with regular lattice distributions are consistently smaller than those obtained with random distributions. Although the regular lattice and random distribution models resulted in statistically meaningful eigenvalue differences, their magnitudes were generally small $(<400 \mathrm{pcm} \Delta \rho$ ). Since the random distribution model is not practical for whole-core calculations, the regular lattice distribution model was utilized in this study. 


\subsubsection{Number of Neutron Histories in Monte Carlo Calculations}

A whole-core Monte Carlo depletion calculation for DB-MHR requires an excessive amount of computation time because of the large problem size and the complexity of geometry. Thus, prior to whole-core depletion calculations, sensitivity calculations were performed to determine the reasonable number of neutron histories in the MCNP calculations. Note that the accuracy and computation time of the MCNP calculations are dependent on the number of neutron histories: a small number of neutron histories reduces the computation time but increases the uncertainties of calculated quantities.

Sensitivity calculations were performed using an R-Z core model and a simple cubic (SC) lattice distribution of coated fuel particles. In R-Z core model, the active core was divided by 40 burn-zones (4 radial rings and 10 axial nodes) to make each burn-zone size similar to a fuel element of the DB-MHR. The radial and axial reflectors were modeled as shown in Figure 3.1. The kernel size and packing fractions were assumed to be $300 \mu \mathrm{m}$ and $24 \%$, respectively. Noreturn-current boundary condition was imposed on all external surfaces.

Figure 3.2 shows the eigenvalue changes during the Monte Carlo calculations using different version of MCNP codes (i.e., MCNP4C and MCNP5) and the eigenvalues are provided in Table 3.1. In Figure 3.2 and Table 3.1, 50K and 100K denotes 50,000 and 100,000 neutron histories. The reference solution was obtained using the one-million neutron histories and results with $50 \mathrm{~K}$ and $100 \mathrm{~K}$ histories were obtained by skipping 10 and 50 cycles before beginning tally accumulations. The histories per cycle in the reference calculation are 10,000 while 1,000 histories in $50 \mathrm{~K}$ and $100 \mathrm{~K}$ history cases.

The results of MCNP4C and MCNP5 calculations are close to each other for the reference case, while they are different for the cases of smaller numbers of neutron histories: this implies that the eigenvalues were not fully converged for these cases. Even though the uncertainties of $100 \mathrm{~K}$ history cases are comparable to those of 50K history cases, the eigenvalues (in particular, MCNP5 calculation) are closer to the reference values. Figure 3.2 shows that the eigenvalue fluctuates significantly during first 40 - 50 cycles and then converges to the reference value. This fluctuation implies that the fission source distribution has not been converged. To 
avoid the influence of un-converged fission source distribution, a sufficient number of inactive cycles needs to be used. The results suggest that at least 40 cycles need to be skipped before accumulating the tallies.

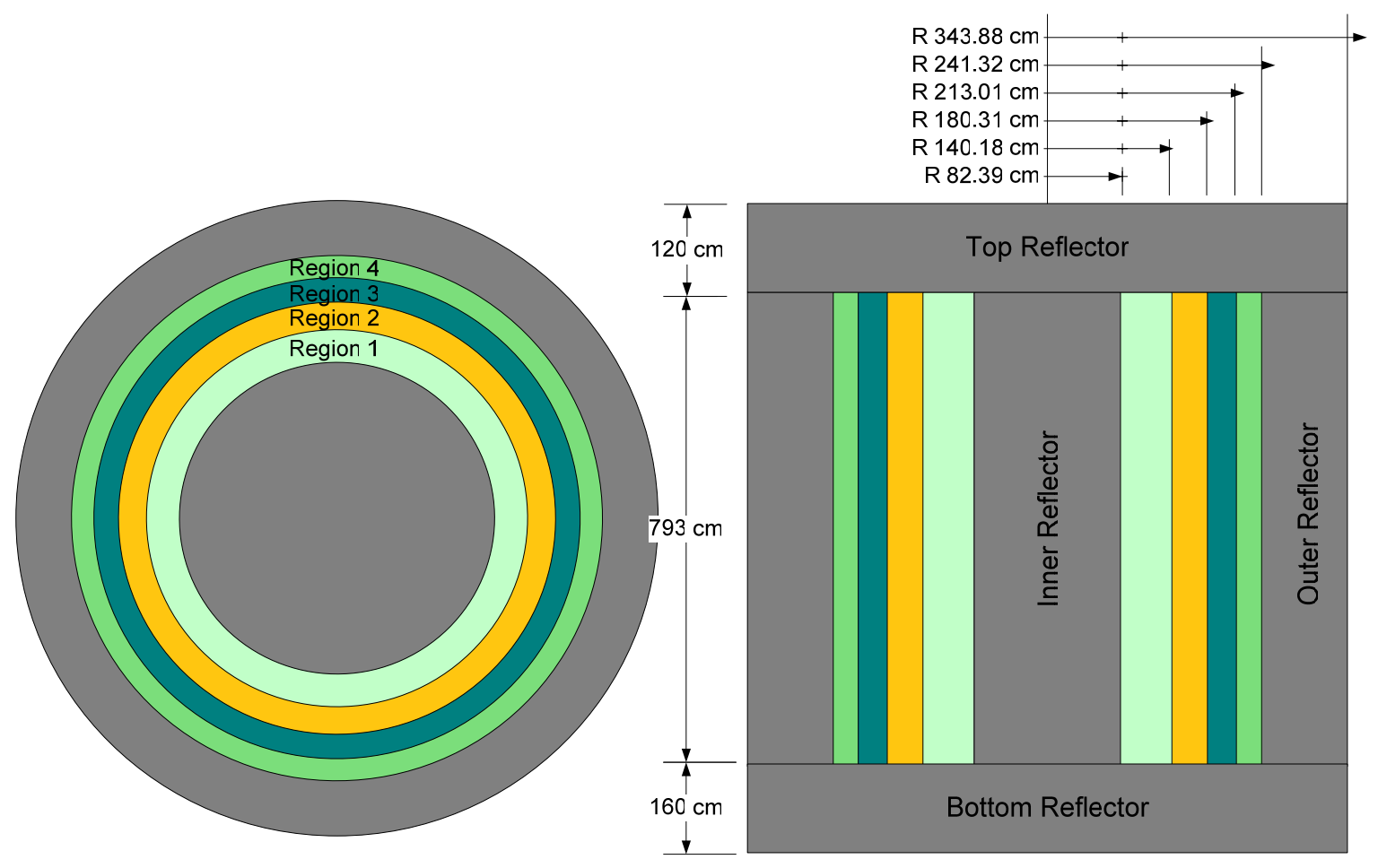

Figure 3.1. R-Z Core Model

Table 3.1. Comparison of MCNP Whole-Core Calculations

\begin{tabular}{|c|c|c|c|c|}
\hline $\begin{array}{l}\text { Number of } \\
\text { histories }\end{array}$ & $\begin{array}{l}\text { Free gas } \\
\text { temperature }(\mathrm{K})\end{array}$ & $\begin{array}{l}\mathrm{S}(\alpha, \beta) \\
\text { Temperature }(\mathrm{K})\end{array}$ & MCNP4C & MCNP5 \\
\hline 1 Million $^{\mathrm{a})}$ & 900 & 800 & $1.03444 \pm 0.00077$ & $1.03410 \pm 0.00074$ \\
\hline $50 \mathrm{~K}^{\mathrm{b})}$ & 900 & 800 & $1.04274 \pm 0.00289$ & $1.03643 \pm 0.00360$ \\
\hline $100 \mathrm{~K}^{\mathrm{c})}$ & 900 & 800 & $1.03198 \pm 0.00325$ & $1.03441 \pm 0.00313$ \\
\hline
\end{tabular}

a) 10,000 histories per cycle and first 10 cycle was ignored

b) 1,000 histories per cycle and first 10 cycle was ignored

c) 1,000 histories per cycle and first 50 cycle was ignored 


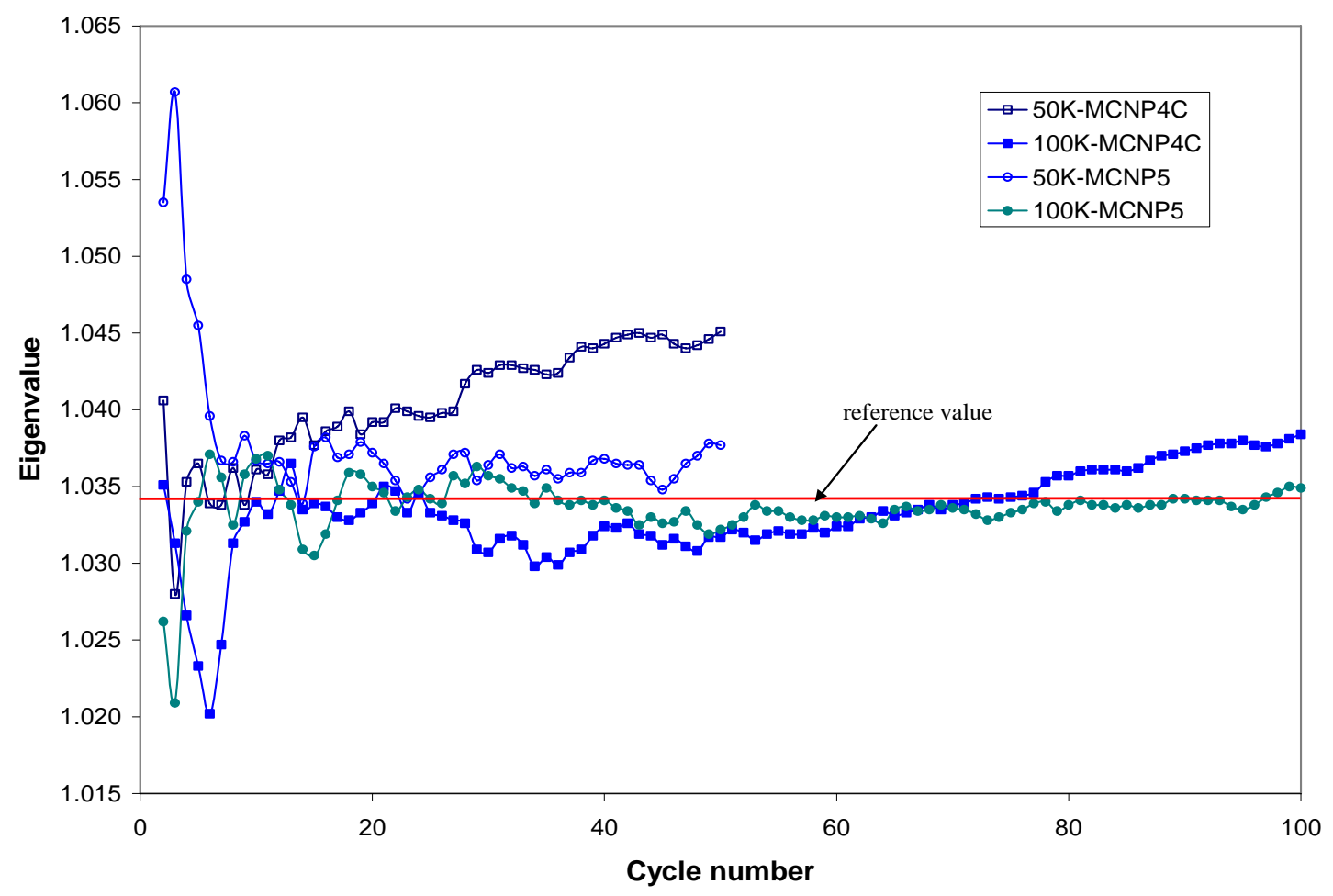

Figure 3.2. Eigenvalue Convergence in MCNP Calculations

\subsubsection{Temperature Defect of DB-MHR Core}

In order to estimate the temperature defect in the DB-MHR core, a series of MCNP4C whole-core calculations was performed. The fuel particle, graphite block, and coolant temperatures at operating condition were assumed to be 1273, 1073 and $943 \mathrm{~K}$, respectively. The $\mathrm{S}(\alpha, \beta)$ data of graphite is currently available in the temperature range of 300 - $2000 \mathrm{~K}$, but the exported version of the MCNP library includes only the data at 294K. Thus, the temperature defect from the cold state to the operating condition could not be obtained directly. The Doppler effect, free gas temperature effect, and $S(\alpha, \beta)$ temperature effect of graphite were estimated indirectly, and the results are illustrated in Figure 3.3. The Doppler effect from $294 \mathrm{~K}$ to $900 \mathrm{~K}$ was evaluated using the KAERI's MCNP libraries [17] while other effects were determined using the MCNP libraries obtained from the RSICC code center along with the MCNP4C code. 


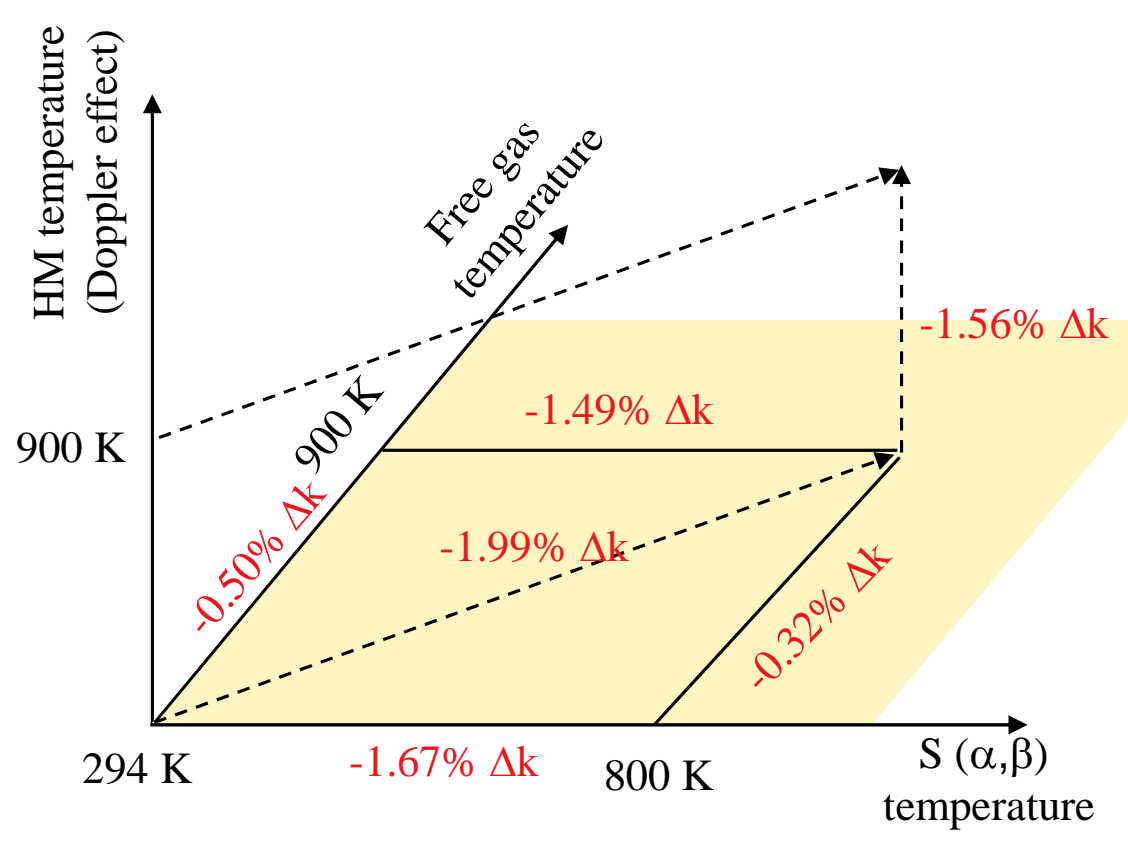

Figure 3.3. Temperature Defect in DB-MHR Core

The temperature effect corresponding to the free gas temperature change from $294 \mathrm{~K}$ to $900 \mathrm{~K}$ and the graphite temperature change from $294 \mathrm{~K}$ to $800 \mathrm{~K}$ is $-1.99 \% \Delta \mathrm{k}$. The Doppler effect due to the heavy metal nuclide temperature change from $294 \mathrm{~K}$ to $900 \mathrm{~K}$ is $-1.56 \% \Delta \mathrm{k}$. From these results, the temperature defect of the DB-MHR from the cold state to the operating condition was estimated to be about $-5.1 \% \Delta \mathrm{k}$; Doppler effect is $-2.5 \%$, and free gas and $S(\alpha, \beta)$ effect is $-2.6 \%$.

\subsubsection{Whole-Core Depletion Calculation with Monte Carlo Code}

Using the MONTEBURNS [18] code, whole-core Monte Carlo depletion calculations were performed. This code is an interface program that couples the Monte Carlo transport code MCNP and the radioactive decay and burnup code ORIGEN2. The MCNP code determines onegroup cross sections of individual burn regions by solving the transport equation and provides the cross section and flux data to the ORIGEN2 code. Using these one-group cross sections and flux data and a specified time step, the ORIGEN2 code determines the nuclide densities at the 
end of time step by solving the system of depletion equations for each burn region. The calculated number densities are provided to the MCNP code for the subsequent flux calculation.

MONTEBURNS calculations were performed with the R-Z core model discussed in Section 3.1.1. The cycle length was assumed 540 days, and a four-batch fuel management scheme was utilized. When the active regions are numbered from 1 to 4 , starting from the innermost region, as shown in Figure 3.1, the fresh fuel is loaded into the region 3, and sequentially moved into the region 4, 2, and 1 in the subsequent cycles. Axial shuffling was done by interchanging the $1^{\text {st }}$ and $5^{\text {th }}, 6^{\text {th }}$ and $10^{\text {th }}, 2^{\text {nd }}$ and $4^{\text {th }}$, and $7^{\text {th }}$ and $9^{\text {th }}$ axial fuel blocks.

Figure 3.4 compares the time evolutions of the DB-MHR core k-effective determined by three organizations: GA, ANL, and BNL [Todosow et al]. At ANL, the MONTEBURNS calculations were run on a PC (Pentium-4 processor, $2.0 \mathrm{GHz}, 256 \mathrm{MB}$ RAM) for total 7 cycles and the MCNP5 code was used as the Monte Carlo code. Each cycle was divided into three time steps (i.e., 180-day time interval), and the predict-and-corrector method was employed. It took about $\sim 40$ hours per time step for 50,000 neutron histories and 100 hours per time step for 100,000 histories.

The k-effective has its maximum value at time zero because the whole-core is loaded with fresh TRU, and decreases with increasing burnup. The k-effective shows a jump increase every 540 days, because burnt fuels are replaced with fresh fuels. The initial values of k-effective determined by three organizations are similar, but the time evolutions are different. This result indicates that the coupled neutron and nuclide fields determined by MCNP and ORIGEN2 calculations have not been fully converged because of the small number of histories and the large time interval. 


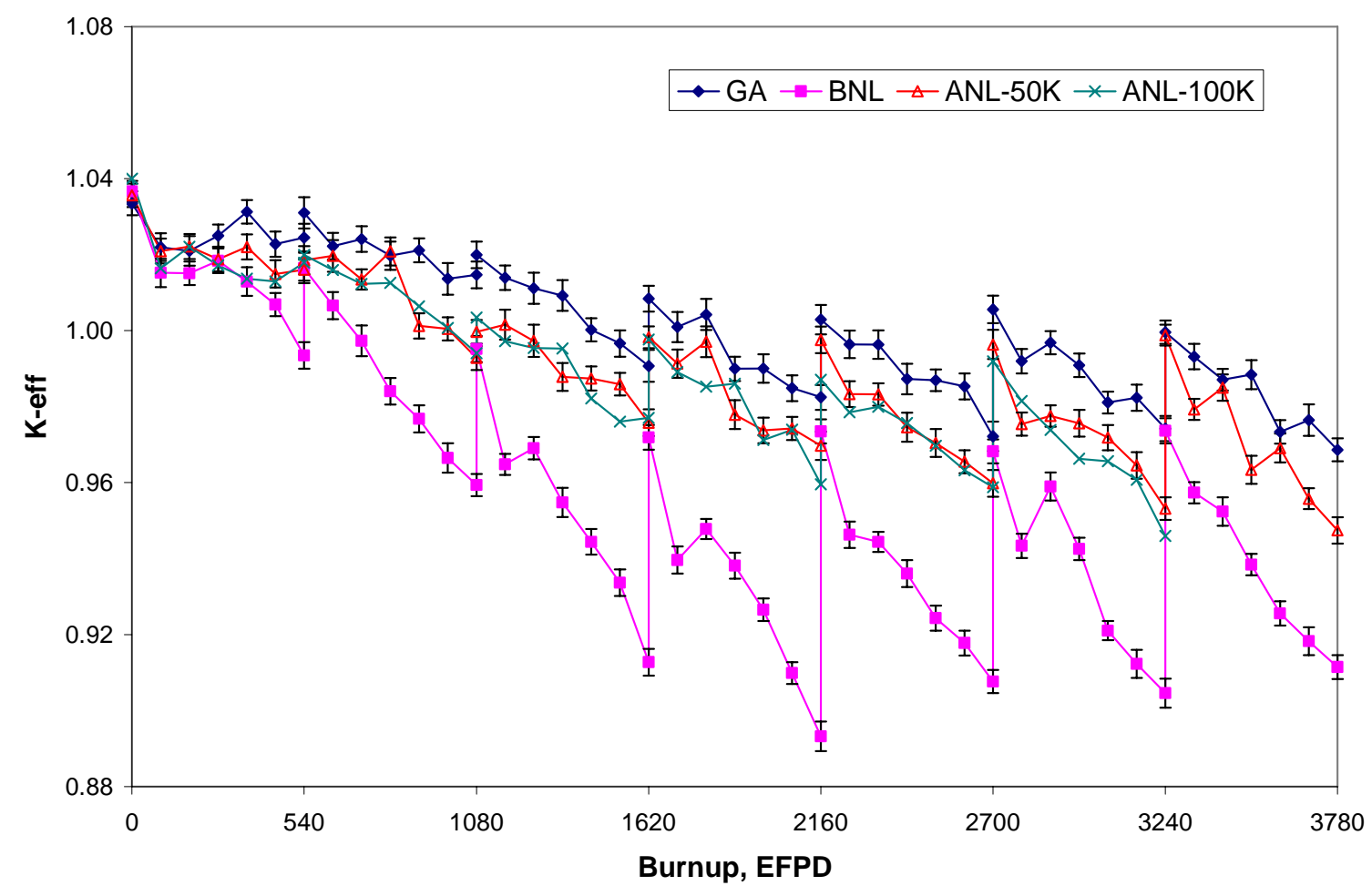

Figure 3.4. Whole Core Depletion with MONTEBURNS Code

\subsection{Deterministic Whole-Core Depletion Calculations}

\subsubsection{Deterministic Lattice Codes and Models}

The WIMS8 code provides an extensive software package for neutronics calculations. The code employs an open structure that permits the linking of various methods to create a calculation scheme for a given thermal reactor design. These could range from simple homogeneous cells to complex whole-core calculations. Most generally, however, the lattice capabilities of the code are used for reactor analysis. Geometries are available for analyzing PWR, BWR, VVER, AGR, RBMK, CANDU, other reactor core designs, storage pools, and experiments.

Methods for the neutron flux solution in WIMS8 include collision probability (1-D or 2-D), method of characteristics, $S_{n}$ method (1-D or 2-D), diffusion theory, and hybrid methods. 
The code also provides an integrated Monte Carlo method (MONK) for the purpose of internal validation. WIMS8 is supplied with 69- and 172-group libraries based on the validated JEF2.2 nuclear data. It is noted that the WIMS8 code has the PROCOL module that provides a capability for calculating the collision probabilities of particulate fuel in an annular geometry that could be used in flux solvers to model the double heterogeneity effect of that fuel form.

The WIMS8 code does not provide the particulate-fuel double heterogeneity treatment at the assembly level even though the code can treat the double heterogeneity effect in the fuel pin cell level. A two-step scheme is therefore utilized in the WIMS8 calculation. In the first step, the PROCOL module is used for detailed treatment of the double heterogeneity at the pin-cell level; other items, such as Doppler and resonance treatments are considered. A super-cell calculation is performed at this stage. The super-cell model is prepared by converting the hexagonal unit pincell to an equivalent annular cell and introducing an extra region representing a fraction of the graphite block outside the fuel cells. The fraction is determined such that the graphite volume in the super-cell is equal to the ratio of the graphite block volume to the number of fuel cells. The result of the pin-cell calculation is homogenized fuel pin-cell cross sections. These cross sections are then used in the second step, which embodies the full-assembly calculation. Besides the homogenized geometry of the fuel pin-cell, the detailed geometries of the other cells are retained in the assembly calculation. The full-assembly calculation is performed using the CACTUS module of the WIMS8 code. A schematic of the two-step procedure is provided in Figure 3.5.

In the previous study [7], the performance of the WIMS8 code was evaluated, and its applicability to the lattice calculations for VHTR design analyses was confirmed against the reference solutions generated by the MCNP4C Monte Carlo code. However, since the previous study indicates that the double heterogeneity effect is more significant in the TRU fuel, an additional assessment of the accuracy of the WIMS8 code has been performed in this study. In this calculation, a two-dimensional fuel element model with $24 \%$ packing fraction and $300 \mu \mathrm{m}$ kernel diameter was selected as a benchmark problem (other data are provided in Table 2.1). The reference solution was obtained from the MCNP4C calculations. The eigenvalues obtained from the WIMS8 calculations are compared with the reference solution. The WIMS8 code underestimated the eigenvalues by about $270 \mathrm{pcm}$. This magnitude is acceptable since the 
primary function of the lattice code is to generate multi-group cross sections for use in wholecore calculations. Other WIMS8 results showed similar trends as in the previous study. [7] In the WIMS8 calculations, the temperature defect was estimated to be about $-5.5 \% \Delta \mathrm{k}$.

Table 3.2. Lattice Code Performance in 2D Fuel Block Calculation

\begin{tabular}{|l|l|c|c|c|}
\hline Code & Conditions & Temperature (K) & k-infinity & Difference, $\mathrm{pcm} \Delta \mathrm{k}$ \\
\hline MCNP4C & $1-\mathrm{M}$ histories & 294 & $1.01882 \pm 0.00078$ & Reference \\
\hline \multirow{3}{*}{ WIMS8 } & 23 group & 294 & 1.01609 & -273 \\
\cline { 2 - 5 } & 172 group & 294 & 1.01608 & -274 \\
\cline { 2 - 5 } & 23 group & Core average $^{\text {a) }}$ & 0.96125 & \\
\hline
\end{tabular}

a) Core average temperature (fuel/graphite/coolant) $=1273 / 1073 / 973 \mathrm{~K}$
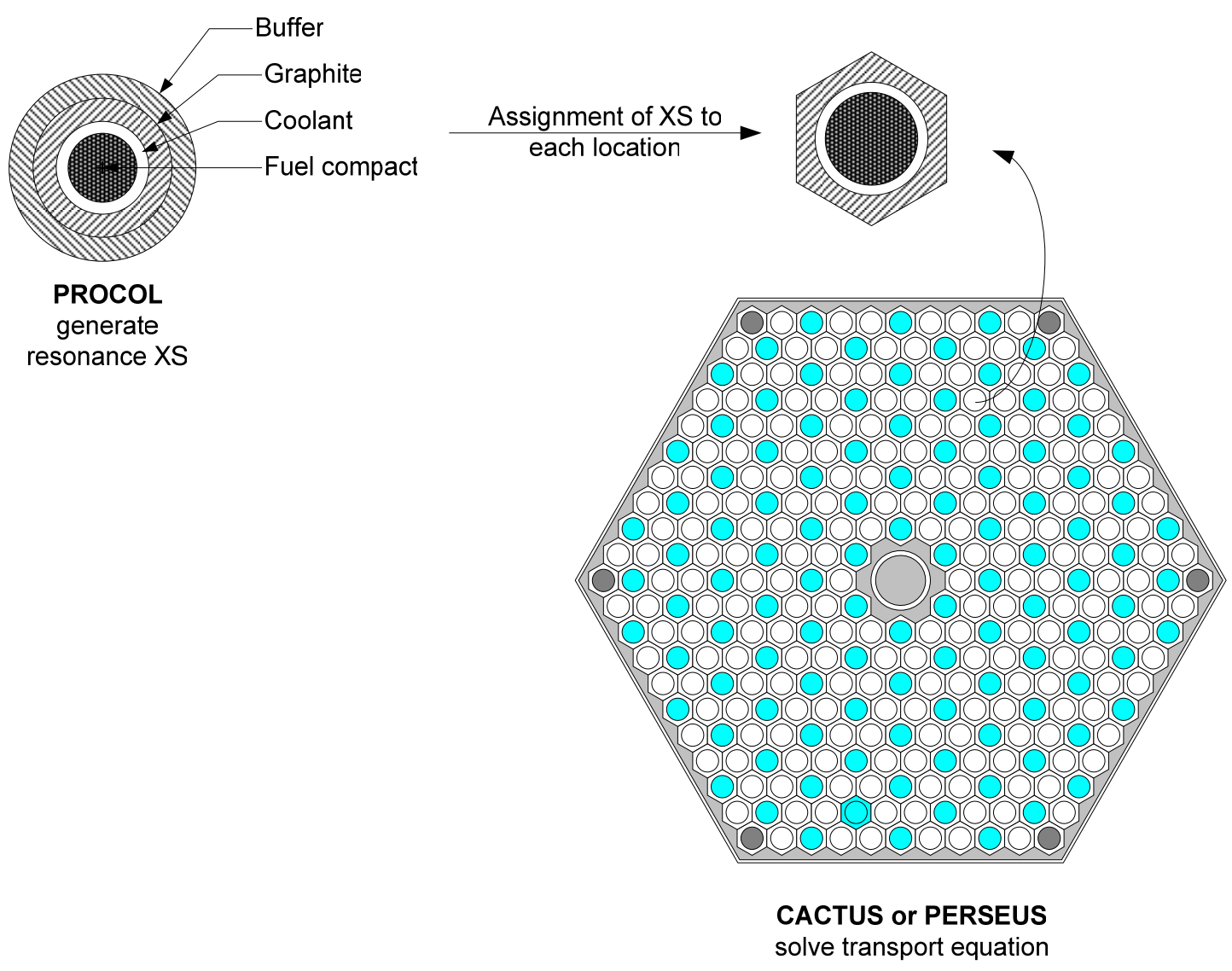

Figure 3.5. WIMS8 Procedure for Lattice Calculations 


\subsubsection{Whole-Core Depletion Calculation with Deterministic Method}

As aforementioned, whole-core fuel cycle analyses were performed using the WIMS8/REBUS-3 coupled calculations. Burnup-dependent, multi-group cross sections are generated from the WIMS8 calculations using the fuel block geometry and a reflective boundary condition. These cross sections are converted to the ISOTXS format and then provided to the REBUS- 3 code. The REBUS-3 code solves the multi-group diffusion equation and the depletion equations. Various geometry options are available in the REBUS-3 calculations with different flux solvers. In this study, the R-Z core model with finite difference method or Hexagonal-Z (Hex-Z) core model with nodal expansion method were used.

The actinides from U-233 to Cm-245 were modeled in the REBUS-3 depletion calculations. About 100 fission products are traced in the WIMS8 lattice calculations, and they can be modeled explicitly in the REBUS-3 calculations. However, this model is time-consuming because of the large size of the transmutation matrix. A sensitivity study indicated that a simplified fission product model with a few nuclides (Xe-135, I-135, Sm-149, Pm-149 and parent-dependent lumped fission products) does not degrade the solution accuracy significantly but reduces the computation time substantially.[5] Thus, a simplified lumped fission product (LFP) model was predominately used in sensitivity calculations, but the explicit fission product model with about 100 fission products was occasionally used to confirm the accuracy of the lumped fission product model. Thermal feedback was not considered in this study, since this capability is not available in the current version of the REBUS-3 code.

In order to confirm the applicability of the WIMS8/REBUS-3 coupling calculations to the DB-MHR whole-core depletion calculations, the interpolation scheme for burnup-dependent cross sections and the depletion chain data such as decay constants and fission product yields were examined. For this purpose, a homogeneous unit assembly (fuel element) problem with a reflective boundary condition was prepared, and the reference solution was obtained from a WIMS8 calculation. For this problem, the REBUS-3 code should reproduce the WIMS reference solution, because the cross sections and depletion data of the WIMS8 calculations are used in the REBUS-3 calculation. Figure 3.6 compares the time evolutions of k-infinity determined by WIMS8 and REBUS-3 calculations. Over the entire depletion period, the k-infinity evaluated by 
the WIMS8/REBUS-3 coupled calculation is very close to the reference WIMS8 solution. This result indicates that the burn-dependent cross sections prepared by WIMS8 calculations are correctly interpolated in the coupling procedure.

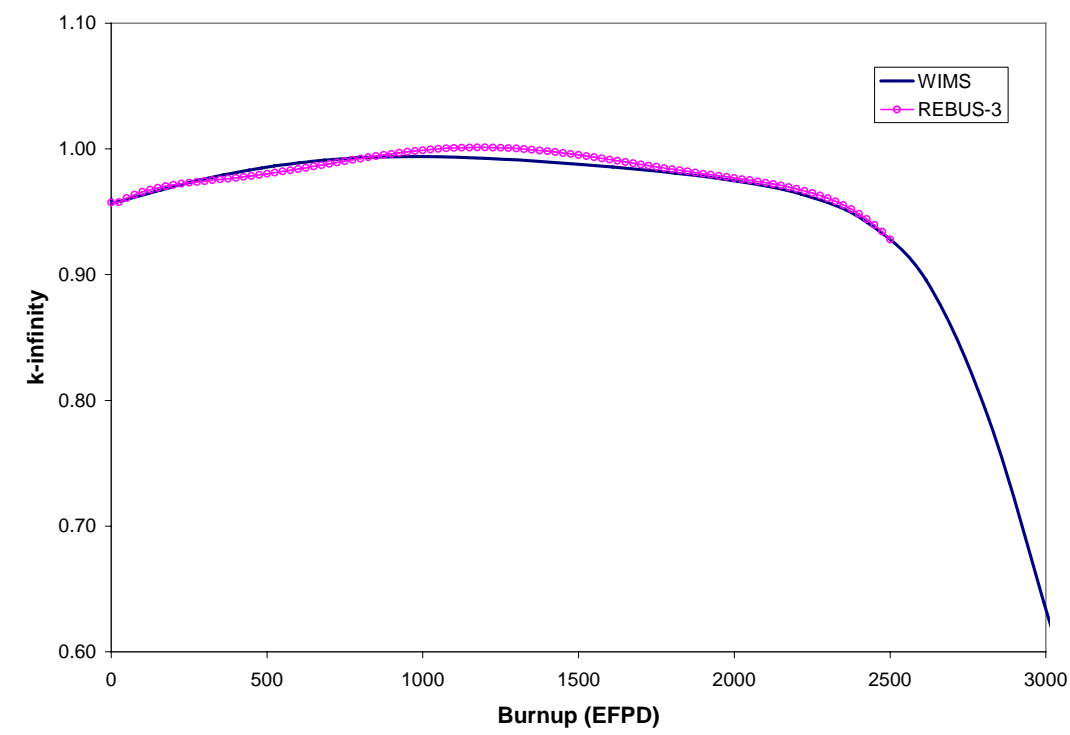

Figure 3.6. Benchmarking of Coupled WIMS8/REBUS-3 Calculation

Additionally, the over-all accuracy of the whole-core depletion analyses performed with the WIMS8/REBUS-3 coupled calculations has been evaluated. The R-Z core model used in the Monte Carlo whole-core-depletion calculations (see Figure 3.1) was selected as a benchmark problem. Before the whole-core depletion calculations, the static core calculations were first performed at cold temperature. The reference solution was obtained from the MCNP calculations. The WIMS8/REBUS-3 coupled calculations solved 23-group (15 fast groups and 8 thermal groups) diffusion equations. The core k-effective values at the initial state are compared in Table 3.3.

Table 3.3. Eigenvalue of Initial DB-MHR Core at Cold State

\begin{tabular}{|l|l|l|l|l|}
\hline Code & Conditions & Temperature $(\mathrm{K})$ & k-effective & Difference, $\mathrm{pcm}(\Delta \mathrm{k})$ \\
\hline MCNP5 & 100 K histories & $294^{\text {a) }}$ & $1.05428 \pm 0.004$ & \\
\hline MCNP4C & $1 \mathrm{M}$ histories & 294 & $1.05493 \pm 0.004$ & +65 \\
\hline \multirow{2}{*}{$\begin{array}{l}\text { WIMS8/ } \\
\text { REBUS-3 }\end{array}$} & $23 \mathrm{G}$ & 294 & 1.04583 & -845 \\
\cline { 2 - 5 } & $23 \mathrm{G}$ & Core average $^{\text {b) }}$ & 0.99929 & \\
\hline
\end{tabular}

a) All temperature (fuel, graphite, coolant) of core is $294 \mathrm{~K}$

b) Core average temperature (fuel/graphite/coolant) $=1273 / 1073 / 973 \mathrm{~K}$ 
The WIMS8/REBUS-3 coupled calculation underestimated the core initial k-effective value by $845 \mathrm{pcm}(\Delta \mathrm{k})$. While this accuracy is considered sufficient for this study, it is planned to improve it in future work (e.g., using extended calculations for cross section generation and higher fidelity nodal solutions offered by DIF3D/VARIANT). The temperature defect determined by WIMS8/REBUS-3 coupled calculation was $-4.7 \%$, whose magnitude is smaller than the value (-5.1\%) deduced from several MCNP calculations.

The time evolutions of core k-effective are compared in Figure 3.7. The curves labeled as REBUS-cold and REBUS-hot denote the whole-core depletion results obtained from the WIMS8/REBUS-3 coupled calculations at the cold and operating conditions. For the whole-core depletion calculation with the MONTEBURNS code, the cross sections at $294 \mathrm{~K}$ were used, but the temperatures for free gas and $S(\alpha, \beta)$ models were $900 \mathrm{~K}$ and $800 \mathrm{~K}$, respectively. Thus, the MONTEBURNS calculation was not performed at the exact cold state, and thereby the results should be between the results of the cold and operating conditions. In the MONTEBURNS calculations, 100,000 neutron histories were used for the flux calculation at a time point, the neutron tallies were started after skipping first 50 cycles (1,000 histories per cycle).

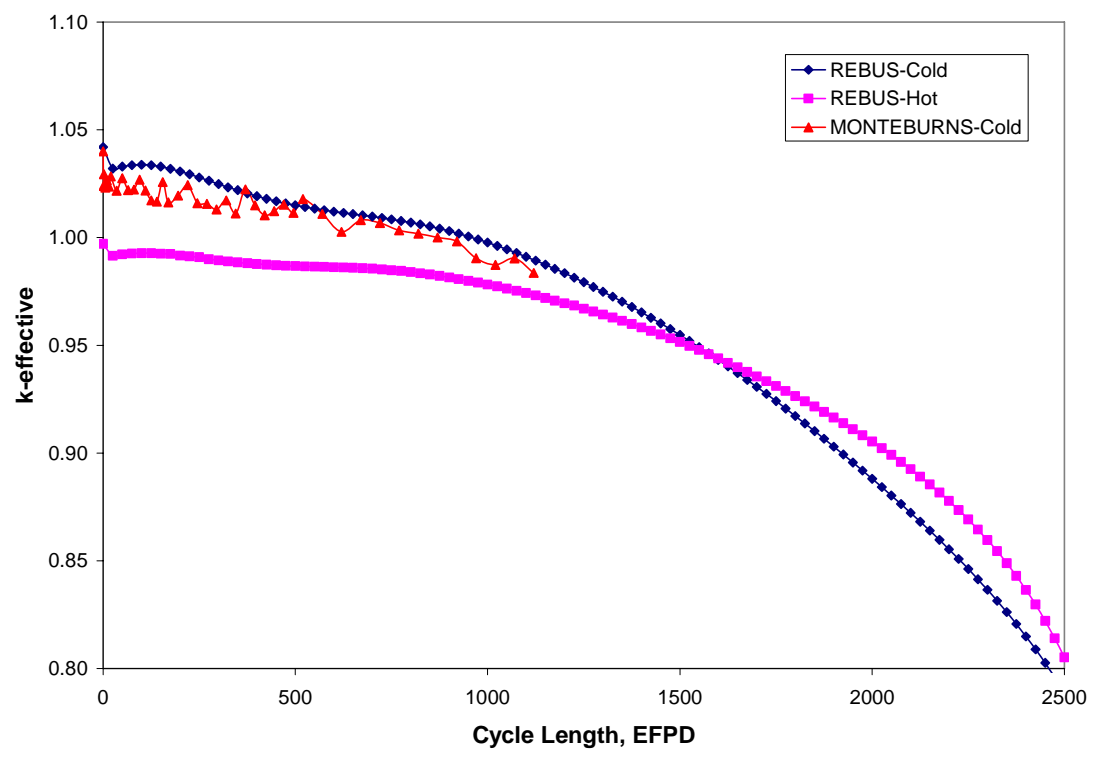

Figure 3.7. Whole-Core Depletions with Monte Carlo and Deterministic Methods 
The results of the WIMS8/REBUS-3 coupled calculations show that the initial k-effective of the cold state is higher than that of the operating condition due to the temperature feedback effect. In the MONTEBURNS calculations, the fluctuation of k-effective is observed due to the small number of neutron histories and large time intervals. This implies that a refinement of the Monte Carlo depletion calculation is necessary. Despite this fact, the MONTEBURNS results are in between the WIMS8/REBUS-3 results for the cold and hot conditions, as expected. This result indicates that the WIMS8/REBUS-3 coupling procedure is applicable to the DB-MHR core analysis. 


\section{ONE-PASS DEEP-BURN TRANSMUTATION}

\subsection{Fuel Shuffling in One-Pass DB-MHR}

Figure 4.1 shows the radial shuffling scheme of the one-pass deep-burn concept. For the NGNP core composed of 102 fuel columns, a two-batch fuel management scheme was proposed to meet the targeted cycle length and discharge burnup simultaneously. [5] For the one-pass DB-MHR concept, a four-batch fuel management scheme with an increased number of fuel columns to 144 was proposed to increase the discharge burnup (or TRU consumption). In Figure 4.1, the gray hexagons denote the inner and outer reflectors, and the active core is represented by colored hexagons.

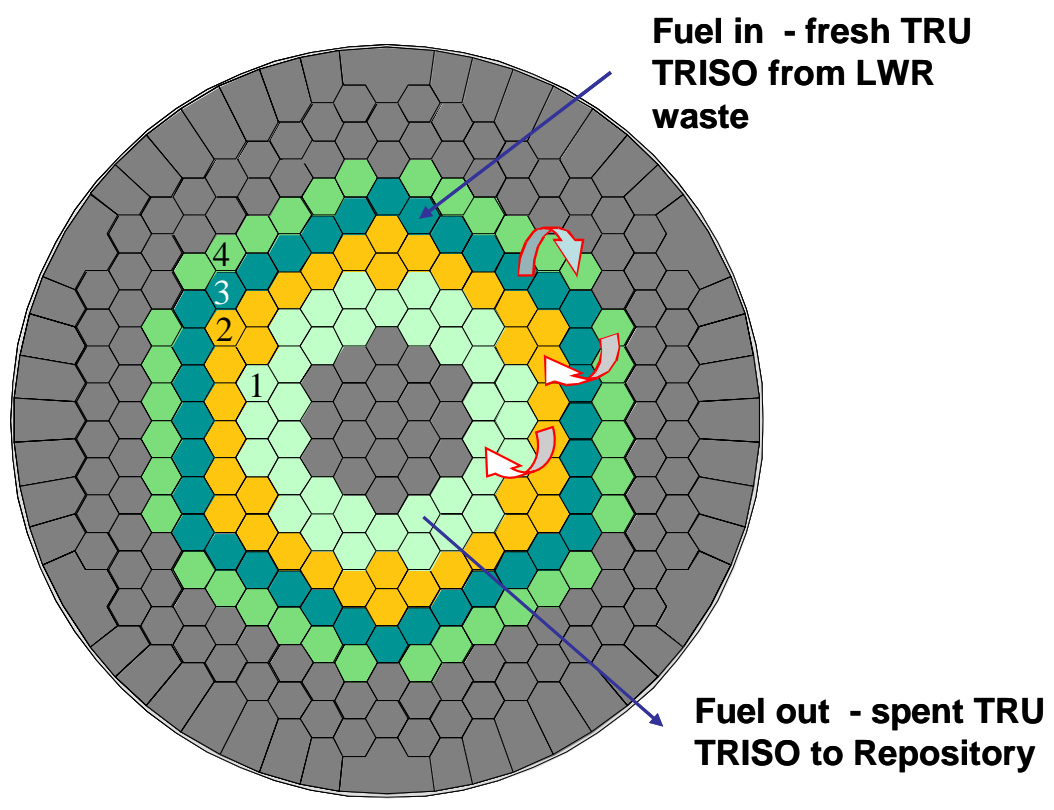

Figure 4.1. Radial Shuffling Scheme of One-Pass Deep-Burn Concept

The active core is divided into four regions, each of which is composed of 36 fuel columns. Fresh TRU fuel is loaded into the dark green region (denoted by 3 in Figure 4.1), and moved sequentially into the green (4), yellow (2), and light-green (1) regions in the subsequent cycles. In this fuel management scheme, loading of fresh fuel near the inner and outer reflectors is avoided, to prevent excessive power peaking at the interface between the graphite reflectors 
and fuel blocks. An axial shuffling was additionally proposed to deplete TRU more effectively by achieving a flatter discharge burnup distribution. At each shuffling time, the fuel blocks located at the middle of the core are shuffled with those at the top and bottom of the core. Based on this axial shuffling strategy, the $5^{\text {th }}$ and $6 t^{\mathrm{t}}$ axial fuel blocks are interchanged with the $1^{\text {st }}$ and $10^{\text {th }}$ axial fuel blocks, respectively, and the $4^{\text {th }}$ and $7^{\text {th }}$ axial fuel blocks are interchanged with the $2^{\text {nd }}$ and $9^{\text {th }}$ axial fuel blocks, respectively. The $3^{\text {rd }}$ and $8^{\text {th }}$ axial fuel blocks are not moved.

\subsection{Sensitivity Calculations for One-Pass DB-MHR}

\subsubsection{Characteristics of DB-MHR Fuel}

Assembly depletion calculations can be used for the scoping fuel cycle study, if an assembly spectrum is representative of the core spectrum. However, the thermal spectrum of the DB-MHR core is noticeably different from that of a fuel block as shown in Figure 4.2, which compares the spectrum of the DB-MHR core with the spectra of DB-MHR fuel block and typical PWR assembly. In this comparison, the kernel size and packing fraction of the DB-MHR fuel are $200 \mu \mathrm{m}$ and $20 \%$, respectively.

The primary cause for the different spectrum between the core and unit fuel block of DB-MHR is the inner reflector. Since the absorption cross section of graphite is practically zero, the fast neutrons leaking out of the core into the inner reflector are slowed down and return to the active core as thermal neutrons. Thus, the thermal neutron flux of the DB-MHR core is higher than that of the unit fuel block. This difference in spectrum results in different time-evolutions of nuclide densities between the core and unit fuel block.

For three representative cases of fuel-to-moderator ratios, the time-evolutions of the core k-effective and fuel block k-infinity are compared in Figure 4.3 in two units of time (burnup and effective full power days (EFPD)). These cases, which are labeled by the fuel kernel diameter in Figure 4.3, represent two bounding points and one middle point in the potential range of fuel-tomoderator ratio of the DB-MHR fuel. The cases of $150 \mu \mathrm{m}$ and $300 \mu \mathrm{m}$ kernel diameters correspond to the smallest and the largest fuel-to-moderator ratio, respectively, and the $200 \mu \mathrm{m}$ 
case represents a middle value. The corresponding packing fractions of the 150, 200, and $300 \mu \mathrm{m}$ cases are $15 \%$, $20 \%$ and $24 \%$, respectively.

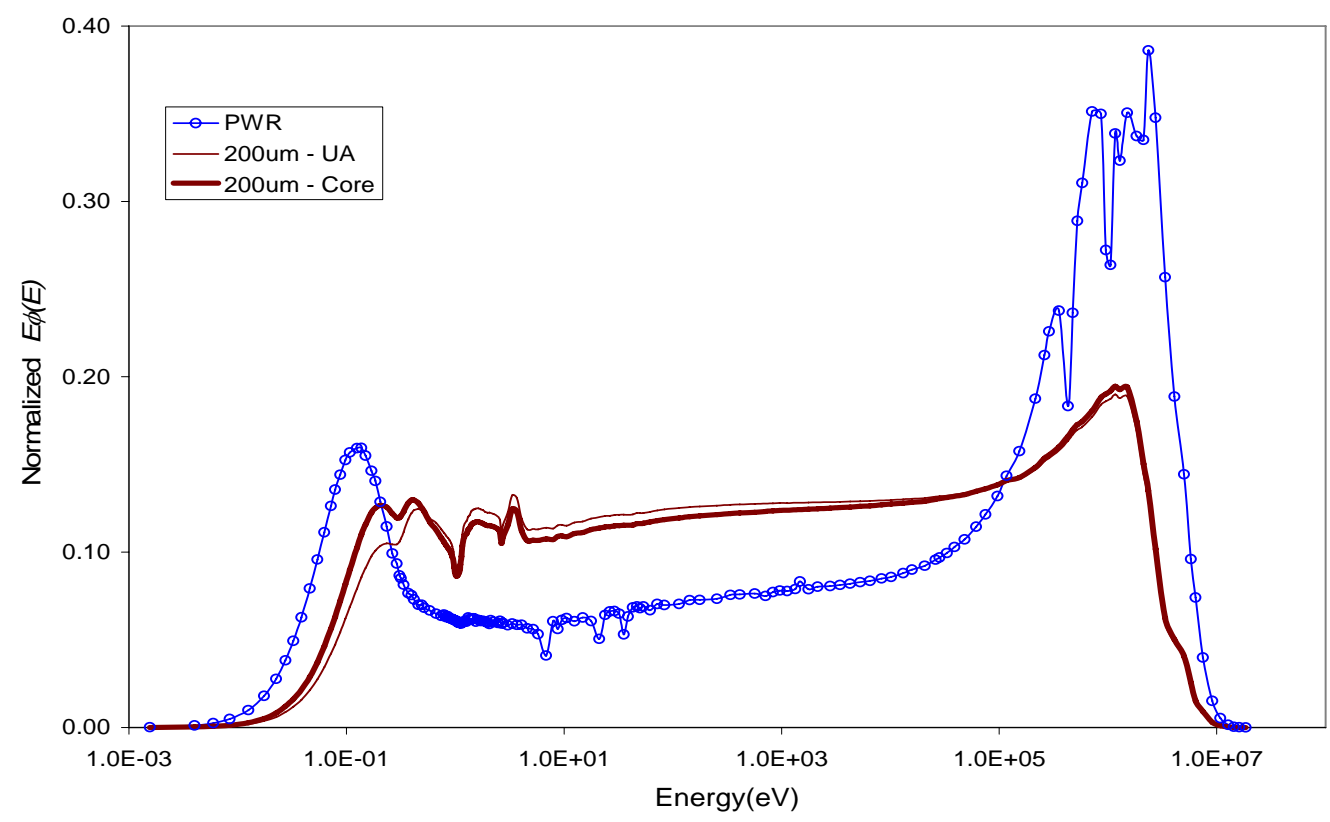

Figure 4.2. Comparison DB-MHR Core and Assembly Spectra
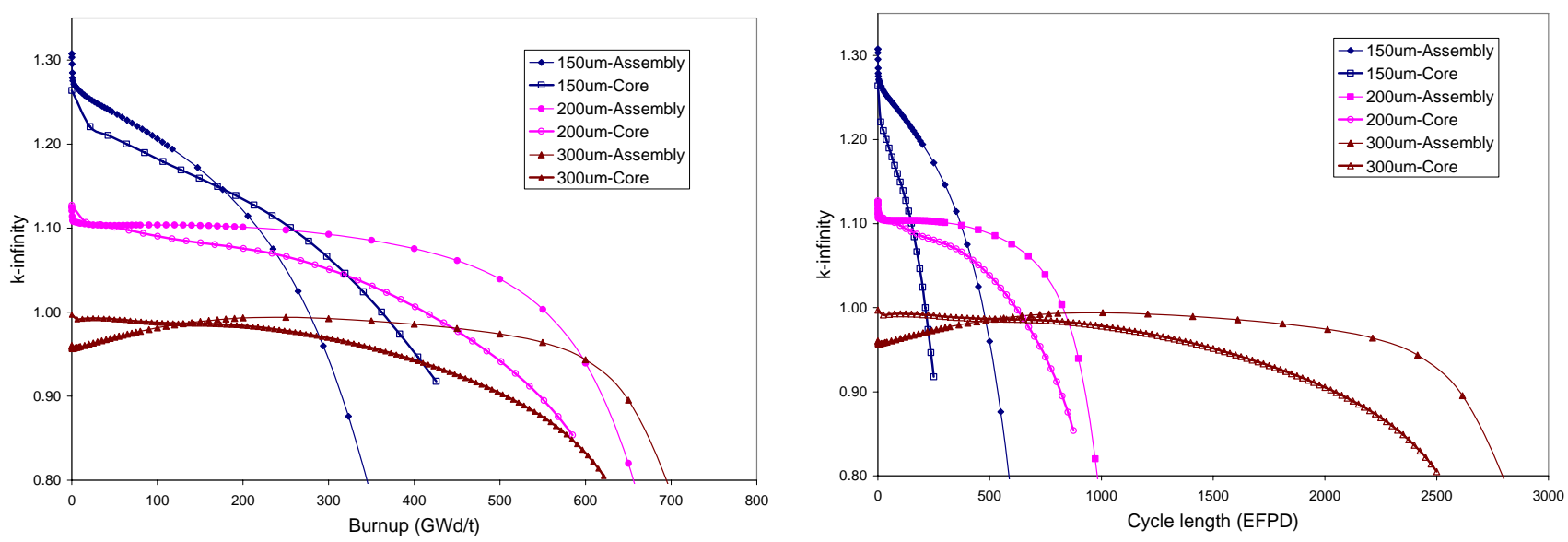

Figure 4.3. Depletion Calculations of DB-MHR Whole-Core and Unit Assembly

As the fuel-to-moderator ratio decreases, the initial k-effective and k-infinity increase because the resonance escape probability increases. Typically, it is expected that for the same composition, the fuel block k-infinity is greater than the core k-effective because of the neutron 
leakages at the core boundary. In the $150 \mu \mathrm{m}$ case, the initial k-infinity is greater than the initial k-effective, and thus this expectation is met. As the fuel-to-moderator ratio increases, however, the k-infinity becomes smaller than the k-effective. The thermal neutrons returned from the inner reflector increase the k-effective significantly for the high TRU loading case (see $300 \mu \mathrm{m}$ case).

The cycle length decreases with decreasing fuel-to-moderator ratio, because of the high specific power density. The critical cycle lengths of the 150 and $200 \mu \mathrm{m}$ cases are about 210 and 610 days, respectively, and the corresponding critical burnups are 360 and $410 \mathrm{GWd} / \mathrm{t}$. These results suggest that the high fuel-to-moderator ratio is favorable to increase the cycle length and discharge burnup. However, since the initial k-effective decreases with increasing fuel-tomoderator ratio, the high fuel-to-moderator ratio can make the k-effective smaller than unity. Note that the $300 \mu \mathrm{m}$ case could not maintain the critical state; the initial k-effective is smaller than one. In this study, the optimum fuel-to-moderator ratio was determined from a series of parametric studies discussed in Section 4.2.5.

\subsubsection{Comparison of Equilibrium Core and Transitional Core}

Equilibrium cycle is a more valid basis than some arbitrary sequence of startup cycles to access the relative core performance. Thus, it is desirable to evaluate the TRU consumption of the DB-MHR concept based on the equilibrium cycle performance. The equilibrium cycle implies a reactor condition that is invariant for successive operating cycles for a fixed fuel management scheme and specific operating requirements. In other words, it is the limiting cycle achieved after an infinite number of burn cycles. The REBUS-3 code has a unique capability that provides estimates of the burn cycle time, control requirements, fuel enrichments, and general system performance characteristics of the equilibrium cycle at a lower overall computational cost than the explicit calculation of a number of start-up burn cycles. Thus, the performance of the DB-MHR concept was evaluated using the equilibrium cycle analysis capability of the REBUS-3 code.

The REUBS-3 code allows several search options: 1) cycle length to achieve a specified discharge burnup, 2) fuel enrichment to achieve a specified multiplication factor at a specified burnup point, 3) control poison material to maintain a specified multiplication factor, and 4) 
cycle length to achieve a specified multiplication factor at the end of burnup step. In this study, the fourth option was utilized to determine the equilibrium DB-MHR core, that is, using a fixed fresh TRU composition recovered from a typical LWR spent fuel, the equilibrium cycle length was determined such that the k-effective at the end of cycle is one.

To confirm the equilibrium state searched by the REBUS-3 code, the transitional cycle analysis (i.e., cycle-by-cycle) was performed up to the $7^{\text {th }}$ cycles. The core k-effective values are compared in Figure 4.4. This calculation was performed using a power level of $800 \mathrm{MWt}$, kernel diameter of $200 \mu \mathrm{m}$, and packing fraction of $20 \%$. The k-effective value of the cycle-by-cycle analysis is initially higher than that of the equilibrium core, because the entire core is loaded with fresh fuel. However, it decreases with increasing number of burn cycles and approaches the equilibrium core value. The seventh cycle shows a k-effective trend very similar to that of the equilibrium cycle, although it has not reached the equilibrium cycle completely. This result implies that the REBUS-3 code can search the equilibrium core effectively.

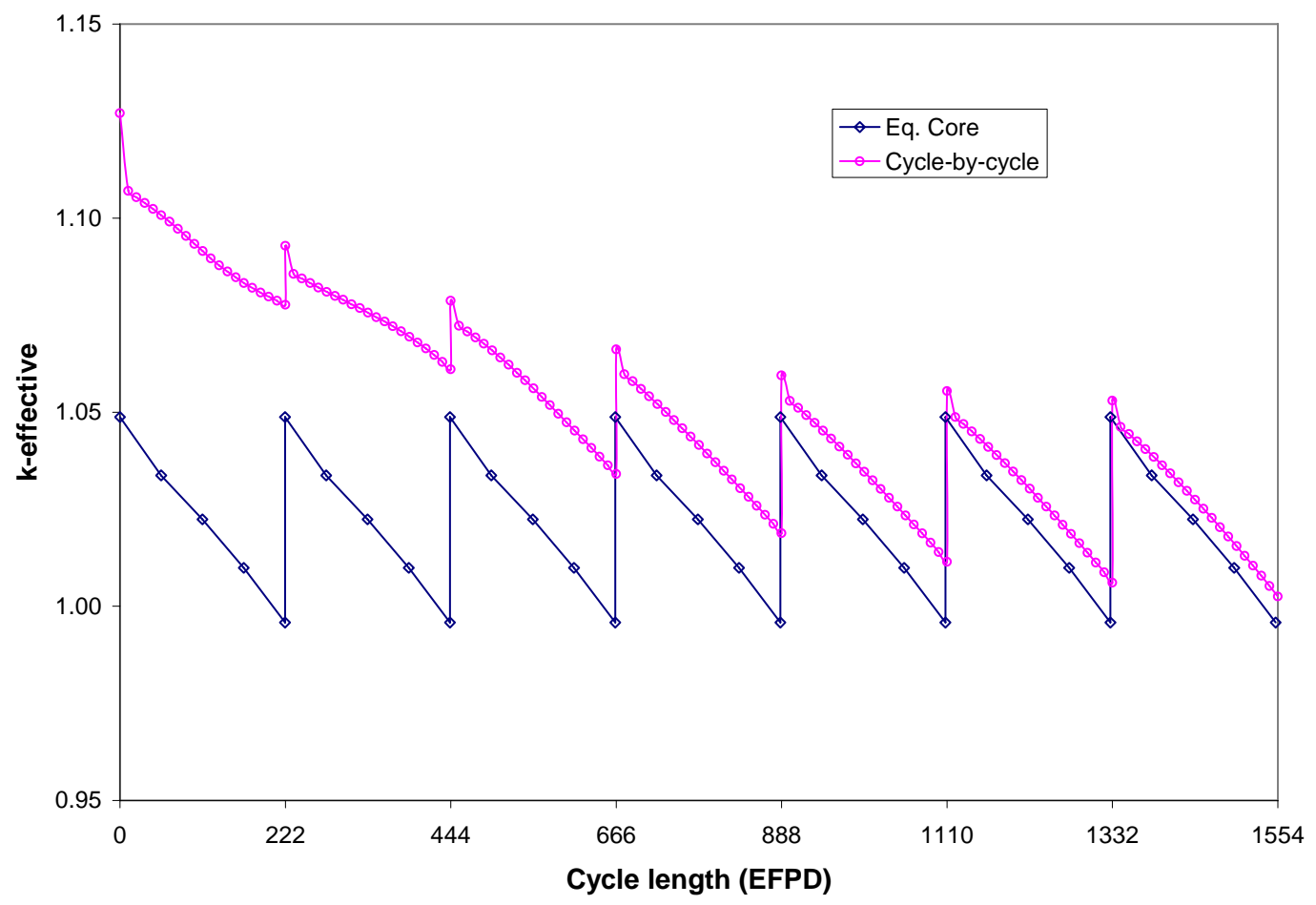

Figure 4.4. Core Multiplication Factors of Equilibrium and Transitional Cores 


\subsubsection{Effects of Fission Product Model and Core Model}

The WIMS8 code traces about 100 fission products in the depletion calculations. Because there is no limitation on the size of the depletion chain in the REBUS-3 code, all fission products (AFP) of the WIMS8 code can be traced explicitly in the WIMS8/REBUS-3 coupling calculations. This model is however time consuming because of the size of the transmutation matrix. Thus, a simplified lumped fission product (LFP) model was developed and used predominantly in whole-core depletion calculations in this study. To reduce the computation time, another simplification was utilized by simplifying the core geometry: i.e., cylindrical-Z (R-Z) core model instead of Hexagonal-Z (Hex-Z) core model.

Since these simplifications may affect the results, the effects were evaluated. Table 4.1 provides the sensitivity results for the fission product and core geometry models. In these calculations, the kernel diameter and packing fraction were assumed to be $200 \mu \mathrm{m}$ and 20\%, respectively, and the core power was assumed to be $600 \mathrm{MWt}$. The LFP model underestimates the cycle length and the TRU consumption if the target k-effective value at the end of cycle is the same as used in the all fission product model (unity). To compensate this effect, the target $\mathrm{k}_{\mathrm{eff}}$ at the end of cycle was set to 0.98 in the LFP model. In Table 4.1, the results of the LFP model with $k_{\text {eff }}=0.98$ are seen to be very close to those obtained with the AFP model. Thus, a k-effective of 0.98 is employed in this work when the LFP model is utilized. Compared to the Hex-Z core model, the R-Z model overestimates the cycle length and TRU consumption by about 9 EFPD and 1.9\%, respectively. However, since the magnitude is not big, the results of the R-Z code models were used without any biasing factor in this study.

Table 4.1. Comparison of Fission Product and Core Geometry Models

\begin{tabular}{|c|c|c|c|c|c|}
\hline \multirow{2}{*}{ Core Model } & \multirow{2}{*}{ FP model } & \multirow{2}{*}{$\begin{array}{c}\text { Target } \\
\text { keff }\end{array}$} & $\begin{array}{c}\text { Cycle length } \\
\text { at EOC }\end{array}$ & \multicolumn{2}{|c|}{ Consumption (\%) } \\
\cline { 3 - 6 } & & 1.00 & 277 & Pu & HM \\
\hline \multirow{3}{*}{ Hex-Z } & AFP & 1.00 & 258 & 59.9 & 56.3 \\
\cline { 2 - 6 } & \multirow{2}{*}{ LFP } & 0.98 & 279 & 60.4 & 52.4 \\
\cline { 3 - 6 } & AFP & 1.00 & 286 & 61.8 & 56.8 \\
\cline { 2 - 6 } RZ & LFP & 0.98 & 284 & 61.4 & 57.7 \\
\hline
\end{tabular}




\subsubsection{Effect of Burnup-Independent Cross Section}

Burnup-dependent cross sections should be used in whole-core depletion calculations for the DB-MHR because the neutron spectrum changes during depletion. In the coupled WIMS8REBUS-3 calculation procedure, the REBUS-3 code interpolates pre-stored burnup-dependent, multi-group microscopic cross sections to obtain the cross sections at a specific burnup point. The WIMS8 code is used to generate the multigroup cross sections at 20 to 50 burnup points and the cross sections are stored in ISOTXS format. The size of the cross section file is dependent on the number of nuclides, number of neutron energy groups, and number of burnup steps in the lattice calculations. In an attempt to reduce the cross section file size and the computation time of the REBUS-3 calculations, the applicability of the burnup-independent cross sections for core depletion calculations was evaluated in this study.

In Table 4.2, the results for the one-pass DB-MHR core obtained with burnup-dependent and burnup-independent cross sections are compared. In these calculations, the DB-MHR fuel data of the previous section were used and the LFP model was utilized. In Table 4.2, BOC-XS and MOC-XS denote the burnup-independent cross sections obtained at beginning of cycle and middle of cycle (100 GWd/t). Generally, the use of BOC cross sections underestimate the cycle lengths (or discharge burnup) and TRU consumption, while the use of MOC cross sections overestimate them. The error ranges are about \pm 5 EFPD for the cycle length and $\pm 0.8 \%$ for TRU consumption.

Table 4.2. Sensitivity Results of Burnup-Dependent and Independent Cross Sections

\begin{tabular}{|c|c|c|c|c|}
\hline \multirow{2}{*}{ Cross section model } & Cycle Length & \multicolumn{2}{|c|}{ Consumption (\%) } & \multirow{2}{*}{$\begin{array}{c}\text { Discharge burnup } \\
\text { (GWd/t) }\end{array}$} \\
\cline { 3 - 4 } & (EFP) & $\mathrm{Pu}$ & $\mathrm{HM}$ & 534 \\
\hline Burnup dependent & 279 & 60.4 & 56.8 & 523 \\
\hline BOC-XS & 274 & 59.7 & 56.0 & 543 \\
\hline MOC-XS & 284 & 61.4 & 57.6 & \\
\hline
\end{tabular}

\subsubsection{Optimum Fuel Data for One-Pass DB-MHR}

To search the optimum fuel design data (kernel size and packing fraction), a bunch of the whole-core depletion calculations was performed within a fuel design domain for which the kernel diameter and packing fraction are within $150 \mu \mathrm{m}$ to $300 \mu \mathrm{m}$ and $15 \%$ to $30 \%$, 
respectively. The R-Z core model and lumped fission product (LFP) model were utilized and the burnup-dependent cross sections were used in the sensitivity calculations.

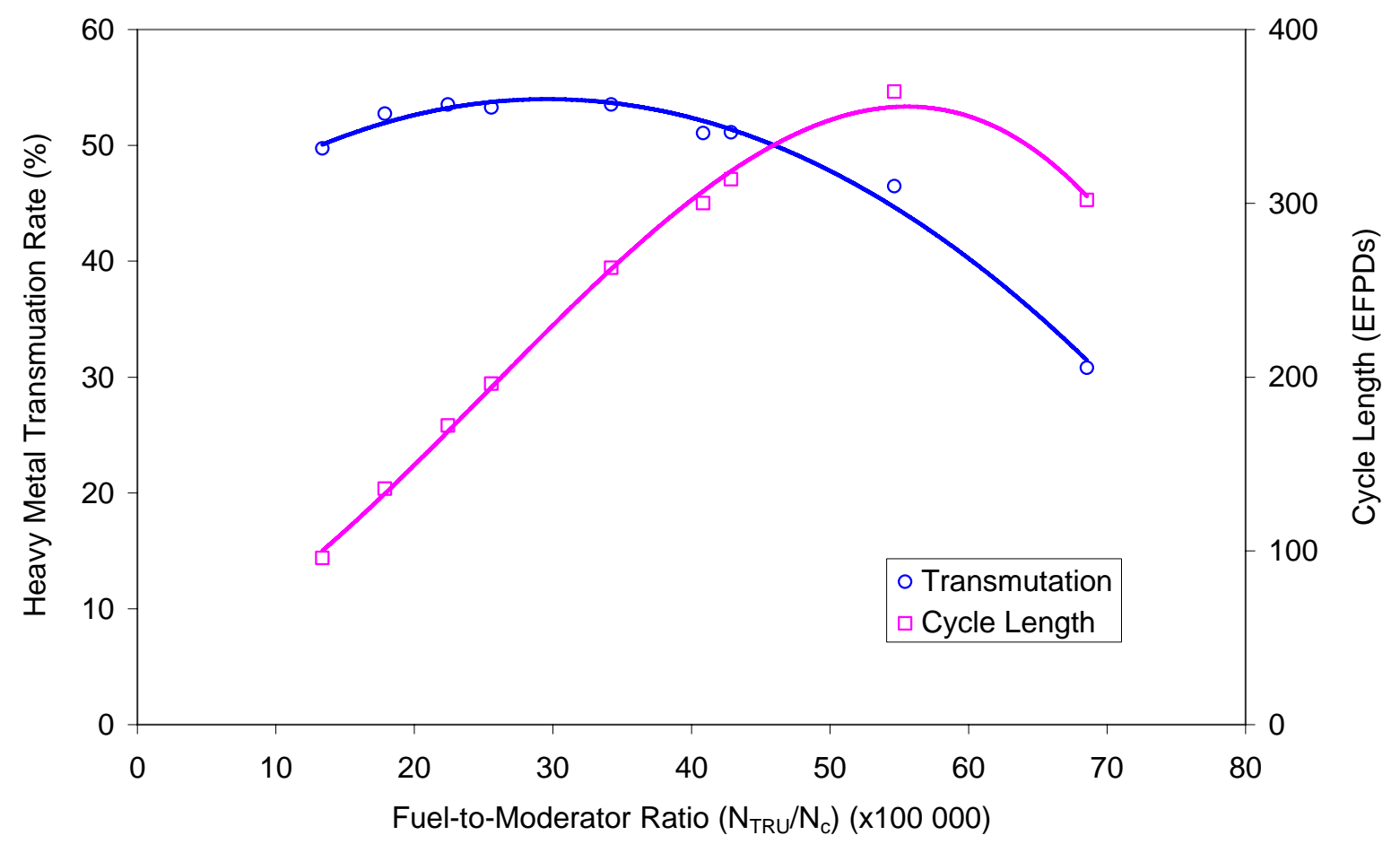

Figure 4.5. DB-MHR Performance as Function of Fuel-to-Moderator Ratio

In Figure 4.5 are displayed the TRU consumption (heavy-metal transmutation rate) and cycle length of the one-pass DB-MHR core as functions of the fuel-to-moderator ratio. Note that the fuel-to-moderator ratio can be changed by varying the kernel size and packing fraction. Both the TRU consumption and the cycle length increase initially, attain peak values and then decrease. This trend is similar to the one observed for the k-infinity. As the $\mathrm{N}_{\mathrm{TRU}} / \mathrm{N}_{\mathrm{C}}$ ratio increases, the k-infinity (burnup) increases, simply because of more fuel in the system (at the limit of zero fuel, the k-infinity is zero). At higher fuel fraction, resonance capture becomes important and the k-infinity (burnup) reaches a maximum and starts to decrease with further increase in fuel loading. The different curves for the cycle length and the burnup or TRU consumption (transmutation rate) are due to the different dependencies of the burnup and cycle length on the fuel mass. 
It is attractive to choose the fuel-to-moderator ratio that maximizes the TRU consumption and the cycle length; but they correspond to difference values. Since the primary purpose of the deep-burn concept is to transmute the LWR spent TRU, fuel-to-moderator ratio corresponding to the maximum TRU consumption was selected (i.e., 0.00034). The kernel diameter and packing fraction corresponding to this ratio are $200 \mu \mathrm{m}$ and $20 \%$, respectively.

\subsection{Performance of One-Pass DB-MHR}

In the previous section, the optimum kernel diameter and packing fraction for the onepass DB-MHR were determined as $200 \mu \mathrm{m}$ and 20\%, respectively. Based on these fuel design data, the transmutation performance of the one-pass DB-MHR was evaluated. The R-Z core model and the all fission product model were utilized in the performance evaluation. Table 4.3 is a summary of the transmutation performance of the one pass DB-MHR. In this table, the TRU consumption is defined as $\left(M-M_{o}\right) / M_{o}$, where $M$ and $M_{o}$ denote the discharged and charged masses, respectively. Thus, a negative value denotes the consumption of nuclide, while a positive value indicates net production of the nuclide.

The discharge burnup of the one-pass DB-MHR is $546 \mathrm{GWd} / \mathrm{t}$ and the corresponding cycle length is 286 EFPD. The initial fresh TRU mass is $299 \mathrm{~kg}$ and the discharge mass is about $126 \mathrm{~kg}$. This indicates that the overall TRU consumption of the total heavy metal is 58\%. The consumption of Plutonium is 62\%, including 97\% for Pu-239 depletion. About 55\% of the $\mathrm{Np}$-237 is destroyed in the DB-MHR core. Regarding the power sharing, those for regions 3 and 4 are greater than the core average value while those for regions 2 and 1 are less. The power of the DB-MHR core is thus skewed to the regions 3 and 4. This results in high power peaking factors in region 3 or 4 . In particular, the power sharing of region 4 is greater than that of the region 3 even though the region average burnup is higher. This effect is caused by the return of thermal neutrons to the outer region 4 . Note that the regions 3, 4, 2, and 1 are the locations of the fresh, once, twice and triple burnt fuels. At the bottom of Table 4.3, the regional TRU consumptions are provided. Generally, the regional TRU consumptions are proportional to the power sharing. Thus, the TRU consumption is highest for the region 4. 
Table 4.3. Performance of 600 MWt One-Pass DB-MHR

\begin{tabular}{|c|c|c|c|c|c|c|c|}
\hline & & \multicolumn{4}{|c|}{ Charge } & \multirow[t]{2}{*}{ Discharge } & \multirow{2}{*}{$\begin{array}{c}\text { Consumption } \\
\text { (\%) }\end{array}$} \\
\hline \multicolumn{2}{|c|}{ Region } & R3 & $\mathrm{R} 4$ & R2 & $\mathrm{R} 1$ & & \\
\hline \multirow{22}{*}{$\begin{array}{c}\text { Mass } \\
(\mathrm{kg})\end{array}$} & U-233 & 0.00 & 0.00 & 0.00 & 0.00 & 0.00 & \\
\hline & U-234 & 0.00 & 0.03 & 0.10 & 0.19 & 0.28 & \\
\hline & U-235 & 0.00 & 0.00 & 0.01 & 0.02 & 0.04 & \\
\hline & U-236 & 0.00 & 0.00 & 0.01 & 0.01 & 0.02 & \\
\hline & U-237 & 0.00 & 0.00 & 0.00 & 0.00 & 0.00 & \\
\hline & U-238 & 0.00 & 0.00 & 0.00 & 0.00 & 0.00 & \\
\hline & Np-237 & 13.75 & 11.51 & 9.48 & 7.73 & 6.20 & -54.9 \\
\hline & Np-239 & 0.00 & 0.00 & 0.00 & 0.00 & 0.00 & \\
\hline & Pu-238 & 3.99 & 8.70 & 14.58 & 18.84 & 20.33 & 409.1 \\
\hline & Pu-239 & 152.63 & 86.52 & 33.97 & 13.48 & 4.84 & -96.8 \\
\hline & $\mathrm{Pu}-240$ & 62.24 & 56.65 & 49.21 & 31.68 & 18.20 & -70.8 \\
\hline & Pu-241 & 22.65 & 37.48 & 36.28 & 33.43 & 21.02 & -7.2 \\
\hline & Pu-242 & 14.80 & 17.60 & 23.46 & 28.16 & 33.49 & 126.2 \\
\hline & Am-241 & 24.60 & 15.99 & 9.16 & 5.33 & 2.71 & -89.0 \\
\hline & Am-242 ${ }^{\mathrm{m}}$ & 0.09 & 0.38 & 0.21 & 0.13 & 0.05 & -40.1 \\
\hline & Am-243 & 4.52 & 5.63 & 6.78 & 8.12 & 9.19 & 103.1 \\
\hline & Cm-242 & 0.00 & 4.11 & 4.64 & 3.52 & 2.54 & \\
\hline & Cm-243 & 0.00 & 0.05 & 0.11 & 0.14 & 0.13 & \\
\hline & $\mathrm{Cm}-244$ & 0.00 & 1.47 & 2.88 & 4.57 & 6.06 & \\
\hline & Cm-245 & 0.00 & 0.07 & 0.19 & 0.37 & 0.43 & \\
\hline & $\mathrm{Pu}$ & 256.3 & 206.9 & 157.5 & 125.6 & 97.9 & -61.8 \\
\hline & $\mathrm{HM}$ & 299.3 & 246.2 & 191.1 & 155.7 & 125.5 & -58.1 \\
\hline \multicolumn{2}{|c|}{ Burnup (GWd/t) } & 0.0 & 167.4 & 340.7 & 451.6 & 546.1 & \\
\hline \multicolumn{2}{|c|}{ Power sharing } & 1.23 & 1.27 & 0.81 & 0.69 & & \\
\hline \multicolumn{2}{|c|}{ Consumption (\%) } & $\begin{array}{l}-17.8 \\
\end{array}$ & -18.4 & -11.8 & -10.1 & & \\
\hline
\end{tabular}

\subsubsection{Impact of Power Level on DB-MHR TRU Consumption}

The number of fuel columns in the one-pass DB-MHR core is higher by about $41 \%$ compared to the GT-MHR (144 versus 102) for the same core power level. This implies that the power density of the DB-MHR is significantly smaller than that of the GT-MHR. The small power density will obviously have an adverse effect on plant economics. To obtain a similar power density as the GT-MHR, the power level of the DB-MHR was increased to $800 \mathrm{MWt}$ and its performance was evaluated in a sensitivity study. Table 4.4 is a summary of the transmutation data for the 800 MWt DB-MHR core. In this calculation, all data except for the core power level were conserved from the 600 MWt DB-MHR design. 
Because of the higher specific power of the 800 MWt core, one might expect the cycle length to decrease relative to that for the $600 \mathrm{MWt}$ core. This is the case; its cycle length is 222 EFPD (compared 286 EFPD for the $600 \mathrm{MWt}$ core). The discharge burnup of the $800 \mathrm{MWt}$ core is, however, slightly increased compared to that of the $600 \mathrm{MWt}$ core $(561 \mathrm{GWd} / \mathrm{t}$ versus 546 GWd/t) because the higher power density (higher flux level) reduces the decay-to-fission rate of $\mathrm{Pu}-241$. Note that the Pu-241 decays to a neutron absorber, and the presence of this absorber reduces core reactivity over the irradiation time and hence the discharge burnup. Thus, the overall performance of the $800 \mathrm{MWt}$ core is slightly better than for the $600 \mathrm{MWt}$ core due to its higher discharge burnup; the TRU consumption is $60.1 \%$.

Table 4.4. Performance of 800 MWt One-Pass DB-MHR

\begin{tabular}{|c|c|c|c|c|c|c|c|}
\hline \multirow{2}{*}{ Region } & & \multicolumn{4}{|c|}{ Charge } & \multirow{2}{*}{ Discharge } & \multirow{2}{*}{$\begin{array}{c}\text { Consumption } \\
(\%)\end{array}$} \\
\hline & & R3 & R4 & R2 & R1 & & \\
\hline \multirow{22}{*}{$\begin{array}{l}\text { Mass } \\
\text { (kg) }\end{array}$} & U-233 & 0.00 & 0.00 & 0.00 & 0.00 & 0.00 & \\
\hline & U-234 & 0.00 & 0.03 & 0.07 & 0.14 & 0.21 & \\
\hline & U-235 & 0.00 & 0.00 & 0.01 & 0.02 & 0.03 & \\
\hline & U-236 & 0.00 & 0.00 & 0.01 & 0.01 & 0.01 & \\
\hline & U-237 & 0.00 & 0.00 & 0.00 & 0.00 & 0.00 & \\
\hline & U-238 & 0.00 & 0.00 & 0.00 & 0.00 & 0.00 & \\
\hline & $\mathrm{Np}-237$ & 13.75 & 11.41 & 9.31 & 7.47 & 5.87 & -57.3 \\
\hline & Np-239 & 0.00 & 0.00 & 0.00 & 0.00 & 0.00 & \\
\hline & Pu-238 & 3.99 & 8.39 & 13.94 & 18.04 & 19.29 & 383.1 \\
\hline & Pu-239 & 152.63 & 83.64 & 31.01 & 11.29 & 3.85 & -97.5 \\
\hline & Pu-240 & 62.24 & 56.35 & 47.49 & 28.92 & 16.00 & -74.3 \\
\hline & Pu-241 & 22.65 & 37.98 & 36.62 & 32.15 & 17.97 & -20.7 \\
\hline & Pu-242 & 14.80 & 17.82 & 24.03 & 29.16 & 34.52 & 133.2 \\
\hline & Am-241 & 24.60 & 15.39 & 8.32 & 4.42 & 1.95 & -92.1 \\
\hline & $\mathrm{Am}-242^{\mathrm{m}}$ & 0.09 & 0.38 & 0.19 & 0.10 & 0.04 & -57.5 \\
\hline & Am-243 & 4.52 & 5.69 & 6.90 & 8.31 & 9.42 & 108.1 \\
\hline & Cm-242 & 0.00 & 4.76 & 5.64 & 4.46 & 3.18 & \\
\hline & Cm-243 & 0.00 & 0.06 & 0.13 & 0.17 & 0.16 & \\
\hline & Cm-244 & 0.00 & 1.55 & 3.04 & 4.87 & 6.51 & \\
\hline & Cm-245 & 0.00 & 0.08 & 0.20 & 0.40 & 0.44 & \\
\hline & $\mathrm{Pu}$ & 256.3 & 204.2 & 153.1 & 119.6 & 91.6 & -64.3 \\
\hline & HM & 299.3 & 243.5 & 186.9 & 149.9 & 119.4 & -60.1 \\
\hline \multicolumn{2}{|c|}{ Burnup (GWd/t) } & 0.0 & 175.8 & 353.8 & 469.8 & 565.2 & \\
\hline \multicolumn{2}{|c|}{ Power sharing } & 1.24 & 1.26 & 0.82 & 0.67 & & \\
\hline
\end{tabular}




\subsubsection{Axial Shuffling Effect}

The use of axial shuffling in the one-pass deep-burn concept was proposed to deplete TRU more effectively. However, axial shuffling might require increased effort during the reloading period because of its complexity. The effect of no axial shuffling on the DB-MHR performance has been evaluated in this study, and the results are summarized in Table 4.5. In this table, the axial shuffling case is the DB-MHR core utilizing the axial shuffling scheme, while the non-axial shuffling case does not utilize axial shuffling. The axial burnup distributions of charge and discharge stages are plotted in Figure 4.6.

Table 4.5. Axial Shuffling Effect

\begin{tabular}{|c|c|c|c|c|c|c|c|}
\hline & Region & R3 & $\mathrm{R} 4$ & $\mathrm{R} 2$ & $\mathrm{R} 1$ & $\begin{array}{c}\text { Discharge } \\
\text { burnup }\end{array}$ & $\begin{array}{c}\text { Consumption } \\
\text { (\%) }\end{array}$ \\
\hline \multirow{2}{*}{$\begin{array}{c}\text { Axial } \\
\text { shuffling }\end{array}$} & Burnup (GWd/t) & 0.0 & 175.8 & 353.8 & 469.8 & \multirow{2}{*}{546} & \multirow{2}{*}{$\begin{aligned} \mathrm{Pu} & =61.8 \\
\mathrm{HM} & =58.1\end{aligned}$} \\
\hline & Power sharing & 1.24 & 1.26 & 0.82 & 0.67 & & \\
\hline \multirow{2}{*}{$\begin{array}{l}\text { Non-axial } \\
\text { shuffling }\end{array}$} & Burnup (GWd/t) & 0.0 & 164.5 & 334.4 & 444.1 & \multirow{2}{*}{538} & \multirow{2}{*}{$\begin{aligned} \mathrm{Pu} & =60.9 \\
\mathrm{HM} & =57.2\end{aligned}$} \\
\hline & Power sharing & 1.22 & 1.26 & 0.82 & 0.70 & & \\
\hline
\end{tabular}
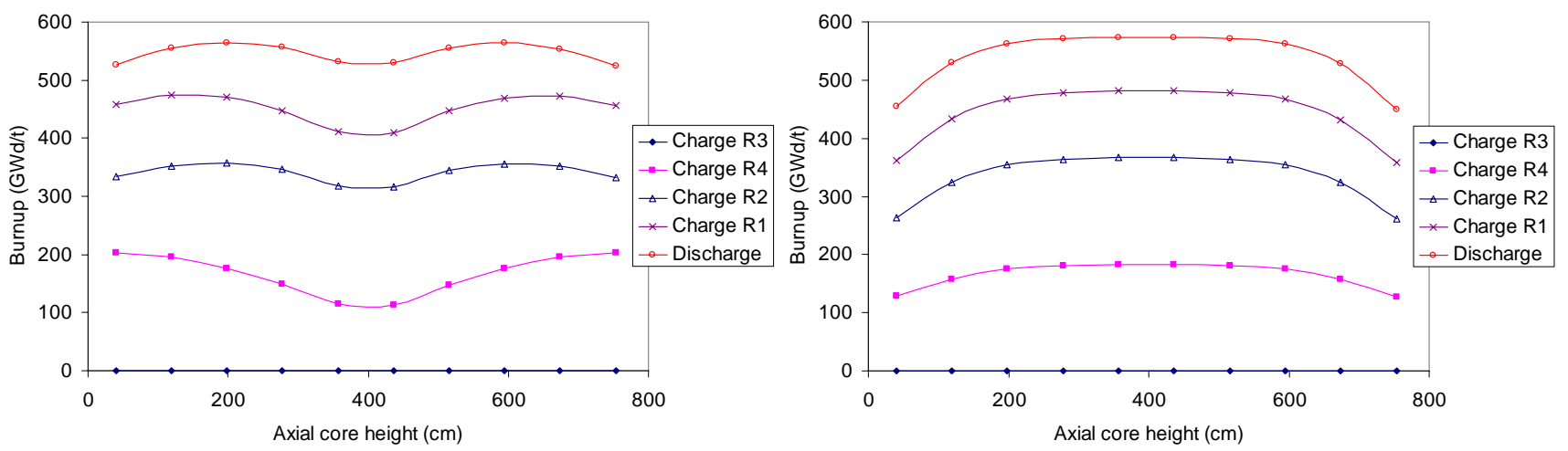

Figure 4.6. Axial Burnup Distributions

(Left: Axial Shuffling case, Right: Non-axial shuffling case) 
The axial burnup distributions of the non-axial shuffling stages are cosine shape because neutron leakage at the top and bottom of the core reduces the power sharing at those locations. However, the axial burnup distribution of the axial shuffling case is depressed at the core center and the discharge burnup distribution is relatively flatter than that of the non-axial shuffling case. This flatter burnup distribution results in a higher discharge burnup and the TRU consumption for the case using axial shuffling is higher by about $0.9 \%$. This trend is likely due to the effective utilization of all the fuel in the core (including the peripheral one) in the case with axial shuffling, which tends to increase the effective core reactivity.

Conversely, however, the axial shuffling scheme increases the peak power. The axial power distribution of the axial shuffling case is plotted in Figure 4.7, including the axial power shape of the non-axial shuffling case in region 4 . Note that the peak power occurs in region 4 for both cases. Since the fuel elements with low burnup are shuffled to the center of region 4 (see charge burnup distribution in Figure 4.6), the axial power shape of the axial shuffling case is more skewed to the core center compared to the no-axial shuffling case.

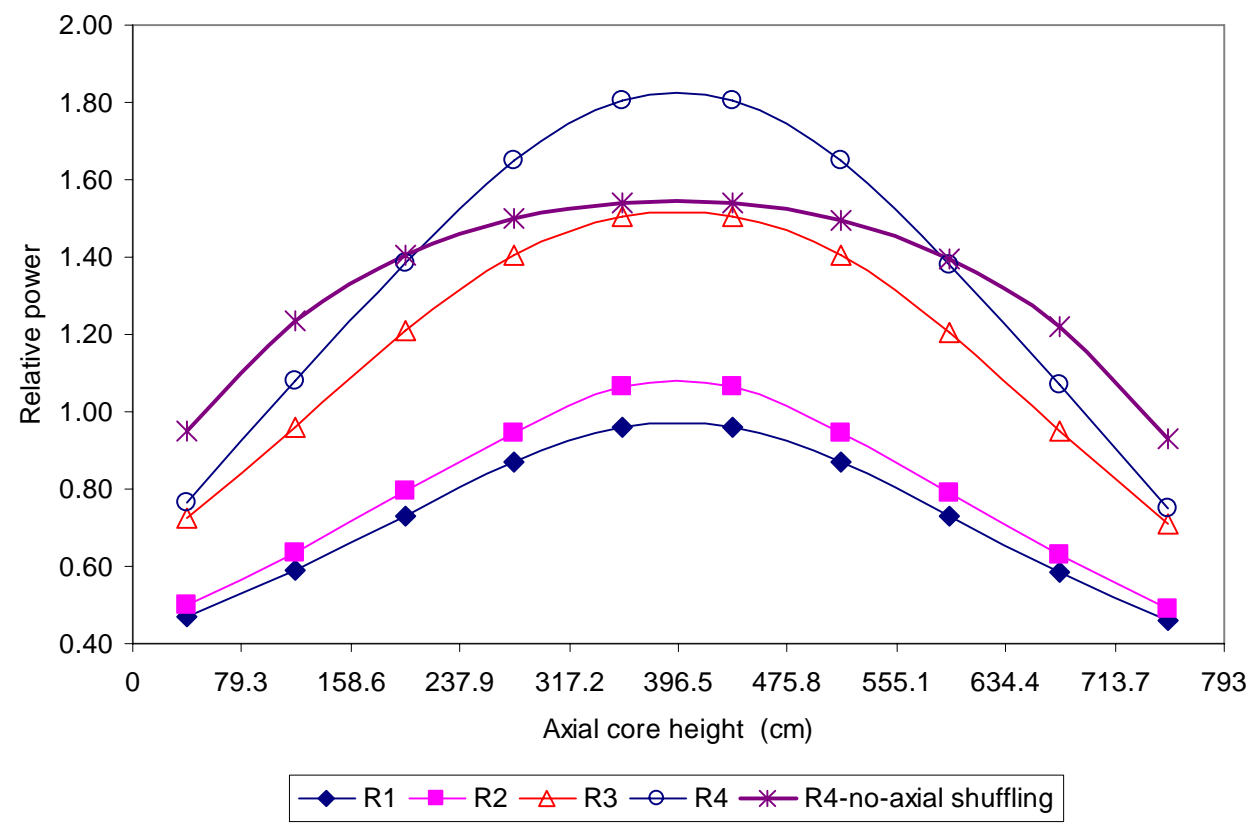

Figure 4.7. Axial Power Distributions 


\subsubsection{Initial TRU Vector Effect}

The initial TRU vector for the deep-burn concept was provided by General Atomics (see Table 2.1), but the burnup of the spent nuclear fuel (SNF) and cooling time after discharge were not provided. To determine the attributes of the TRU vector provided by GA, the TRU vectors of the LWR SNF having different discharge burnup and cooling time are compared in Table 4.6. The Medium burnup PWR and Standard burnup PWR denote the current commercial PWR and the Generation-III, Advanced Light Water Reactors. The average discharge burnups of the medium and standard burnup PWRs are assumed to be $33.0 \mathrm{GWd} / \mathrm{t}$ and $50.0 \mathrm{GWd} / \mathrm{t}$, respectively. The total fissile content of the original TRU vector provided by GA is similar to the medium burnup PWR case with 20-year cooling time, while the individual contents of $\mathrm{Pu}-239$ and Pu-241 are different (GA vector has lower $\mathrm{Pu}-239$ content and higher $\mathrm{Pu}-241$ content). This implies that the original TRU vector is from a fuel with a discharge burnup higher than $33.0 \mathrm{GWd} / \mathrm{t}$ (because of the smaller Pu-239 content) and cooling time shorter than 20 years (because of the higher Pu-241 content).

Table 4.6. Comparison of TRU Vector of LWR Spent Nuclear Fuel (\%)

\begin{tabular}{|c|r|r|r|r|r|}
\hline & Original TRU & \multicolumn{2}{|c|}{ Medium burnup PWR SNF } & \multicolumn{2}{|c|}{ Standard burnup PWR SNF } \\
\hline Discharge burnup & $?$ & \multicolumn{2}{|c|}{$33.0 \mathrm{GWd} / \mathrm{t}$} & \multicolumn{2}{|c|}{$50.0 \mathrm{GWd} / \mathrm{t}$} \\
\hline Cooling time & $?$ & 5 years & 20 years & 5 years & 20 years \\
\hline $\mathrm{Np}-237$ & 4.59 & 4.84 & 4.98 & 4.75 & 4.91 \\
$\mathrm{Pu}-238$ & 1.33 & 1.50 & 1.33 & 2.31 & 2.05 \\
Pu-239 & 51.00 & 53.46 & 53.50 & 48.04 & 48.07 \\
Pu-240 & 20.80 & 21.55 & 21.64 & 22.67 & 22.89 \\
Pu-241 & 7.57 & 9.95 & 4.84 & 10.70 & 5.20 \\
Pu-242 & 4.95 & 4.71 & 4.71 & 6.62 & 6.63 \\
Am-241 & 8.22 & 3.07 & 8.05 & 3.40 & 8.75 \\
Am-242m & 0.03 & 0.02 & 0.01 & 0.01 & 0.01 \\
Am-243 & 1.51 & 0.93 & 0.93 & 1.51 & 1.50 \\
\hline Fissile content & 58.60 & 63.42 & 58.35 & 58.75 & 53.28 \\
\hline
\end{tabular}

Table 4.7 provides the comparison of the TRU consumptions for the one-pass DB-MHR using different initial TRU vectors. Because of a higher fissile content, the cycle length and the discharge burnup of the case with 5-year cooling case are higher (327 EFPDs and $628 \mathrm{GWd} / \mathrm{t}$ ), and the corresponding TRU consumption is $67 \%$. The overall performance of the case with 
20-year cooling is however similar to that using the original TRU vector because of similar initial fissile content. The nuclide consumptions for the cases using the original TRU and the 20-year cooled TRU vector are quite similar except for Pu-241. The Pu-241 consumption is sensitive to its initial mass fraction in the TRU fuel. The Pu-241 mass produced from the $(n, \gamma)$ reaction of $\mathrm{Pu}-240$ are similar because both cores have similar spectrum and initial Pu-240 content. However, due to the high initial content of Pu-241 (7.57\% versus 4.84\%), the destructed Pu-241 mass (via decay and neutron absorption) in original TRU case is higher than that of the case with 20-year cooling. Thus, the net mass Pu-241 change (i.e., production minus destruction) of the original TRU case becomes negative while it is positive in the 20-year cooling case. The produced Pu-241 mass decreases with increasing burnup because its precursors (i.e., Pu-240 \& $\mathrm{Pu}$-239) are depleted. Therefore, the consumption of Pu-241 became more negative for the case with 5-year cooling, due to its higher discharge burnup.

Table 4.7. TRU Consumption of One-Pass DB-MHR for Different TRU Vectors

\begin{tabular}{|l|r|r|r|}
\hline & Original TRU & $\begin{array}{c}\text { Medium burnup PWR } \\
\text { 5-year cooling TRU }\end{array}$ & $\begin{array}{c}\text { Medium burnup PWR } \\
\text { 20-year cooling TRU }\end{array}$ \\
\hline Np-237 & -54.9 & -65.1 & -55.2 \\
Pu-238 & 409.1 & 199.2 & 403.7 \\
Pu-239 & -96.8 & -98.7 & -96.8 \\
Pu-240 & -70.8 & -76.3 & -62.3 \\
Pu-241 & -7.2 & -67.1 & 30.9 \\
Pu-242 & 126.2 & 145.1 & 120.6 \\
Am-241 & -89.0 & -90.1 & -89.0 \\
Am-243 & 103.1 & 251.5 & 204.7 \\
\hline Pu & -61.8 & -72.5 & -61.3 \\
\hline HM & -58.1 & -66.9 & -58.0 \\
\hline Discharge Burnup (GWd/t) & 546 & 628 & 546 \\
\hline Cycle Length (EFPD) & 286 & 327 & 281 \\
\hline
\end{tabular}

\subsubsection{Operating Temperature Effect}

The high operating temperature of the GT-MHR allows to obtain a higher plant efficiency than for light water cooled reactors. The nominal plant efficiency of the GT-MHR is $47.7 \%$, compared to $\sim 33 \%$ for light water reactors. High operating temperature is also attractive for hydrogen production, as is currently being considered for the Next Generation Nuclear Plant. 
However, higher temperature typically implies a lower core reactivity state because of increased resonance absorption. This tends to reduce the core cycle length as the temperature is elevated. For example, the temperature reactivity defect of the DB-MHR core was evaluated to about $4.7 \% \Delta \mathrm{k}$ in the whole-core calculation using the REBUS-3/WIMS8 system (see section 3). Thus, the DB-MHR core can gain additional reactivity by decreasing the operating temperature; this implies that the DB-MHR core can have a longer cycle length (or higher TRU consumption) by decreasing the operating temperature. In addition, the core would gain operational safety margin because of the larger difference between the operating fuel temperature and the limiting fuel temperature; of course plant thermal efficiency would be degraded.

To evaluate the performance of the low operating temperature core, the overall temperatures of the DB-MHR core were reduced by $200 \mathrm{~K}$ : thus, the temperatures of kernel, graphite and coolant are 1073, 873, and $743 \mathrm{~K}$, respectively. The k-infinities of unit assemblies (fuel elements) at the high (i.e., normal operating condition) and low temperatures are compared in Figure 4.8. Due to the temperature reactivity defect, the initial k-infinity of the low temperature assembly is higher than that of the high temperature assembly and this higher value holds till 800 days. Thus, a longer cycle length (or discharge burnup) is expected from this comparison when the operating temperature decreases.

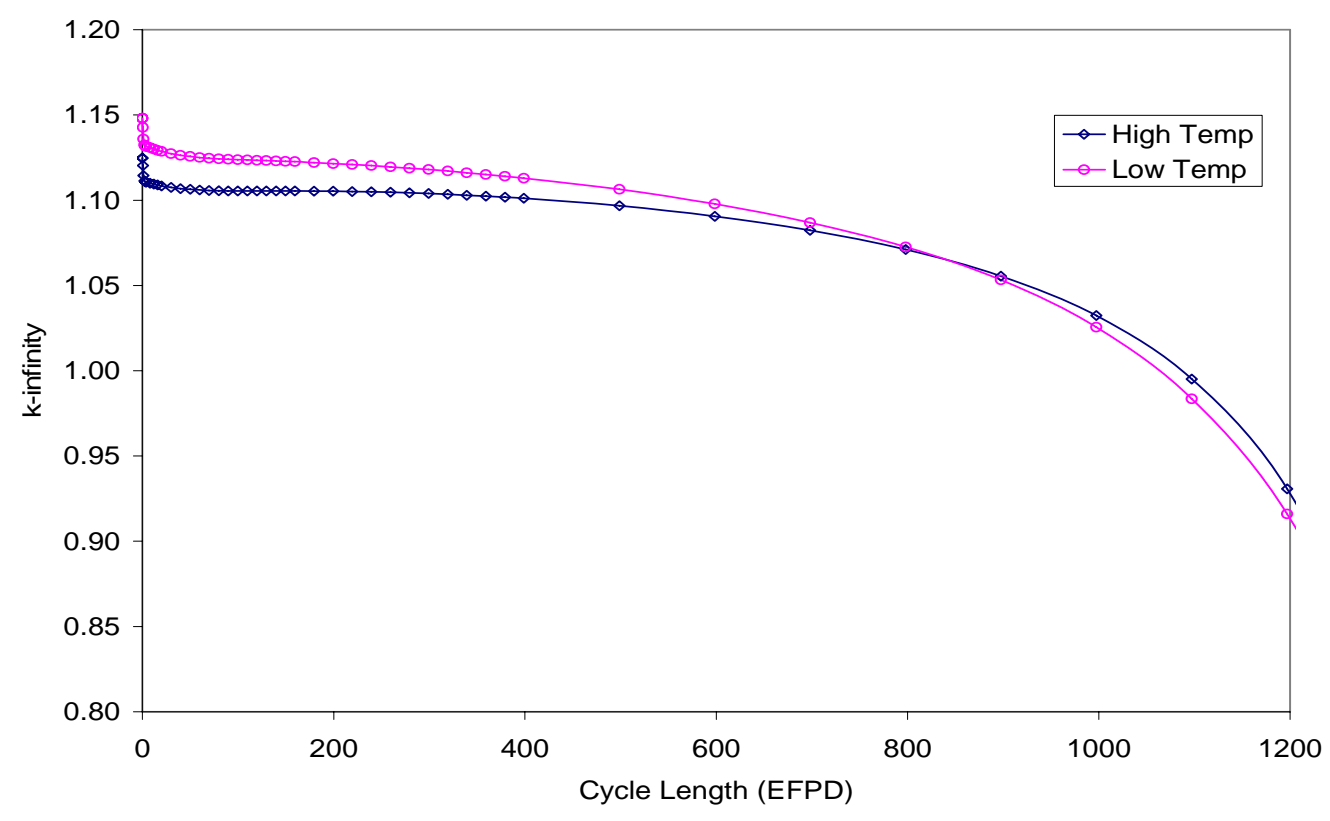

Figure 4.8. k-infinities of Fuel Elements at High and Low Temperatures 
In Table 4.8, the performance of the one-pass DB-MHR having lower operating temperature is compared to the normal operating condition. As expected, the cycle length and the corresponding discharge burnup increase to 312 EFPDs and $598 \mathrm{GWd} / \mathrm{t}$ (compared to 286 EFPD and $546 \mathrm{GWd} / \mathrm{t}$ ). Due to the high discharge burnup, the TRU consumption is also increased about 5\% (63.4 \% versus $58.1 \%$ ). Except for the Pu-241, the nuclide consumptions in the low temperature reactor are similar to those for the high temperature reactor. The Pu-241 consumption is significantly increased in the low temperature reactor mainly due to the high discharge burnup (-43.1\% versus $-7.2 \%)$.

Table 4.8. One-Pass DB-MHR TRU Consumption at Different Temperatures

\begin{tabular}{|c|c|c|}
\hline \multirow{2}{*}{} & \multicolumn{2}{|c|}{ Consumption (\%) } \\
\cline { 2 - 3 } & $\begin{array}{c}\text { High Temperature } \\
\text { (normal operating temperature) }\end{array}$ & $\begin{array}{c}\text { Low Temperate } \\
\text { (High temperature - 200 K) }\end{array}$ \\
\hline $\mathrm{Np}-237$ & -54.9 & -54.4 \\
$\mathrm{Pu}-238$ & 409.1 & 378.0 \\
$\mathrm{Pu}-239$ & -96.8 & -97.8 \\
$\mathrm{Pu}-240$ & -70.8 & -83.5 \\
$\mathrm{Pu}-241$ & -7.2 & -43.1 \\
$\mathrm{Pu}-242$ & 126.2 & 134.4 \\
$\mathrm{Am}-241$ & -89.0 & -92.5 \\
$\mathrm{Am}-242^{\mathrm{m}}$ & -40.1 & -69.0 \\
$\mathrm{Am}-243$ & 103.1 & 138.1 \\
\hline $\mathrm{Pu}$ & -61.8 & -68.7 \\
\hline $\mathrm{HM}$ & -58.1 & -63.4 \\
\hline Discharge Burnup (GWd/t) & 546 & 598 \\
\hline Cycle Length (EFPD) & 286 & 312 \\
\hline
\end{tabular}




\section{TWO-PASS DEEP-BURN TRANSMUTATION}

\subsection{External Fuel Cycle and Fuel Shuffling in Two-Pass DB-MHR}

The two-pass deep-burn concept has been proposed to increase the fuel consumption by significantly increasing the fuel residence time. The increased residence time is obtained by reprocessing the remnant TRU fuel (except for curium) from the first pass and reloading it in the core.

Figure 5.1 illustrates the external fuel cycle of the two-pass deep-burn concept. In this figure, the external feed denotes the LWR spent TRU (initial TRU vector is provided in Table 2.1). Sufficient amount of the external feed is assumed in external fuel cycle to allow the core to approach the equilibrium state. There are two TRU flow passes: fresh TRU and recycled TRU flow passes. The fresh TRU comes from the external feed and is irradiated in the core and discharged. This discharged TRU is then reloaded into the core after reprocessing. In the reprocessing state, the fission product and $\mathrm{Cm}$ are separated and sent to the repository (or interim storage). A seven-year cooling time is assumed in the external fuel cycle: five years before reprocessing and two years after. The time delays at the reprocessing and fabrication stages were ignored in this study. For the purpose of discussion, the fresh and recycled TRU fuel passes are named first pass and second pass, respectively.

The radial shuffling scheme of the two-pass deep-burn concept is illustrated in Figure 5.2. The active core is divided into four zones similarly to the one-pass DB-MHR core. Three of the zones (regions 2, 3, and 4) are allocated for the first pass and one zone (region 1) for the second pass. Thus, the volume of the second pass is one-third of the first pass. The second pass zone is also divided into three sub-zones (i.e., regions $1 \mathrm{~A}, 1 \mathrm{~B}$, and $1 \mathrm{C}$ ). Based on this zoning structure of the active core, the two-pass deep-burn concept utilizes a three-batch fuel management scheme. In the first pass, the fresh TRU is loaded into region 3, and shuffled to regions 4 and 2, and then the fuel is discharged. After five-year cooling, the $\mathrm{Pu}, \mathrm{Np}$ and $\mathrm{Am}$ are extracted in the reprocessing plant and delivered to the fabrication plant. The fission products and $\mathrm{Cm}$ are sent to the repository. After additional 2-year cooling, the TRU is reloaded into the region $1 \mathrm{~A}$ and then 
sequentially shuffled to regions $1 \mathrm{~B}$ and $1 \mathrm{C}$. The discharged fuel from the second pass is sent to the repository.

To represent the shuffling scheme of the second pass explicitly, an Hexagonal-Z core model was developed for REBUS-3 whole-core depletion calculations. Note that the R-Z core model cannot represent explicitly the fuel shuffling of the second pass because the reloaded TRU fuels are shuffled in the same radial region. The axial shuffling scheme utilized in the one-pass concept has also been considered in the two-pass deep-burn concept.

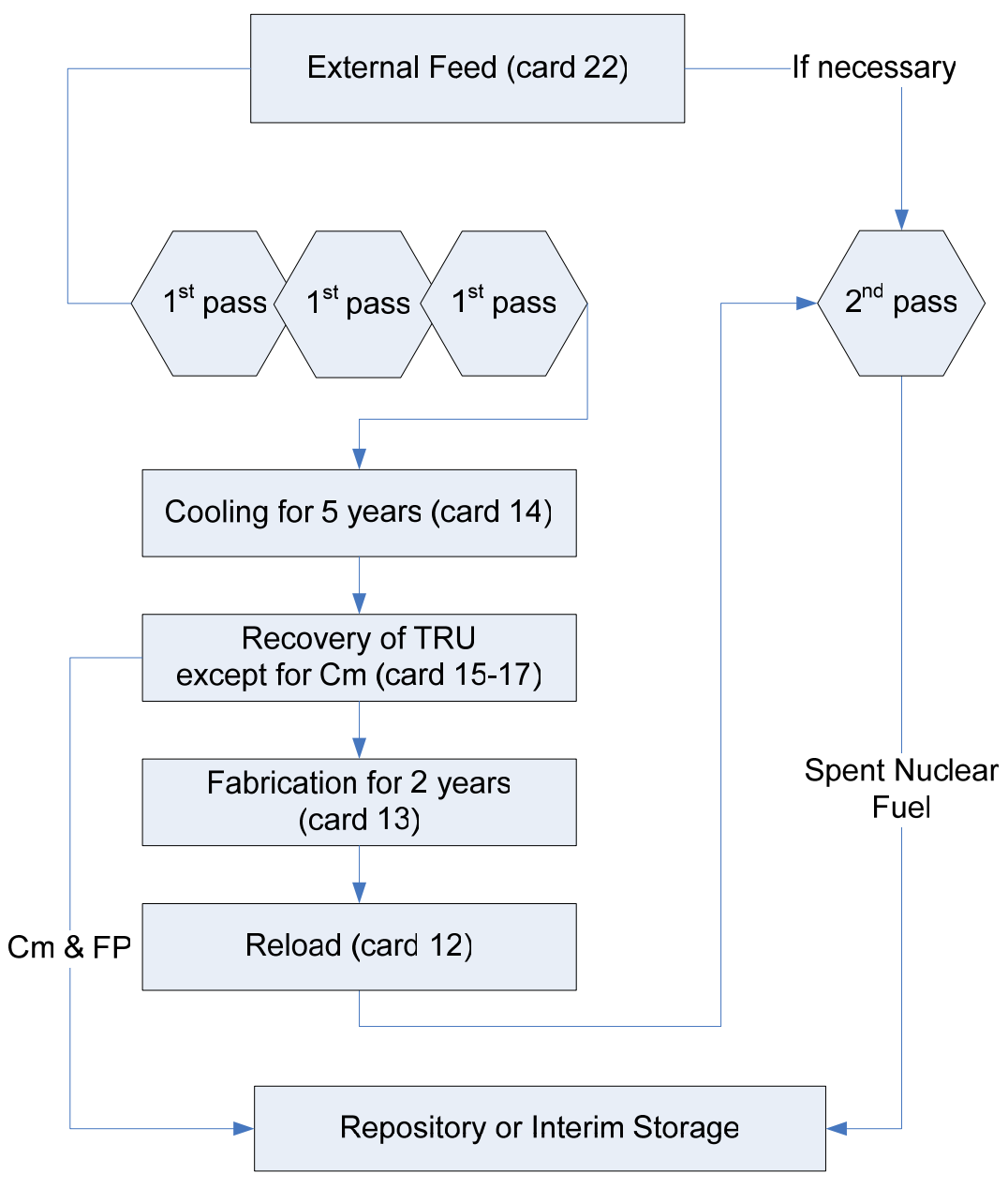

Figure 5.1. External Fuel Cycle of Two-Pass DB-MHR Concept 


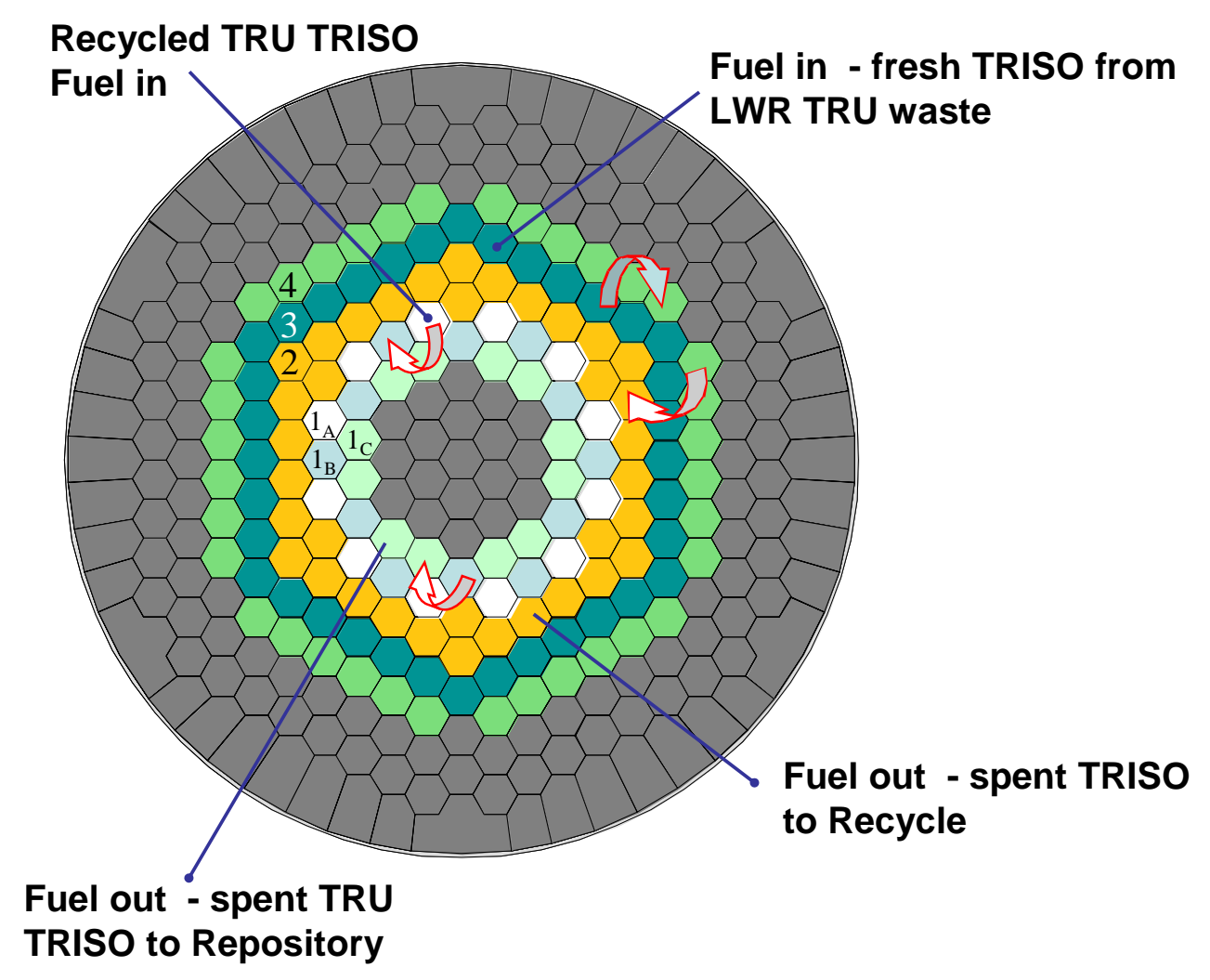

Figure 5.2. Radial Shuffling Scheme of Two Pass Deep Burn Concept 


\subsection{Determination of Packing Fraction for Second Pass Fuel}

To implement the two-pass deep-burn concept, the TRU masses between the discharge of the first pass and the charge of the second pass should be balanced: i.e., the discharged TRU mass (excluding $\mathrm{Cm}$ ) from the first pass should be same to the charge TRU mass of the second pass. The mass balance can be obtained by adjusting the packing fraction and the kernel size. In this study, the packing fraction of the first pass was fixed by $20 \%$ and the kernel diameters of the first and second passes were fixed to $200 \mu \mathrm{m}$. Note that the $200 \mu \mathrm{m}$ of kernel diameter and $20 \%$ packing fraction are based on the parametric studies for the one-pass deep-burn concept. Thus, the packing fraction of the second pass is the only variable that can be used to obtain the mass balance between the first and second passes. The packing faction of the second pass can be determined by using the mass balance relation,

$$
\rho_{H M}^{2 n d} V^{2 n d} P_{f}^{2 n d}=\left(1-T^{1 s t}\right)(1-W) \times \rho_{H M}^{1 s t} V^{1 s t} P_{f}^{1 s t},
$$

where $P_{f}$ denotes the packing fraction, $T^{1 s t}$ is the TRU consumption of the first pass, and $W$ denotes the fraction of the TRU sent to the repository at the reprocessing process. In addition, $\rho$ and $V$ denotes the heavy metal density and total compact volume, respectively. Because Cm is separated at the reprocess stage and sent to the repository, $W$ is the Cm mass fraction in the spent TRU of the first pass. In Eq. (5.1), the left and right hand sides denote the charged TRU mass of the second pass and the discharged TRU mass from the first pass, respectively. In two-pass concept, the volume of the second pass is one-third of the first pass and both heavy metal densities are assumed to be the same in this study. Equation (5.1) is a non-linear equation because the TRU consumption in the first pass is related to the packing fraction used in the second pass and vice versa. Thus, sensitivity calculations were used for determining the packing fraction for the second pass.

Because the cross-sections of the second pass fuels are dependent on the packing fraction, detailed trade studies would require separate lattice calculations for each case. However, in order to estimate the performance of the two-pass concept quickly (as required in this work), the cross sections used in the one-pass DB-MHR calculations (i.e., the cross sections of $20 \%$ packing fraction and $200 \mu \mathrm{m}$ kernel diameter fuel) were used. Furthermore, instead of generating burnup- 
dependent cross sections, the burnup-independent multigroup microscopic cross sections were used: this reduces the computation time and cross section generation effort significantly. The sensitivity calculations indicate that the use of burnup-independent multigroup cross sections does not much affect the results (see section 4.2.4).

Figure 5.3 summarizes the results of the sensitivity calculations used to determine the packing fraction of the second pass fuel. In this figure, the "required TRU mass from the external feed" denotes the additional TRU mass to fabricate the second pass fuel. Note that the discharged TRU mass from the first pass is less than the required TRU mass in the second pass if the packing fraction of the second pass fuel is larger than that of the mass balanced case. Based on this result, the packing fraction of the second pass was determined to be $29.7 \%$.

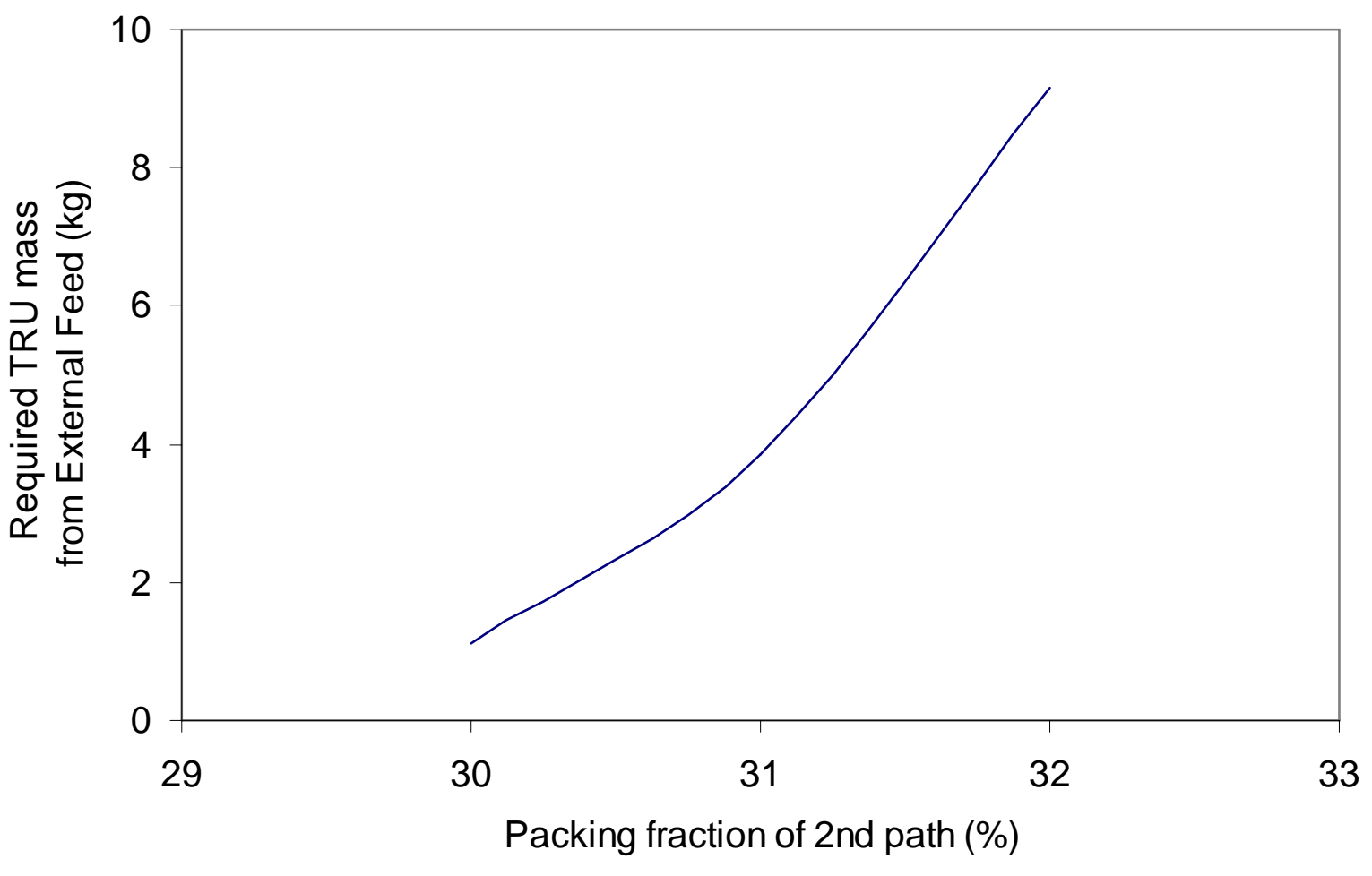

Figure 5.3. Required TRU Mass from External Feeds for Second Pass

\subsection{Performance of Two-Pass DB-MHR}

The heavy metal mass flow of the equilibrium two-pass DB-MHR core is summarized in Table 5.1. In this calculation, the kernel diameter of the fuels for the first and second passes is 
identically $200 \mu \mathrm{m}$. The packing fraction of the first pass is $20 \%$ (which is same to the one-pass DB-MHR) while the packing fraction of the second pass is $29.7 \%$. The cycle length and discharge burnup of the two-pass DB-MHR core are 267 EFPD and $580 \mathrm{GWd} / \mathrm{t}$, respectively (compared with $286 \mathrm{EFPD}$ and $546 \mathrm{GWd} / \mathrm{t}$ of the one-pass concept). A longer cycle length was expected in the two-pass concept because the fission products are removed from the second pass fuel. However, the cycle length of the two-pass concept is shorter than that of the one-pass DB-MHR. The reason for this behavior is the fissile-depleted composition of the second-pass fuel form. Compared to previous calculations by GA, this fissile depletion is exacerbated by the cooling interval between the discharge from the first pass and the charge of the second pass. The primary fissile nuclide in the second pass fuel is Pu-241 (because about 90\% Pu-239 are destroyed at the first pass), but the content is significantly reduced during 7-year cooling time $\left(\mathrm{h}_{1 / 2}=14.4\right.$ years); in Table 5.1, the discharged Pu-241 mass is $33.1 \mathrm{~kg}$, but it is decreased to 22.8 kg after 7 year cooling.

Because the cycle length decreases for the two-pass concept, the discharge burnup is also reduced. The total residence time of TRU in the two-pass DB-MHR core is much longer than that in the one-pass DB-MHR core $(267 \times 6$ EFPDs versus $285 \times 4$ EFPDs), but the discharge burnup is not increased because the two-pass core uses a larger TRU mass than the one-pass core (30\% higher).

The charge fresh TRU mass is $299 \mathrm{~kg}$ and the discharge TRU mass from the second pass is $136 \mathrm{~kg}$, including $6.3 \mathrm{~kg}$ of $\mathrm{Cm}$ from the first pass. Thus, the overall TRU consumption is $55 \%$. This value is much smaller than the expected TRU consumption in the two-pass deep-burn concept (originally projected as $\sim 70 \%$ ). Note that the total TRU consumption of the two-pass deep-burn concept can be represented by

$$
T=T^{1 s t}+\left(1-T^{1 s t}\right) \times T^{2 n d},
$$

where $T^{1 s t}$ and $T^{2 n d}$ denote the TRU consumptions in the first and second passes, respectively. The TRU consumptions of the first and second passes are about $47 \%$ and $15 \%$, respectively. 
Table 5.1. Mass Flow of Two-Pass DB-MHR (kg)

\begin{tabular}{|c|c|c|c|c|c|c|c|c|c|}
\hline & \multicolumn{4}{|c|}{ First pass } & \multicolumn{4}{|c|}{ Second pass } & \multirow{3}{*}{$\begin{array}{c}\text { Consumption } \\
\text { (\%) }\end{array}$} \\
\hline & \multicolumn{3}{|c|}{ Charge mass } & \multirow{2}{*}{$\begin{array}{c}\text { Discharge } \\
\text { mass }\end{array}$} & \multicolumn{3}{|c|}{ Charge mass } & \multirow{2}{*}{$\begin{array}{c}\text { Discharge } \\
\text { mass }\end{array}$} & \\
\hline & Region 3 & Region 4 & Region 2 & & Region 1A & Region 1B & Region 1C & & \\
\hline U-233 & 0.00 & 0.00 & 0.00 & 0.00 & 0.00 & 0.00 & 0.00 & 0.00 & \\
\hline U-234 & 0.00 & 0.03 & 0.09 & 0.18 & 0.33 & 0.43 & 0.53 & 0.64 & \\
\hline U-235 & 0.00 & 0.00 & 0.01 & 0.02 & 0.00 & 0.02 & 0.05 & 0.07 & \\
\hline U-236 & 0.00 & 0.00 & 0.01 & 0.01 & 0.01 & 0.01 & 0.01 & 0.01 & \\
\hline U-237 & 0.00 & 0.00 & 0.00 & 0.00 & 0.00 & 0.00 & 0.00 & 0.00 & \\
\hline U-238 & 0.00 & 0.00 & 0.00 & 0.00 & 0.00 & 0.00 & 0.00 & 0.00 & \\
\hline Np-237 & 13.73 & 11.45 & 9.33 & 7.82 & 7.77 & 7.08 & 6.45 & 5.96 & -56.6 \\
\hline Pu-238 & 3.99 & 8.70 & 14.59 & 18.69 & 21.13 & 21.69 & 22.99 & 24.02 & 432.9 \\
\hline Pu-239 & 152.42 & 83.54 & 31.26 & 15.13 & 15.21 & 11.55 & 8.80 & 6.90 & -95.5 \\
\hline $\mathrm{Pu}-240$ & 62.16 & 56.40 & 47.87 & 34.41 & 34.16 & 28.41 & 23.68 & 20.55 & -66.7 \\
\hline Pu-241 & 22.62 & 37.81 & 35.92 & 33.13 & 22.81 & 23.06 & 21.83 & 19.19 & 23.2 \\
\hline $\mathrm{Pu}-242$ & 14.78 & 17.88 & 23.97 & 27.08 & 28.03 & 28.03 & 28.18 & 28.64 & 87.2 \\
\hline Am-241 & 24.57 & 15.60 & 8.63 & 5.72 & 14.61 & 11.83 & 9.60 & 7.96 & -87.3 \\
\hline Am-242m & 0.09 & 0.38 & 0.19 & 0.13 & 0.12 & 0.24 & 0.23 & 0.18 & 114.8 \\
\hline Am-243 & 4.52 & 5.62 & 6.91 & 8.24 & 8.54 & 9.44 & 10.16 & 10.63 & 126.9 \\
\hline $\mathrm{Cm}-242$ & 0.00 & 4.34 & 4.88 & 3.35 & 0.00 & 1.61 & 1.87 & 1.66 & \\
\hline Cm-243 & 0.00 & 0.05 & 0.12 & 0.14 & 0.00 & 0.01 & 0.03 & 0.04 & \\
\hline $\mathrm{Cm}-244$ & 0.00 & 1.49 & 2.98 & 4.54 & 0.00 & 1.30 & 2.52 & 3.44 & \\
\hline $\mathrm{Cm}-245$ & 0.00 & 0.07 & 0.19 & 0.38 & 0.00 & 0.04 & 0.12 & 0.20 & \\
\hline $\mathrm{Pu}$ & 256.0 & 204.3 & 153.6 & 128.5 & 121.3 & 112.8 & 105.5 & 99.3 & -58.9 \\
\hline HM & 298.9 & 243.4 & 186.9 & 159.0 & 152.7 & 144.8 & 137.1 & 130.1 & -54.7 \\
\hline Power fraction (BOC/EOC) & $0.33 / 0.35$ & $0.39 / 0.30$ & $0.16 / 0.18$ & & $0.04 / 0.06$ & $0.04 / 0.06$ & $0.04 / 0.05$ & & \\
\hline Discharge burnup (GWd/t) & 175 & 353 & 441 & & 490 & 537 & 580 & & \\
\hline TRU consumption (\%) & -18.6 & -18.9 & -9.4 & & -5.2 & -5.0 & -4.6 & & \\
\hline
\end{tabular}




\subsection{Performance of Two-Pass DB-MHR With Zero Cooling Time}

A cooling period is used in practice to allow reduction in both the radiation and heating levels before spent nuclear is handled. In the study reported in Section 5.3, a 7-year time delay is assumed for this purpose. While a zero cooling time is impractical, the performance of the twopass DB-MHR core has however been evaluated for this case to investigate the impact of cooling period on the two-pass TRU consumption. In the study, the fuel data for the first and second passes were identical to those used in the previous section.

The heavy metal mass flow of the two-pass DB-MHR core with zero cooling time between passes is summarized in Table 5.2. As expected, the cycle length and discharge burnup increase to $312 \mathrm{EFPD}$ and $716 \mathrm{GWd} / \mathrm{t}$, respectively (compared to $267 \mathrm{EFPD}$ and $580 \mathrm{GWd} / \mathrm{t}$ for the 7-year cooling case). The high discharge burnup increases the TRU consumption of the first and second passes (50\% and 26\%, respectively). Subsequently, the total TRU consumption is increased to $63.1 \%$ (compared to 55\% for the 7-year cooling case). Due to the higher TRU consumption in the first pass, the discharge TRU mass from the first pass is not enough to fabricate the second pass TRU fuel (compare the discharge mass of first pass and charge mass of second pass in Table 5.2). This means that the packing fraction of the second pass should be decreased to ensure mass balance for this case (note that the packing fraction of the second pass was determined based on the case with a 7-year cooling period).

The primary reason of the high discharge burnup of the no-cooling case is the relatively high Pu-241 content in the second pass fuel. The initial Pu-241 mass of the second pass fuel is $22.8 \mathrm{~kg}$ in the 7-year cooling case (see Table 5.1), but becomes $30.9 \mathrm{~kg}$ without cooling time. The high Pu-241 content of the second pass increases the power sharing and TRU consumption. The result indicates that the Pu-241 content of the second pass fuel plays an important role to improve the performance of the two-pass concept. However, due to its short half-life, the Pu-241 content is significantly deceased after 7 year cooling, and therefore the performance of the twopass concept cannot be improved significantly with a long cooling interval. 
Table 5.2. Mass Flow of Two-Pass DB-MHR Without Cooling Time (kg)

\begin{tabular}{|c|c|c|c|c|c|c|c|c|c|}
\hline & \multicolumn{4}{|c|}{ First pass } & \multicolumn{4}{|c|}{ Second pass } & \multirow{3}{*}{$\begin{array}{l}\text { Trans. } \\
\text { rate (\%) }\end{array}$} \\
\hline & \multicolumn{3}{|c|}{ Charge mass } & \multirow{2}{*}{$\begin{array}{c}\text { Discharge } \\
\text { mass }\end{array}$} & \multicolumn{3}{|c|}{ Charge mass } & \multirow{2}{*}{$\begin{array}{c}\text { Discharge } \\
\text { mass }\end{array}$} & \\
\hline & Region 3 & Region 4 & Region 2 & & Region 1A & Region 1B & Region 1C & & \\
\hline U233 & 0.00 & 0.00 & 0.00 & 0.00 & 0.00 & 0.00 & 0.00 & 0.00 & \\
\hline U234 & 0.00 & 0.04 & 0.12 & 0.21 & 0.00 & 0.13 & 0.24 & 0.35 & \\
\hline U235 & 0.00 & 0.00 & 0.01 & 0.03 & 0.00 & 0.01 & 0.02 & 0.04 & \\
\hline U236 & 0.00 & 0.01 & 0.01 & 0.01 & 0.00 & 0.00 & 0.00 & 0.01 & \\
\hline U237 & 0.00 & 0.00 & 0.00 & 0.00 & 0.00 & 0.00 & 0.00 & 0.00 & \\
\hline U238 & 0.00 & 0.00 & 0.00 & 0.00 & 0.00 & 0.00 & 0.00 & 0.00 & \\
\hline Np237 & 13.73 & 11.25 & 9.04 & 7.26 & 7.86 & 6.84 & 5.91 & 5.10 & -62.9 \\
\hline Pu238 & 3.99 & 9.41 & 15.67 & 19.61 & 19.69 & 19.84 & 20.26 & 20.19 & 404.3 \\
\hline Pu239 & 152.42 & 77.29 & 26.64 & 10.83 & 17.35 & 11.27 & 7.15 & 4.60 & -98.1 \\
\hline Pu240 & 62.16 & 55.95 & 45.92 & 29.97 & 32.87 & 25.21 & 19.05 & 14.77 & -78.3 \\
\hline Pu241 & 22.62 & 38.18 & 34.78 & 29.77 & 30.87 & 27.77 & 22.74 & 16.30 & -30.5 \\
\hline Pu242 & 14.78 & 18.36 & 24.86 & 28.47 & 29.03 & 29.20 & 29.52 & 30.13 & 99.9 \\
\hline Am241 & 24.57 & 14.90 & 8.00 & 4.72 & 5.78 & 4.81 & 3.84 & 2.87 & -90.5 \\
\hline Am242m & 0.09 & 0.36 & 0.17 & 0.11 & 0.11 & 0.11 & 0.09 & 0.06 & -38.5 \\
\hline Am243 & 4.52 & 5.74 & 7.11 & 8.74 & 8.90 & 10.16 & 11.11 & 11.73 & 155.1 \\
\hline $\mathrm{Cm} 242$ & 0.00 & 4.37 & 4.44 & 3.00 & 0.00 & 0.91 & 1.07 & 1.01 & \\
\hline $\mathrm{Cm} 243$ & 0.00 & 0.06 & 0.12 & 0.14 & 0.00 & 0.01 & 0.02 & 0.03 & \\
\hline $\mathrm{Cm} 244$ & 0.00 & 1.62 & 3.20 & 5.15 & 0.00 & 2.01 & 3.97 & 5.63 & \\
\hline Cm245 & 0.00 & 0.08 & 0.21 & 0.44 & 0.00 & 0.08 & 0.25 & 0.42 & \\
\hline $\mathrm{Pu}$ & 256.0 & 199.2 & 147.9 & 118.6 & 129.8 & 113.3 & 98.7 & 86.0 & -69.3 \\
\hline HM & 298. 9 & 237.6 & 180.3 & 148.5 & 152.5 & 138.4 & 125.3 & 113.2 & -63.1 \\
\hline Power fraction (BOCEOC) & $0.31 / 0.34$ & $0.34 / 0.27$ & $0.16 / 0.17$ & & $0.06 / 0.09$ & $0.06 / 0.08$ & $0.06 / 0.07$ & & \\
\hline Discharge burnup (GWd/t) & 194 & 374 & 474 & & 561 & 642 & 716 & & \\
\hline TRU consumption (\%) & -20.5 & -19.2 & -10.6 & & -9.3 & -8.6 & -7.9 & & \\
\hline
\end{tabular}




\subsection{Cylindrical Core of Two-pass Concept}

In the two-pass DB-MHR core, the kernel diameter of the second pass fuel is the same as that for the first pass, but the packing fraction is higher (29.7\% versus $20 \%)$. The fuel-tomoderator ratio of the second pass fuel is higher than the optimum packing fraction (see Figure 4.5). The packing fraction of the second pass fuel was determined to ensure mass balance between the first and second passes. Because the high fuel-to-moderator ratio decreases the TRU consumption, the high packing fraction of the second pass is not favorable to improve the transmutation performance. Thus, an alternative two-pass concept, in cylindrical core geometry, has been proposed to improve the TRU consumption of the two-pass concept (see Figure 5.4).

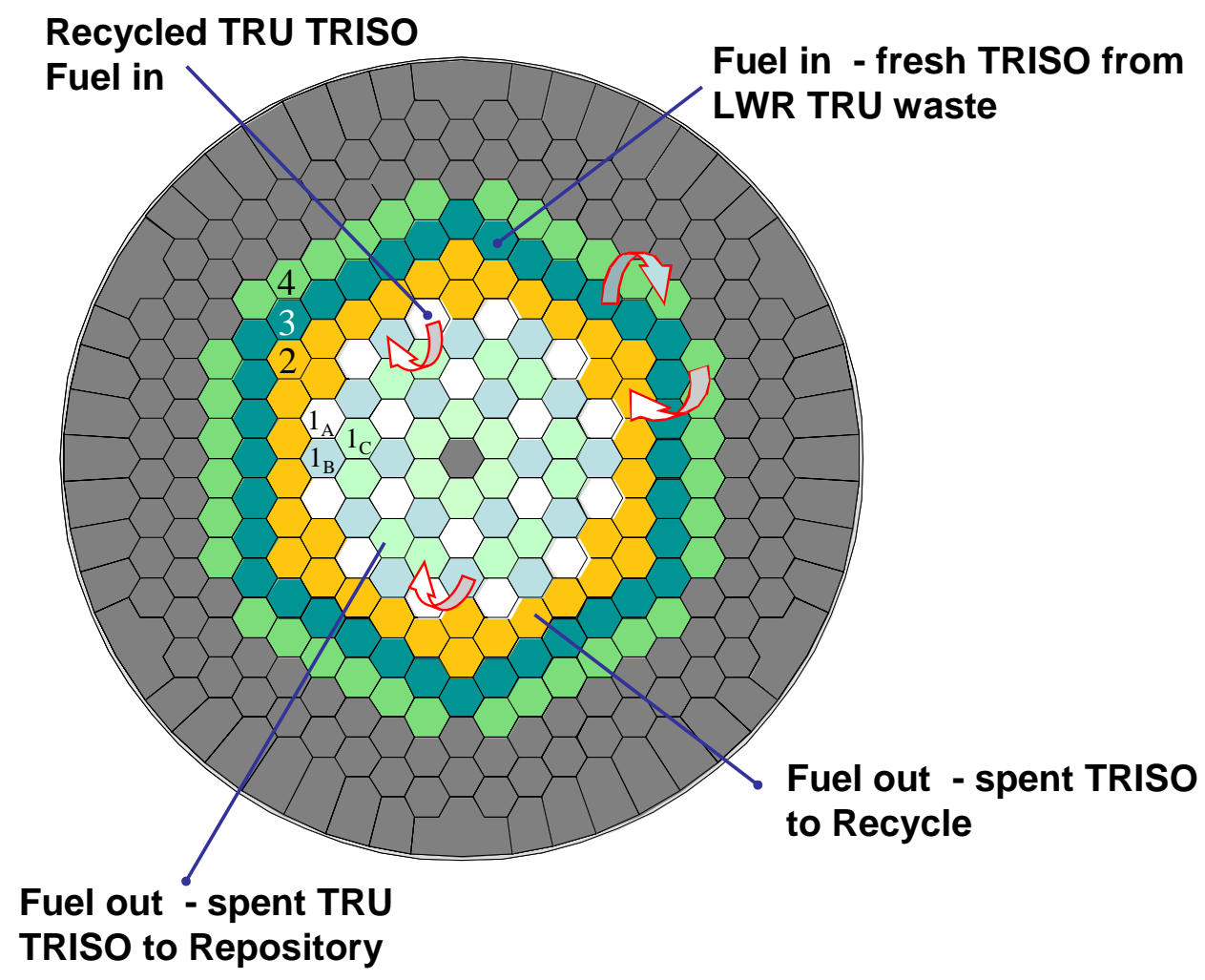

Figure 5.4. Cylindrical Core for Two-Pass Concept

In the cylindrical DB-MHR core, the first and second passes have the same kernel diameter and packing fraction. The kernel diameter and packing fraction for the cylindrical 
DB-MHR core were determined at the optimum fuel-to-moderator rate: i.e., $200 \mu \mathrm{m}$ and $20 \%$, respectively. However, this design does not ensure mass balance between the first and second pass because the volume of the second pass is only one-third of the first pass. In order to ensure mass balance, the number of fuel columns for the second pass was increased: i.e., 18 fuel columns are added into the inner reflector region. Because the inner reflector region is filled by fuel columns, the core is called "cylindrical core."

The same external fuel cycle and fuel management scheme of the original two-pass concept was utilized in the cylindrical DB-MHR core: i.e., 7-year cooling and 3-batch scheme. The mass flow of the cylindrical DB-MHR core is provided in Table 5.3. In this table, the discharged TRU mass (excluding $\mathrm{Cm}$ ) from the first pass is less than the required TRU mass to fabricate the second pass fuel. This means that 54 fuel columns for the second pass are too many: one or two fuel columns should be removed to ensure mass balance. However, to make a symmetric core, the 54 fuel columns for the second pass are retained for the solid DB-MHR core. In Table 5.3, the discharged TRU (excluding $\mathrm{Cm}$ ) from the first pass is about $7 \mathrm{~kg}$ less than the required TRU mass for the second pass. In this study, the additional TRU was supplied from the external feed.

Except for the region 1A, region-wise performance (TRU consumption and power sharing) of the cylindrical DB-MHR core is comparable to the original two-pass DB-MHR core (compare Tables 5.3 and 5.1). In the region 1A, the TRU consumption and power sharing are increased about 3\%. Thus, the overall TRU consumption of the solid DB-MHR core increases about 3\%, compared to the original two-pass DB-MHR core (Section 5.1). The cycle length and discharge burnup of the cylindrical core increase to $286 \mathrm{EFPD}$ and $630 \mathrm{GWd} / \mathrm{t}$, respectively, compared to $267 \mathrm{EFPD}$ and $580 \mathrm{GWd} / \mathrm{t}$ of the original two-pass concept.

Similarly to the original two-pass concept, the cooling time effect was evaluated using the cylindrical DB-MHR core. Due to the reason discussed in the previous section, the discharge burnup and the overall TRU consumption were increased: $763 \mathrm{GWd} / \mathrm{t}$ discharge burnup and 65.8\% TRU consumption. 
Table 5.3. Mass Flow of Cylindrical Two-Pass DB-MHR Core (kg)

\begin{tabular}{|c|c|c|c|c|c|c|c|c|c|}
\hline & \multicolumn{4}{|c|}{ First pass } & \multicolumn{4}{|c|}{ Second pass } & \multirow{3}{*}{$\begin{array}{c}\text { Consumption } \\
\text { (\%) }\end{array}$} \\
\hline & \multicolumn{3}{|c|}{ Charge mass } & \multirow{2}{*}{$\begin{array}{l}\text { Discharge } \\
\text { mass }\end{array}$} & \multicolumn{3}{|c|}{ Charge mass } & \multirow{2}{*}{$\begin{array}{c}\text { Discharge } \\
\text { mass }\end{array}$} & \\
\hline & Region 3 & Region 4 & Region 2 & & Region 1A & Region 1B & Region 1C & & \\
\hline U-233 & 0.00 & 0.00 & 0.00 & 0.00 & 0.00 & 0.00 & 0.00 & 0.00 & \\
\hline $\mathrm{U}-234$ & 0.00 & 0.04 & 0.10 & 0.19 & 0.33 & 0.44 & 0.55 & 0.67 & \\
\hline U-235 & 0.00 & 0.00 & 0.01 & 0.02 & 0.00 & 0.03 & 0.05 & 0.07 & \\
\hline U-236 & 0.00 & 0.00 & 0.01 & 0.01 & 0.01 & 0.01 & 0.01 & 0.01 & \\
\hline $\mathrm{U}-237$ & 0.00 & 0.00 & 0.00 & 0.00 & 0.00 & 0.00 & 0.00 & 0.00 & \\
\hline U-238 & 0.00 & 0.00 & 0.00 & 0.00 & 0.00 & 0.00 & 0.00 & 0.00 & \\
\hline Np-237 & 13.73 & 11.35 & 9.17 & 7.54 & 7.83 & 6.88 & 6.22 & 5.75 & -59.7 \\
\hline Np-239 & 0.00 & 0.00 & 0.00 & 0.00 & 0.00 & 0.00 & 0.00 & 0.00 & \\
\hline Pu-238 & 3.99 & 9.03 & 15.11 & 19.12 & 21.34 & 22.01 & 23.53 & 24.50 & 450.6 \\
\hline Pu-239 & 152.42 & 80.46 & 28.61 & 12.60 & 16.36 & 10.20 & 7.34 & 5.84 & -97.1 \\
\hline $\mathrm{Pu}-240$ & 62.16 & 56.16 & 46.79 & 32.43 & 34.09 & 26.70 & 21.81 & 18.78 & -71.3 \\
\hline $\mathrm{Pu}-241$ & 22.62 & 38.00 & 35.33 & 31.06 & 22.11 & 21.34 & 19.51 & 17.13 & 6.4 \\
\hline Pu-242 & 14.78 & 18.12 & 24.47 & 27.94 & 28.84 & 29.60 & 29.97 & 30.31 & 98.7 \\
\hline Am-241 & 24.57 & 15.24 & 8.24 & 5.15 & 14.30 & 9.98 & 7.73 & 6.43 & -90.6 \\
\hline Am-242m & 0.09 & 0.37 & 0.18 & 0.12 & 0.11 & 0.21 & 0.17 & 0.14 & 58.4 \\
\hline Am-243 & 4.52 & 5.68 & 7.02 & 8.47 & 8.75 & 9.81 & 10.50 & 10.93 & 134.2 \\
\hline Cm-242 & 0.00 & 4.37 & 4.71 & 3.21 & 0.00 & 2.21 & 1.97 & 1.46 & \\
\hline $\mathrm{Cm}-243$ & 0.00 & 0.06 & 0.12 & 0.14 & 0.00 & 0.02 & 0.03 & 0.04 & \\
\hline $\mathrm{Cm}-244$ & 0.00 & 1.55 & 3.10 & 4.81 & 0.00 & 1.66 & 2.92 & 3.81 & \\
\hline Cm-245 & 0.00 & 0.08 & 0.21 & 0.40 & 0.00 & 0.05 & 0.13 & 0.21 & \\
\hline $\mathrm{Pu}$ & 255.97 & 201.77 & 150.31 & 123.15 & 122.75 & 109.85 & 102.16 & 96.57 & -62.2 \\
\hline HM & 298.89 & 240.52 & 183.18 & 153.20 & 154.08 & 141.14 & 132.46 & 126.09 & -58.1 \\
\hline Power fraction (BOC/EOC) & $0.33 / 0.34$ & $0.37 / 0.29$ & $0.17 / 0.18$ & & $0.06 / 0.09$ & $0.04 / 0.06$ & $0.03 / 0.05$ & & \\
\hline Discharge burnup (GWd/t) & 184 & 365 & 459 & & 538 & 591 & 630 & & \\
\hline TRU consumption (\%) & -19.5 & -19.2 & -10.0 & & -8.4 & -5.6 & -4.1 & & \\
\hline
\end{tabular}




\subsection{Heterogeneous Element in Two-Pass Concept}

The two-pass concepts were evaluated in previous sections, but the transmutation performance is smaller than that expected. This is due to the sensitivity of TRU consumption to the cooling interval (Pu-241 decay) between the first and second passes. It was noticed in the previous studies that this results in significant differences between the power fractions in the first and second passes. It was therefore decided to investigate the impact of a flatter power distribution on the TRU consumption. This was done using a heterogeneous fuel element design. Figure 5.5 shows the heterogeneous fuel element, which consists of the first pass and the second pass fuels. The kernel size and packing fractions of both fuel were assumed to be same (i.e., $200 \mu \mathrm{m}$ and 20\%, respectively), but the number of fuel rods for the first and second passes are adjusted to obtain mass balance between the first and second passes. In this study, there are assumed to be 144 and 72 fuel rods containing the first and second pass fuels, respectively.

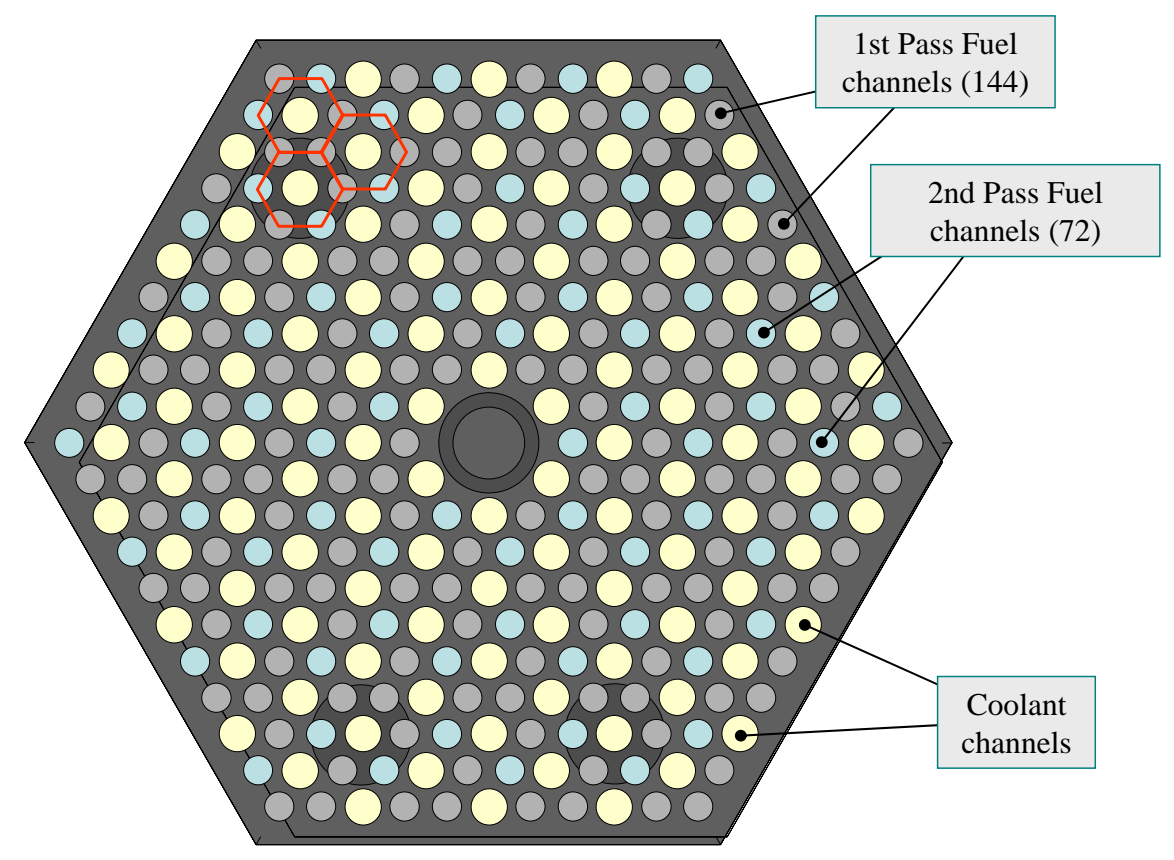

Figure 5.5. Heterogeneous Fuel Element for Two-Pass DB-MHR

The in-core fuel management scheme of the two-pass DB-MHR core using the heterogeneous fuel elements is identical to that for the one-pass DB-MHR core. A four-batch fuel management scheme is utilized and the radial and axial shuffling scheme used in the one- 
pass concept is employed for this core. Figure 5.6 illustrates the conceptual flow of the two-pass DB-MHR core using the heterogeneous fuel element. The actual core is divided into four regions for the four-batch scheme. The fresh heterogeneous fuel elements are loaded into the region 3 initially, and subsequently shuffled to regions 4, 2, and 1 (see Figure 4.1). In Figure 5.6, each region is divided into different colors to represent the heterogeneous fuel element (small rectangle denotes the second pass fuel). Similarly to the other two-pass cores, the discharged first pass TRU is recycled in the second pass (except for the fission products and $\mathrm{Cm}$ ) and the discharged second pass fuel is sent to the repository. A 7-year cooling time is also utilized in this concept. Because the second pass fuel exists with the first pass at the same fuel element, the power sharing of the second pass is improved compared to the original two-pass DB-MHR core.

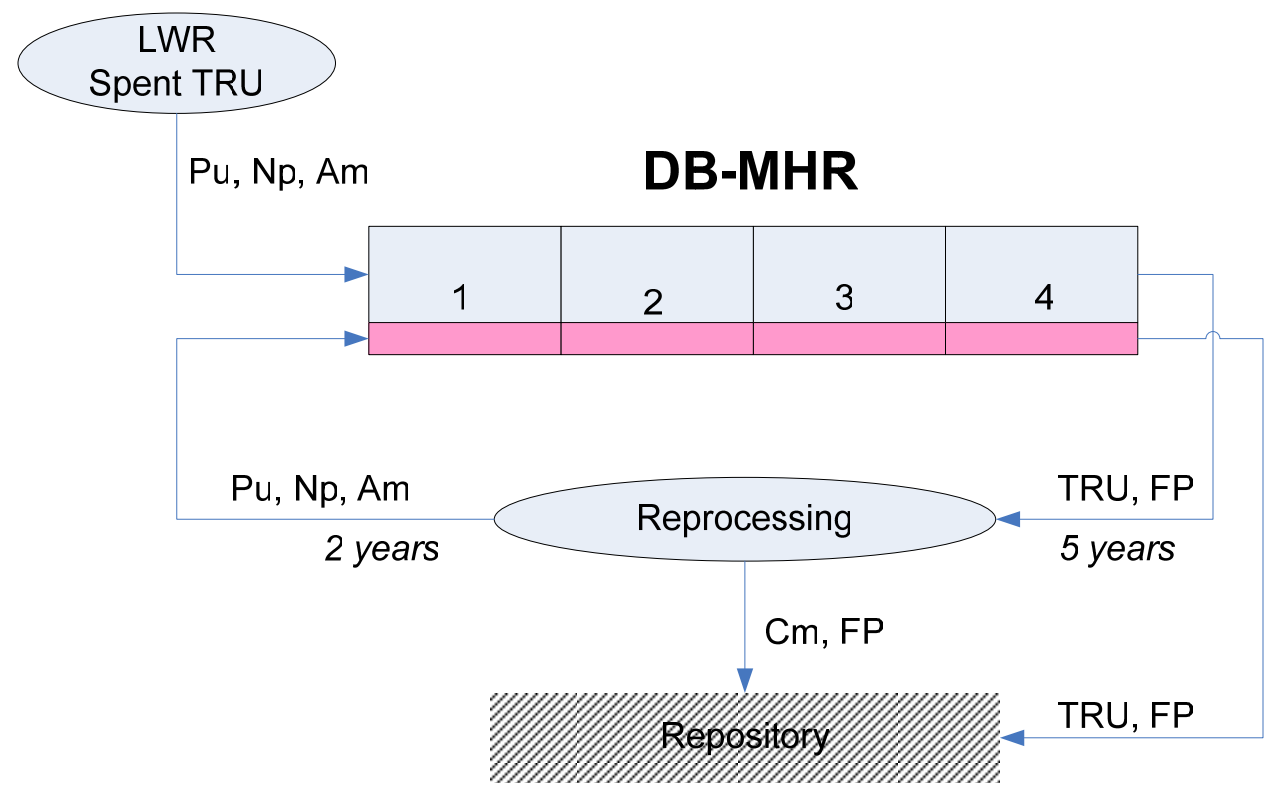

Figure 5.6. Two-Pass DB-MHR Concept Using Heterogeneous Fuel Element

The REBUS-3 code can trace the mass flows of the first and second passes separately, even though two different materials are depleted in the same fuel element (or burn zone). In Figure 5.6, the discharged material from the first pass is reloaded into the second pass. Thus, in order to trace the mass flow of each material, the material name discharged from the first pass should be replaced by the second pass material name after reprocessing. However, the REBUS-3 code technically cannot change the material name during the calculations. Thus, the external cycle was manually treated to implement this concept. Figure 5.7 shows the iteration scheme for 
the two-pass DB-MHR core using a REBUS-3 and ORIGEN2 coupled code path. In Figure 5.7, the flow between the first and second passes is unlinked and the charge TRU vector of the second pass fuel is initially guessed. If this guessed TRU vector is correct (i.e., the vector of the equilibrium state), the result of Figure 5.7 is identical to the equilibrium state. Thus, the key question in Figure 5.7 is how to determine the initial TRU vector for the second pass fuel. For this purpose, the initial TRU vector for the second pass fuel is manually updated from the discharged TRU vector from the first pass (dotted part in Figure 5.7).

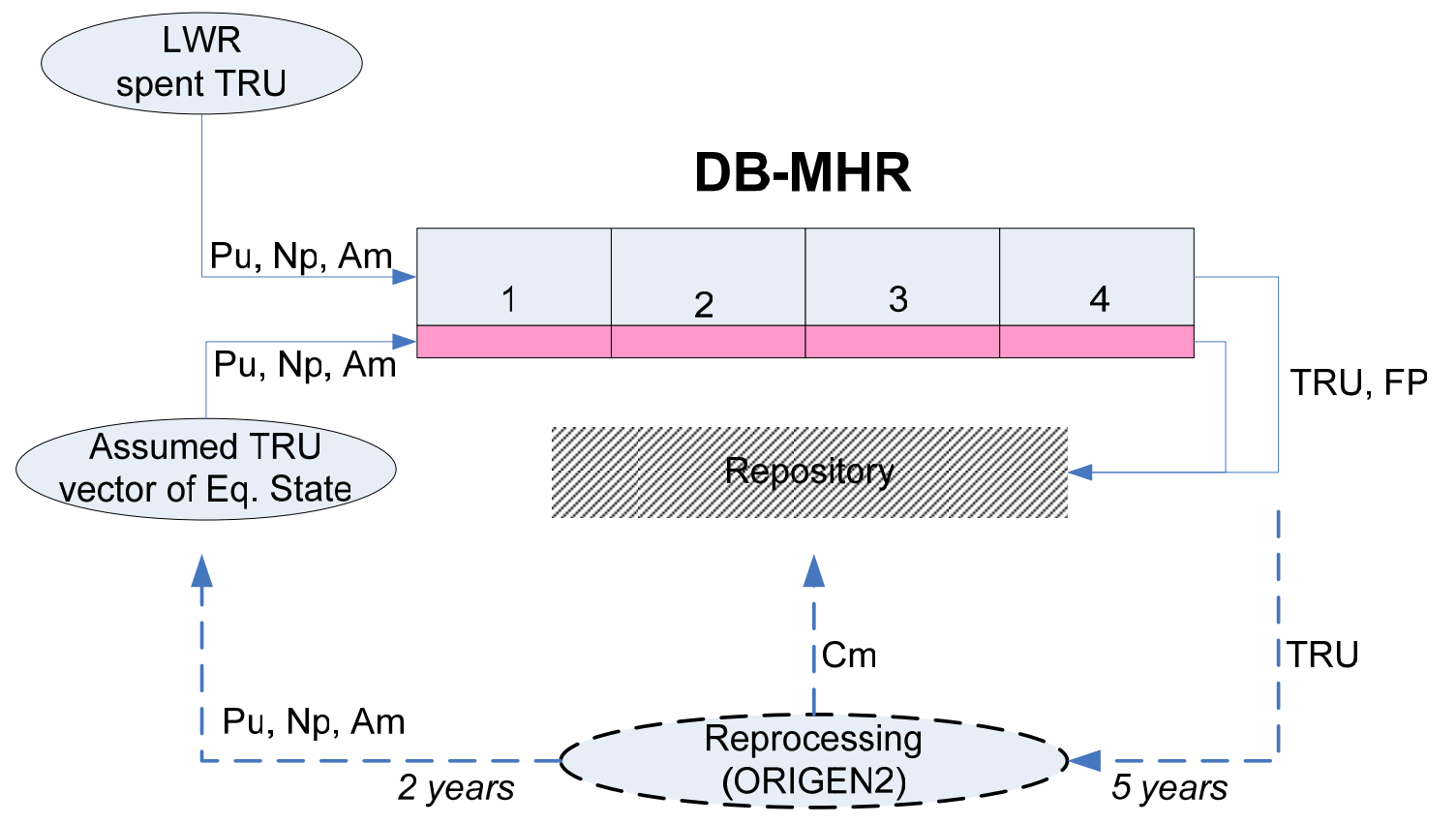

Figure 5.7. REBUS-3 and ORIGEN2 Iteration Scheme for Two-Pass DB-MHR

In manual iterations, the initial TRU vector for the second pass fuel is guessed arbitrary and the REBUS-3 code searches for the equilibrium core. Following the REBUS-3 calculation, the new TRU vector for the second pass is calculated using the discharged fuel from the first pass. This calculation is manually done using the ORIGEN2 [19] code. In the ORIGEN2 calculations, the external fuel cycle strategy of the two-pass concept (i.e., total 7-year cooling time, separation of $\mathrm{Cm}$ from TRU, etc) is employed. If the new TRU vector for the second pass fuel is similar to the vector used in the previous iteration, then the iteration stops. If not, the REBUS-3 calculation is repeated using the new TRU vector. 
Based on the judgment that the iteration will quickly converge using a good initial guess, the TRU vector for the second pass fuel was obtained from the results of the one-pass DB-MHR core. Since the heterogeneous fuel element consists of fresh TRU and recycled TRU (less reactive fuel), a shorter cycle length is expected compared to the one-pass DB-MHR core. Thus, the initial guessed TRU vector was obtained from the thrice burnt fuel (not the 4-times burnt fuel). Figure 5.8 shows the isotopic vector at the charge stage of the second pass, at every iteration. After 4 iterations, the isotopic vector is fully converged.

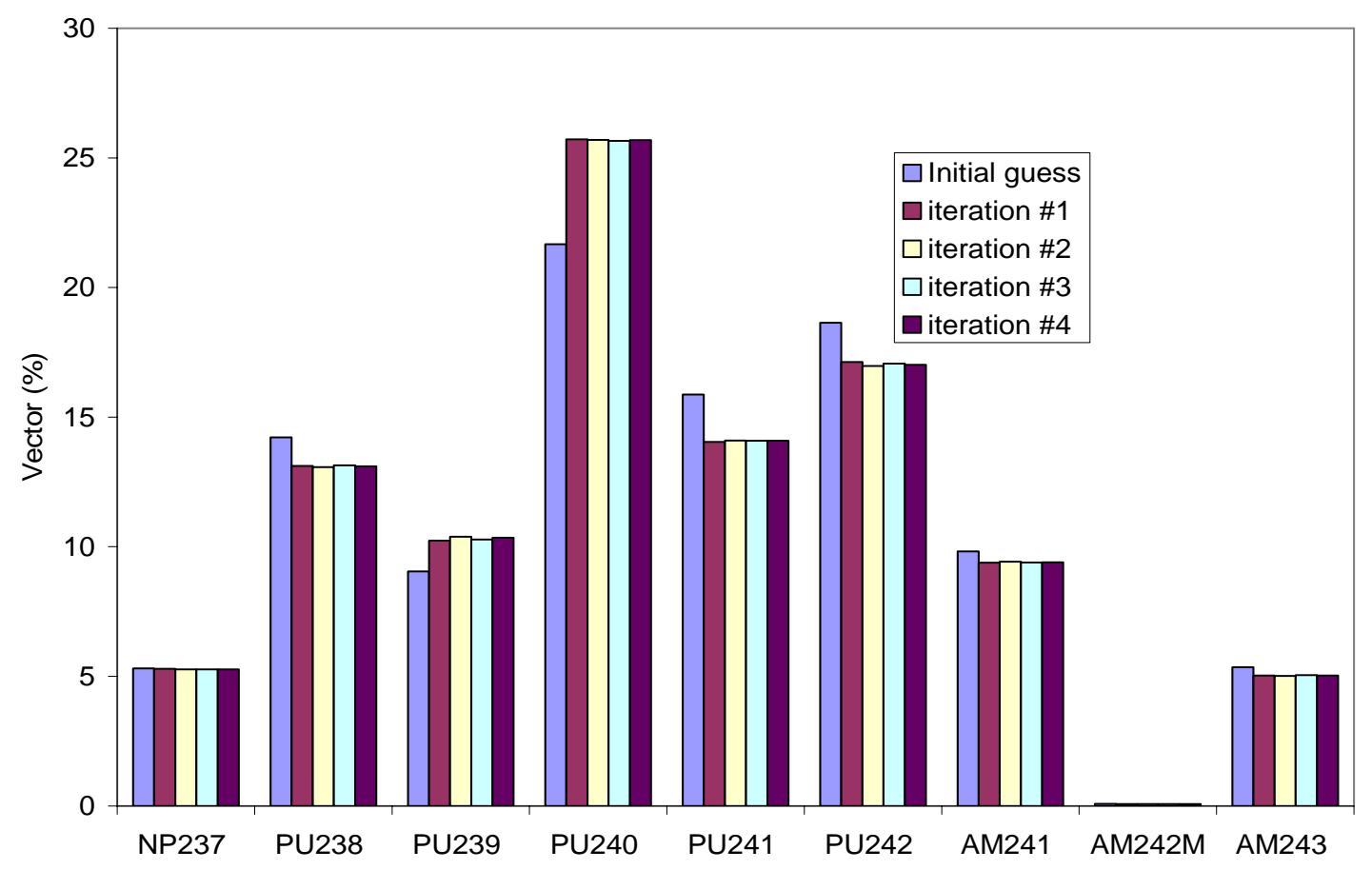

Figure 5.8. TRU Vector Changes in Two-Pass DB-MHR Iterations

The mass flow in the two-pass DB-MHR core using the heterogeneous fuel elements is summarized in Table 5.4. The fresh TRU mass at the charge stage is $199.3 \mathrm{~kg}$, which is about two-third of the original two-pass DB-MHR core because the one-third of the fuel rods are allocated for the recycled TRU fuels in the heterogeneous fuel element. The discharged TRU mass from the first pass is $102.1 \mathrm{~kg}$ excluding $\mathrm{Cm}(5.7 \mathrm{~kg})$, and the charged TRU mass of the second pass is $99.6 \mathrm{~kg}$. Thus, about $2.5 \mathrm{~kg}$ discharged from the first pass was not recycled in this study. Note that, in order to ensure mass balance, the number of fuel rods should be adjusted, but 
the adjustment was not performed in this study because the surplus mass (i.e., $2.5 \mathrm{~kg}$ ) is negligible.

The TRU consumption in the first pass is comparable to that for the other two-pass concepts. However, the TRU consumption in the second pass is much improved compared to the original two-pass DB-MHR core (30\% versus 15\%) because of the flat power sharing in the core; this is presumably because effective power sharing results in additional core reactivity over a core cycle. The overall TRU consumption of this core is $62.4 \%$, which is about $8 \%$ higher than that of the original two-pass DB-MHR core. It is noted that the discharge burnup could not be exactly provided because of the manual two-step used for the calculations.

Table 5.4. Mass Flow of Two-pass DB-MHR Core Using Heterogeneous Fuel Element (kg)

\begin{tabular}{|c|c|c|c|c|c|c|c|}
\hline \multirow{2}{*}{ Pass } & \multirow{2}{*}{ Nuclide } & \multicolumn{4}{|c|}{ Charge } & \multirow{2}{*}{ Discharge } & \multirow{2}{*}{$\begin{array}{c}\text { Consumption } \\
(\%)\end{array}$} \\
\hline & & Region 3 & Region 4 & Region 2 & Region 1 & & \\
\hline \multirow{12}{*}{$\begin{array}{l}\text { First } \\
\text { pass }\end{array}$} & Np-237 & 9.15 & 8.13 & 7.20 & 6.27 & 5.35 & -41.6 \\
\hline & Pu-238 & 2.66 & 4.56 & 7.27 & 9.91 & 11.83 & 345.0 \\
\hline & Pu-239 & 101.62 & 69.07 & 39.93 & 22.85 & 10.66 & -89.5 \\
\hline & $\mathrm{Pu}-240$ & 41.44 & 40.52 & 39.36 & 32.78 & 26.26 & -36.6 \\
\hline & $\mathrm{Pu}-241$ & 15.08 & 21.83 & 23.44 & 24.69 & 20.63 & 36.8 \\
\hline & Pu-242 & 9.86 & 11.03 & 13.23 & 15.17 & 17.92 & 81.9 \\
\hline & Am-241 & 16.38 & 12.25 & 8.76 & 6.21 & 4.00 & -75.6 \\
\hline & Am-242m & 0.06 & 0.25 & 0.19 & 0.14 & 0.08 & 29.6 \\
\hline & Am-243 & 3.01 & 3.51 & 4.00 & 4.66 & 5.32 & 76.6 \\
\hline & Other & 0.00 & 2.98 & 4.33 & 5.09 & 5.73 & - \\
\hline & $\mathrm{Pu}$ & 170.7 & 147.0 & 123.2 & 105.4 & 87.3 & -48.8 \\
\hline & HM & 199.3 & 174.1 & 147.7 & 127.8 & 107.8 & -45.9 \\
\hline \multirow{12}{*}{$\begin{array}{l}\text { Second } \\
\text { pass }\end{array}$} & Np-237 & 5.18 & 4.59 & 4.04 & 3.49 & 2.96 & -43.0 \\
\hline & Pu-238 & 12.91 & 13.37 & 14.17 & 14.93 & 14.95 & 15.9 \\
\hline & Pu-239 & 10.30 & 7.10 & 4.46 & 3.08 & 2.22 & -78.4 \\
\hline & $\mathrm{Pu}-240$ & 25.57 & 18.28 & 13.64 & 9.43 & 6.62 & -74.1 \\
\hline & $\mathrm{Pu}-241$ & 14.09 & 16.79 & 14.59 & 12.39 & 8.34 & -40.8 \\
\hline & Pu-242 & 17.04 & 17.31 & 18.34 & 18.68 & 19.23 & 12.9 \\
\hline & Am-241 & 9.41 & 6.83 & 4.65 & 3.09 & 1.79 & -81.0 \\
\hline & Am-242m & 0.07 & 0.16 & 0.11 & 0.08 & 0.04 & -47.2 \\
\hline & Am-243 & 5.06 & 5.67 & 6.13 & 6.63 & 6.99 & 38.3 \\
\hline & Other & 0.00 & 2.63 & 4.09 & 5.24 & 6.20 & - \\
\hline & $\mathrm{Pu}$ & 79.9 & 72.8 & 65.2 & 58.5 & 51.4 & -35.7 \\
\hline & HM & 99.6 & 92.7 & 84.2 & 77.0 & 69.3 & -30.4 \\
\hline \multicolumn{2}{|c|}{ Power sharing } & 1.06 & 1.15 & 0.89 & 0.91 & & \\
\hline \multirow{3}{*}{$\begin{array}{l}\text { Trans. } \\
\text { rate (\%) }\end{array}$} & $1^{\text {st }}$ pass & -12.6 & -13.3 & -10.0 & -10.0 & & -45.9 \\
\hline & $2^{\text {nd }}$ pass & -6.9 & -8.5 & -7.2 & -7.7 & & -30.4 \\
\hline & Total & & & & & & -62.4 \\
\hline
\end{tabular}




\section{COMPARISON OF DB-MHR AND CONVENTION LWR IMF CONCEPTS}

During FY04, several reactor-based transmutation concepts, such as CORAIL, MOX, IMF, etc., were evaluated under the AFCI program.[4] Among these concepts, the Inert Matrix Fuel (IMF) concept is very similar to the deep-burn concept in terms of TRU recycling in thermal systems. In the IMF concept, the TRU recovered from the LWR spent nuclear fuel is reirradiated in other LWRs. The primary differences between the DB-MHR and the IMF concepts are the reactor type and the fuel form. The deep-burn concept uses a gas-cooled reactor and the coated particle fuels (TRISO), while the IMF concept uses a LWR and the inert-matrix fuel.

In the previous study, the initial TRU vector of the inert-matrix fuel is that obtained from high burnup LWRs (average discharge burnup is about $45-51 \mathrm{GWd} / \mathrm{t}$ ), which is different from the vector used in this study. Thus, for a consistent comparison, the performance of the IMF concept was re-evaluated using the TRU vector utilized in this study (see Table 2.1). In Table 6.1, the TRU consumptions in one-pass DB-MHR core and IMF concept are compared. It is noted that this is purely a neutronic comparison that has not evaluated the feasibility of the systems from a safety viewpoint.

Table 6.1. TRU Consumption (\%) in DB-MHR and IMF Concepts

\begin{tabular}{|l|c|c|}
\hline & One-pass DB-MHR & One-pass IMF \\
\hline Np-237 & -54.9 & -67.0 \\
Pu-238 & 409.1 & 356.7 \\
Pu-239 & -96.8 & -92.8 \\
Pu-240 & -70.8 & -47.5 \\
Pu-241 & -7.2 & -11.5 \\
Pu-242 & 126.2 & 72.6 \\
Am-241 & -89.0 & -86.4 \\
Am-242m & -40.1 & -38.4 \\
Am-243 & 103.1 & 62.6 \\
\hline Pu & -61.8 & -58.0 \\
\hline HM & -58.1 & -55.1 \\
\hline \hline Discharge Burnup, GWd/t & 546 & 545 \\
\hline Repository benefit & 2.0 & 1.64 \\
\hline
\end{tabular}

The one-pass DB-MHR core has a power level of $600 \mathrm{MWt}$, kernel diameter of $200 \mu \mathrm{m}$ and packing fraction of 20\%. The specific power density of the DB-MHR core is about $670 \mathrm{~W} / \mathrm{g}$, while that for the IMF concept is $360 \mathrm{~W} / \mathrm{g}$. The discharge burnup of the DB-MHR core is very 
close to that of the IMF core (546 GWd/t versus $545 \mathrm{GWd} / \mathrm{t}$ ), but the HM TRU consumption of the DB-MHR core is slightly higher than that of the IMF concept. This slightly higher TRU consumption (for about the same burnup) is attributed to the differences in contributions to fission from the nuclides during fuel irradiation and the resulting difference in energy released per fission (different for each nuclide). Furthermore, the higher thermal efficiency of the DB-MHR improves the energy generation for a given thermal energy production, resulting in a significant improvement in the repository benefit (1.6 to 2.0). 


\section{CONCLUSIONS}

A feasibility study for the Deep-Burn, Modular Helium-cooled Reactor (DB-MHR) concepts has been performed. Two fuel cycle concepts proposed by General Atomics (GA) were examined: one-pass and two-pass deep-burn concepts. Among the primary transuranic (TRU) nuclides in Light Water Reactor (LWR) spent fuel, the Pu, Np, and Am isotopes are fed into the DB-MHR, and Cm isotopes are sent to the repository or interim storage. In the one-pass concept, all the TRU nuclides discharged from DB-MHR are directly sent to the repository, but in the two-pass concept, the $\mathrm{Pu}, \mathrm{Np}$, and $\mathrm{Am}$ isotopes discharged from the first pass are recycled into the second pass and only $\mathrm{Cm}$ isotopes are sent to the repository.

The TRU consumption in the DB-MHR concepts were evaluated with whole-core equilibrium cycle analyses. For various fuel management schemes, whole-core fuel cycle analyses were performed by WIMS8/REBUS-3 coupled calculations; burnup-dependent microscopic cross sections were generated from WIMS8 fuel element calculations and provided for whole-core REBUS-3 calculations. Prior to main analyses, to test the performance of the WIMS8/REBUS-3 coupled calculation procedure, Monte Carlo depletion calculations were also performed using the MONTEBRUNS code.

The reference one-pass deep-burn core proposed by GA is a $600 \mathrm{MWt}$ annular core composed of 144 fuel columns, whose power density is $4.7 \mathrm{MW} / \mathrm{m}$. A four-batch fuel management scheme is utilized to increase the TRU consumption by achieving high discharge burnup. For this reference core, the optimum fuel kernel diameter and packing fraction were determined to be $200 \mu \mathrm{m}$ and $20 \%$. The estimated cycle length and discharge burnup with the initial TRU vector of 58.6\% fissile fraction provided by GA were 286 EFPD and $546 \mathrm{GWd} / \mathrm{t}$, respectively. The corresponding TRU consumption was 58.1\%. Using a power level of $800 \mathrm{MWt}$ (power upgrade) increased the discharge burnup and TRU consumption to $561 \mathrm{GWd} / \mathrm{t}$ and $60.1 \%$, respectively, but reduced the cycle length to 222 EFPD due to the high specific power density. Additional sensitivity studies showed that the TRU consumption can be improved either by utilizing axial shuffling or decreasing the operating temperature. It was also observed that the transmutation performance is sensitive to the initial TRU vector. For a high-fissile-fraction 
(63\%) TRU vector recovered from the medium-burnup (33.0 GWd/t) LWR spent fuel after 5-year cooling time, the TRU consumption increased to 66.9\%; for an increased cooling time from 5 years to 20 years, however, it decreased to $58.0 \%$ because of the reduced fissile content resulting from Pu-241 decay.

In the two-pass DB-MHR concept, the fuel design parameters of the first pass are the same to those of the one-pass DB-MHR. To maintain mass balance between the TRU discharged from the first pass and the TRU charged to the second pass, the kernel diameter and packing fraction of the second pass fuel were determined to be $200 \mu \mathrm{m}$ and 29.7\%, respectively. A 7-year time lag between the first pass fuel discharge and the second pass fuel charge was assumed: 5 and 2 years before and after reprocessing. The estimated TRU consumption of the two-pass DB-MHR was comparable to that of the one-pass DB-MHR, because of the Pu-241 decay during the lag time between the first and second passes. It was $54.7 \%$, but increased to $63.1 \%$ when the lag time was neglected. An alternative cylindrical core was also considered for the two-pass concept, in which 18 fuel columns were added into the inner reflector for the second pass. Since this core reduces the neutron leakage from the active core, the TRU consumption was improved (58.1\% versus 54.7\%). Additionally, the heterogeneous fuel element composed of the first and second pass fuels with 2:1 volume fractions was examined. Since the second pass fuel is located close to the first pass fuel within the same fuel element, the power sharing of the second pass fuel was increased and thereby the TRU consumption was increased to $62.4 \%$.

Finally, the repository loading benefits of the deep-burn and Inert Matrix Fuel (IMF) concepts were compared using the same initial TRU vector. The DB-MHR core gives a slightly better TRU consumption and repository loading benefit compared to the IMF concept (58.1\% versus 55.1\% for TRU consumption and 2.0 versus 1.6 for repository benefit). 


\section{References}

1. F. Venneri, et al, "Deep Burn Transmutation: A Practical Approach to the Destruction of Nuclear Waste in the Context of Nuclear Power Sustainability," General Atomics, FDOE00-N-TRT-X-000132, Dec. 19, 2001

2. P. Peterson, Science and Global Security, Vol 6, No 1., pp 1-29 (1996).

3. Potter, and A. Shenoy, “Gas Turbine-Modular Helium Reactor (GTMHR) Conceptual Design Description Report,” GA Report 910720, Revision 1, General Atomics, July 1996.

4. J. A. Stillman, "Homogeneous Recycling Strategies in LWRs for Plutonium, Neptunium, and Americium Management," Argonne National Laboratory AFCI Report, ANL-AFCI-124, August 31, 2004.

5. T. K. Kim, W. S. Yang, T. A. Taiwo, and H. S. Khalil, "Whole-Core Depletion Studied in Support of Fuel Specification for the Next Generation Nuclear Plant (NGNP)," Argonne National Laboratory Gen IV Report, July 30, 2004.

6. T. A. Taiwo, W. S. Yang, M. A. Smith, T. K. Kim, and H. S. Khalil, “Assessment of Reactor Physics Codes for Analysis and Design of the Very High Temperature Reactor (VHTR),” Argonne National Laboratory Gen IV Report, September 30, 2004.

7. T. K. Kim, W. S. Yang, M. A. Smith, T. A. Taiwo, and H. S. Khalil, “Assessment of Monte Carlo and Deterministic Codes for Next Generation Nuclear Plant (NGNP) Core Modeling,” Argonne National Laboratory Gen IV Report, April 15, 2004.

8. "WIMS - A Modular Scheme for Neutronics Calculations," User’s Guide for Version 8, ANSWER/WIMS(99)9, The ANSWERS Software Package, AEA Technology.

9. G. Marleau, et al, “A User Guide for DRAGON,” Technical report IGE-174 Rev. 4, Ecole Polytechnique de Montréal, September 1998 (1998).

10. “MCNP - A General Monte Carlo N-Particle Transport Code,” Version 4C, Los Alamos National Laboratory, LA-13709-M (1993).

11. B. J. Toppel, “A User's Guide to the REBUS-3 Fuel Cycle Analysis Capability," ANL-83-2, Argonne National Laboratory (1983).

12. E. E. Bende, A. H. Hogenbirk, J. L. Kloosterman, and H. Van Dam, “Analytical Calculations of the Average Dancoff Factor for a Fuel Kernel in a Pebble Bed HighTemperature Reactor,” Nuclear Science and Engineering, 133, 147 (1999).

13. Z. Karriem, C. Stoker, and F. Reitsma, “MCNP Modeling of HTGR Pebble-Type Fuel,” Proc. of Monte Carlo 2000 Conference, Lisbon, Portugal, October 23-26, 2000 (2000). 